\title{
WestVirginiaUniversity
}

THE RESEARCH REPOSITORY @ WVU

Graduate Theses, Dissertations, and Problem Reports

2010

\section{Numerical modeling of pressure transient behavior of fractured coal samples}

\author{
Rupesh Kumar Gondle \\ West Virginia University
}

Follow this and additional works at: https://researchrepository.wvu.edu/etd

\section{Recommended Citation}

Gondle, Rupesh Kumar, "Numerical modeling of pressure transient behavior of fractured coal samples" (2010). Graduate Theses, Dissertations, and Problem Reports. 4597.

https://researchrepository.wvu.edu/etd/4597

This Thesis is protected by copyright and/or related rights. It has been brought to you by the The Research Repository @ WVU with permission from the rights-holder(s). You are free to use this Thesis in any way that is permitted by the copyright and related rights legislation that applies to your use. For other uses you must obtain permission from the rights-holder(s) directly, unless additional rights are indicated by a Creative Commons license in the record and/ or on the work itself. This Thesis has been accepted for inclusion in WVU Graduate Theses, Dissertations, and Problem Reports collection by an authorized administrator of The Research Repository @ WVU. For more information, please contact researchrepository@mail.wvu.edu. 


\title{
NUMERICAL MODELING OF PRESSURE TRANSIENT BEHAVIOR OF FRACTURED COAL SAMPLES
}

\section{Rupesh Kumar Gondle}

\author{
Thesis submitted to \\ College of Engineering and Mineral Resources \\ at West Virginia University \\ in partial fulfillment of the requirements \\ for the degree of \\ Master of Science \\ in \\ Civil Engineering
}

Dr. Hema J. Siriwardane, Ph.D., Chair

Dr. Thomas H. Wilson, Ph.D.

Dr. Udaya B. Halabe, Ph.D.

Department of Civil and Environmental Engineering

Morgantown, West Virginia

2010

Keywords: Transient pressure method, Coal Permeability, Fracture Permeability 


\section{ABSTRACT \\ Numerical Modeling of Pressure Transient Behavior of Fractured Coal Samples \\ By \\ Rupesh Kumar Gondle}

In the current study the pressure transient behavior of various coal samples was investigated by using the finite element approach. Finite element analyses were performed on fourteen coal samples with different physical dimensions. Two pressure transients, namely Sine-6 and A-Spike pressure pulses, were used in the research study. Fluid compressibility values of $\mathrm{CO}_{2}$ and Argon were used to perform the analyses. A fracture width of $1 \mathrm{~mm}$ was considered for each sample to investigate the influence of fluid type on coal permeability. The influence of elastic modulus of coal sample, fracture porosity, fracture width, and fluid compressibility were investigated. The finite element analyses for each sample were performed in two different ways: a) without considering a fracture in the coal sample and b) considering a fracture in the coal sample. The permeability of each sample was determined by comparing numerical results with available experimental data.

The calibrated finite element models were extended to determine the permeability of fractured coal samples. The numerically determined fracture permeability is much higher than the reported permeability values obtained by assuming a homogeneous medium. The results obtained from the numerical models compare well with the available experimental data on coal permeability. 


\section{ACKNOWLEDGEMENTS}

I would like to express my sincere appreciation to my research advisor and committee chairman, Dr. Hema J. Siriwardane, for his continuous guidance, advice, and encouragement throughout this report work. I also wish to thank Dr. Thomas Wilson and Dr. Udaya Halabe for serving on my examining committee and for reviewing this report.

I am thankful for the financial support provided by the U.S. Department of Energy for this project - RDS 4187M2169 through a Graduate Research Assistantship at West Virginia University. I would like to thank my friends, Raj Kumar Gondle, Sai Bharath Varre, Benjamin Bowes, Sumanth Gundagatti, Andrew Dietz, Kalyan Varma Bhupathiraju, Suhasini Kalluru, Shilpa Bollineni, Divya Doma, Mettu Ramakanth, Rajesh Vuppala, Ramya Reddy and Subha Marripati for their moral support.

I would like to express my great appreciation to my family for their valuable love and constant support. 


\section{TABLE OF CONTENTS}

ABSTRACT......................................................................................................................ii

ACKNOWLEDGEMENTS _............................................................................iii

TABLE OF CONTENTS ..........................................................................................iv

LIST OF FIGURES.......................................................................................................

LIST OF TABLES................................................................................................vii

CHAPTER 1: INTRODUCTION .............................................................................1

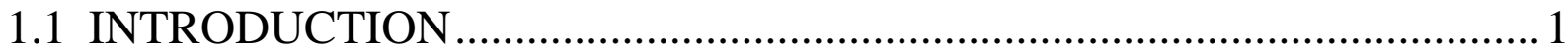

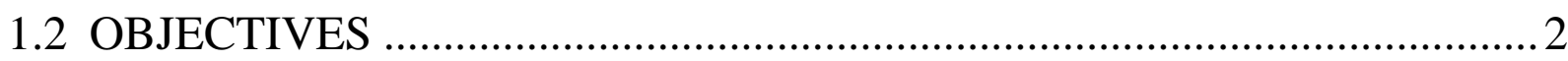

1.3 SCOPE OF THE STUDY …………………………………………....

CHAPTER 2: LITERATURE REVIEW ...............................................................4

2.1 PHYSICAL PROPERTIES OF COAL …………………………………......

2.2 RELEVANT PROPERTIES OF $\mathrm{CO}_{2}$ AND ARGON ……………………...... 6

CHAPTER 3: EXPERIMENTAL RESULTS ...............................................9

3.1 METHODOLOGY …………………………………...................

3.2 EXPERIMENTAL TESTS ………………………………………...... 10

3.3 EXPERIMENTAL RESULTS ...............................................................16

CHAPTER 4: FINITE ELEMENT ANALYSIS ..................................................21

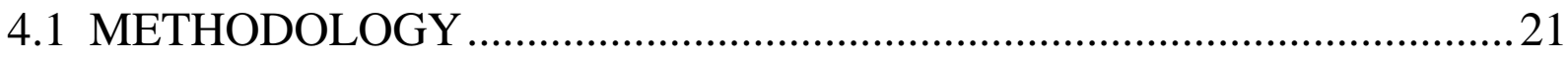

4.2 PROCEDURE FOR NUMERICAL MODELING …………………….......... 22

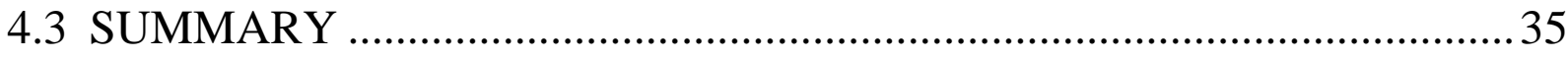

CHAPTER 5: RESULTS AND DISCUSSION.................................................36

5.1 NUMERICAL MODELING RESULTS …………………………….........

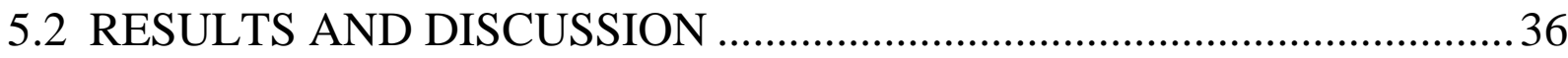

CHAPTER 6: SUMMARY AND CONCLUSIONS.............................................64

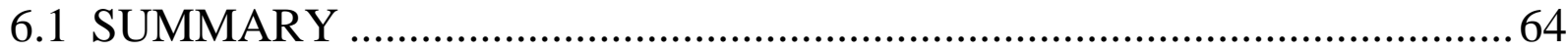

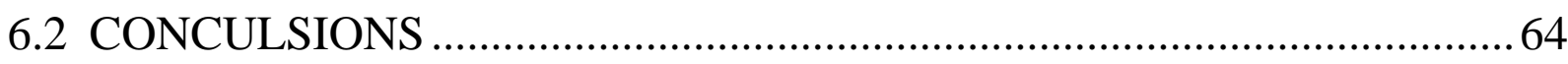

6.3 RECOMMENDATIONS FOR FUTURE .....................................................66

REFERENCES: ..............................................................................................................67 


\section{LIST OF FIGURES}

Figure 2.1: Vertical fracture in a coal matrix …………….................................................... 5

Figure 2.2: Temperature dependence of $\mathrm{CO}_{2}$ (Tang, 2006)................................................... 8

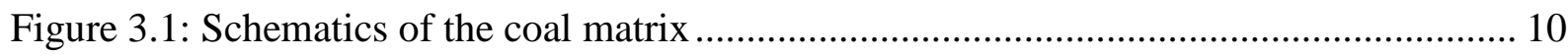

Figure 3.2: A CT Scan of a fractured coal matrix (Haljasmaa et al, 2009)............................... 12

Figure 3.3: Upstream and Downstream boundary conditions ................................................ 13

Figure 3.4: A typical A-Spike pressure pulse for experimental tests........................................ 15

Figure 3.5: A typical Sine-6 pressure pulse for experimental tests........................................ 15

Figure 4.1: A typical fractured coal sample used in an experiment test .................................. 21

Figure 4.2: Schematic of a coal sample with a fracture …………………………………..... 22

Figure 4.3: Finite element mesh for rock sample S10 with a $1 \mathrm{~mm}$ fracture ............................. 23

Figure 4.4: Upstream pressure pulse (A-Spike) …………………………………………..... 26

Figure 4.5: Upstream pressure pulse (Sine - 6) …………………………………………... 27

Figure 4.6: Influence of elastic modulus of the coal matrix................................................... 29

Figure 4.7: Influence of fracture width of the coal matrix ..................................................... 30

Figure 4.8: Influence of fracture width of the coal matrix ...................................................... 31

Figure 4.9: Influence of fluid compressibility - upstream pressure pulse ................................ 33

Figure 4.10: Influence of fluid compressibility - downstream pressure response .................... 33

Figure 4.11: Influence of fluid compressibility - downstream pressure response .................... 34

Figure 4.12: Downstream end - fracture porosity not equal to matrix porosity ....................... 34

Figure 5.1: S02 - pressure rise curve (downstream end) ………………………………….... 38

Figure 5.2: S02 - Downstream pressure response A-Spike (without fracture)........................ 39

Figure 5.3: S02 - Downstream pressure response A-Spike (with fracture)............................. 40

Figure 5.4: S02 - Downstream pressure response Sine-6 (without fracture) ............................. 41

Figure 5.5: S02 - Downstream pressure response Sine-6 (with fracture) …………………...... 41 
Figure 5.6: Downstream pressure response for sample S02 - event 147 A-Spike (without

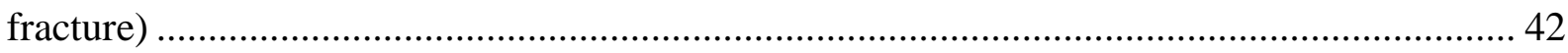

Figure 5.7: Downstream pressure response S02 - event 147 A-Spike (with fracture) ........... 43

Figure 5.8: Downstream pressure response S02 - event 148 Sine-6 (without fracture).......... 43

Figure 5.9: Downstream pressure response S02 - event 148 Sine-6 (with fracture) .............. 44

Figure 5.10: Downstream pressure pulses for S04 - Argon event 4 Sine- 6 ........................ 45

Figure 5.11: Downstream pressure pulses for S04 - Argon event 5 A-Spike......................... 45

Figure 5.12: Downstream pressure pulses for sample S04 - event 0 A-Spike (without fracture)

Figure 5.13: Downstream pressure pulses for sample S04 - event 0 A-Spike (with fracture) 47

Figure 5.14: Downstream pressure pulses for sample S04 - event 1 Sine-6 (without fracture)

Figure 5.15: Downstream pressure pulses for sample S04 - event 1 Sine-6 (with fracture) ... 48

Figure 5.16: Upstream pressure pulse for sample S10 - event 0 A-Spike 49

Figure 5.17: Downstream pressure response of sample S10 - event 0 A-Spike (without fracture)

Figure 5.18: Upstream pressure pulse for sample S10 - event 1 Sine-6.............................. 50

Figure 5.19: Downstream pressure response of sample S10 - event 1 Sine-6 (without fracture)

Figure 5.20: Downstream pressure response of sample S10 - event 1 A-Spike (with fracture)

Figure 5.21: Downstream pressure response of sample S10 - event 1 Sine-6 (with fracture) 52 Figure 5.22: Upstream and downstream pressure pulses of sample S14 - event 16 A-Spike (without fracture). 53

Figure 5.23: Upstream and downstream pressure pulses of sample S14 - event 16 A-Spike (without fracture).

Figure 5.24: Downstream pressure response of sample S14 event 16 A-Spike (with fracture)55 Figure 5.25: Downstream pressure response of sample S14 event 17 A-Spike (with fracture)55 


\section{LIST OF TABLES}

Table 2.1: Relationship between pore size and coal rank ............................................... 6

Table 2.2: Compressibility of Carbon dioxide (NIST: REFPROP, 2010) ............................. 7

Table 2.3: Compressibility values of Argon at different pressures (NIST: REFPROP, 2010).. 8

Table 2.3: Compressibility values of Argon at different pressures (NIST: REFPROP, 2010).. 8

Table 3.1: Physical properties of the experimental samples ............................................. 11

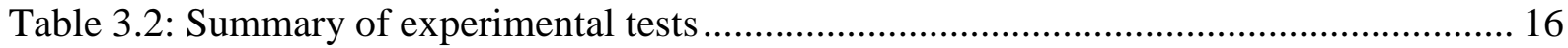

Table 5.1: Comparison of experimental results with computer model results ....................... 57 


\section{CHAPTER 1: INTRODUCTION}

\subsection{INTRODUCTION}

The changes in the atmospheric behavior may be mitigated by significantly reducing the volume of the anthropogenic greenhouse gases in the earth's atmosphere. It is theorized that an increase in carbon dioxide is responsible for the raising of the Earth's temperature, which is termed as Greenhouse Effect (Wikipedia, 2010). The data on global average temperature measured between 1995 and 2006 has been recorded as the twelve warmest years since measurements began to be recorded in the 1850's (IPCC, 2007). In 2007, the total greenhouse gas emissions increased by $1.4 \%$ over the preceding year (DOE, 2007). Global greenhouse gases have shown an increase of approximately $70 \%$ in the earth's atmosphere between 1970 and 2004 due to human activities (IPCC, 2007).

During 2005, approximately $83 \%$ of total U.S. greenhouse gas emissions consisted of carbon dioxide from the combustion of fossil fuels such as coal, petroleum, and natural gas (DOE, 2005). The average increase in sea level due to the global warming was $1.8 \mathrm{~mm}$ per year between 1961 - 2003, and the rate has increased to $3.1 \mathrm{~mm}$ from 1993 - 2003 (IPCC, 2007). Recent studies have shown that the rate of growth of $\mathrm{CO}_{2}$ emissions has increased rapidly during 1995 - 2004 when compared to the previous decades (1970 - 1994) (IPCC, 2007). Carbon sequestration in coal seams is one of the potential techniques to reduce the greenhouse gas emissions.

Large scale geologic sequestration operations will require comprehensive characterization of potential sites. Determination of permeability of reservoir rocks and fractured media is an important part of site characterization. In this study, the potential use of pressure transient methods for determining permeability of fractured coal samples were investigated by using the finite element method. 


\subsection{OBJECTIVES}

The objective of the research work presented in this report was to determine the permeability of fractured coal samples by using the finite element method. Two different fluid mediums (carbon dioxide and argon) were used to determine the permeability of various fractured coal samples. Different physical properties of the samples were used to perform the finite element analyses. Experimental data for these coal samples were made available by the National Energy Technology Laboratory (NETL), U.S. Department of Energy as a collaborative study. The porosity values for coal samples were found to be very low - less than $1 \%$.

The major objectives are:

1) Determine the permeability of samples by using the finite element method assuming that there was no fracture. This is how the permeability is determined in the experimental device.

2) Determine the permeability of the fracture by using the finite element method by incorporating the low matrix permeability into the analysis.

\subsection{SCOPE OF THE STUDY}

The scope of the study was limited to the analysis of fourteen coal samples. The dimensions of these samples are given later in this report (Chapter 3). Finite element analyses were performed on fourteen different samples to compare the finite element results with available experimental results. Numerical modeling of each sample was performed by using Sine-6 and A-Spike pressure transient waves. Two different cases were considered for each sample: (a) with a fracture, and (b) without a fracture. A fracture width of $1 \mathrm{~mm}$ in the coal matrix was considered in the analyses. Experimental results for certain events from each sample were used to compare the results obtained from finite element modeling. Results on the influence of different properties of coal and the fluid medium (Carbon dioxide and Argon) on the pressure transient behavior is shown in this report. A comparison of numerical results with available experimental data is also presented in this report. 
The report consists of six chapters. Chapter 1 is a brief introduction. Chapter 2 summarizes relevant properties of coal and fluids used in the study. Chapter 3 consists of a summary of experimental data used in the analysis. Chapter 4 contains details of the finite element analysis. Results of the analysis are presented in Chapter 5. A summary and conclusions of the study are presented in Chapter 6 of the report. 


\section{CHAPTER 2: LITERATURE REVIEW}

\subsection{PHYSICAL PROPERTIES OF COAL}

Coal, along with natural gas and petroleum, is usually referred to as a fossil fuel. Coal was formed most abundantly during the Carboniferous Age which extends from the end of the Devonian period (about 359 million years ago), to the beginning of the Permian period (about 299 million years in the past) (Wikipedia, 2010). Coal is usually found between the layers of the sedimentary rocks and may be found lying deep under the earth's surface. Various forms of coal have variable compositions of elemental compounds such as carbon, sulfur, and nitrogen. Generally the content of pure carbon in a bituminous coal sample is about $46 \%$ 86\% (Lerner, 2010). Physical properties of coal including density, permeability, porosity, elastic modulus, specific gravity, hardness, etc vary considerably depending on impurities in the coal, heat and pressure exposure (Britannica, 2010).

\section{Permeability:}

Permeability characterizes the ability of rocks to allow the circulation of fluids contained in their pores. Permeability is denoted by ' $k$ '. According to Darcy's law permeability is defined as the proportionality constant relating the volume flow rate $\mathrm{q}$, for an incompressible fluid of viscosity $\mu$, to the pressure gradient $\nabla p$, driving the flow.

$$
q=-\frac{k A}{\mu} \nabla p
$$

where,

$\mathrm{k}$ is the permeability, and

A is the total cross-sectional area of the porous material 


\section{Porosity:}

The volume fraction of the coal occupied by empty spaces is termed as the porosity of coal. In other words, it is the volume fraction of the coal that is occupied by a certain fluid. Dual porosity system can usually be seen in coal - micropores and macropores. The micropores have a pore diameter less than $2 \mathrm{~nm}$ which occur as a part of the coal matrix (Van Krevelen, 1993). The spaces within the cleat system and other natural fractures for the transport of a particular fluid through the seams are known as macropores. Cleat spacing is affected by coal rank and bed thickness. Generally it decreases as a function of decreasing layer thickness. It also decreases with coal rank (Harpalani and Chen, 1997). The cleat spaces usually contain water, free methane, or a mixture of water and methane. Generally the coal matrix has very low values of porosity. Most of the gas flows through the cleat system. Figure 2.1 shows a coal sample fractured in the vertical direction.

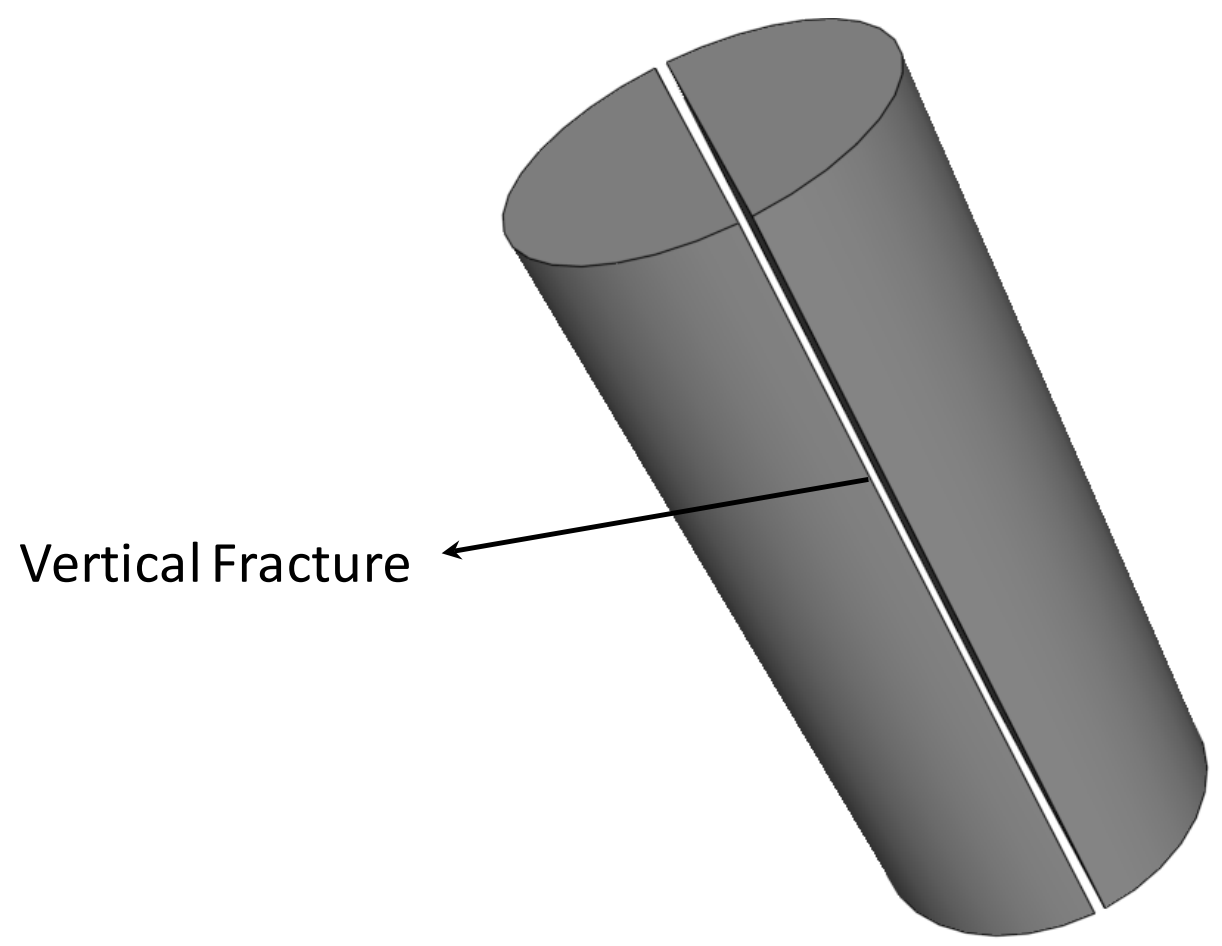

Figure 2.1: Vertical fracture in a coal matrix 
Apart from the cleat system, bedding planes, or surfaces, are another set of fractures that are present in coal. These are of little interest for the gas flow (Harpalani and Chen, 1997). In a coal matrix over $95 \%$ of the gas that is stored is absorbed gas (Gray, 1987). While the movement of gas in the matrix is governed by diffusion, the movement of gas in the cleat system and fractures is governed by Darcy's law (Haljasmaa et al, 2009). Table 2.1 shows different pore sizes.

Table 2.1: Relationship between pore size and coal rank

\begin{tabular}{|c|c|c|}
\hline & Pore Sizes (D) & $\begin{array}{c}\text { Coal Rank (ASTM Designation D388-98a) } \\
\text { (Standard Classification of Coals by Rank) }\end{array}$ \\
\hline Micropores & $\mathrm{D}<2 \mathrm{~nm}$ & High volatile bituminous coal and higher \\
\hline Mesopores & $2 \mathrm{~nm}<\mathrm{D}<50 \mathrm{~nm}$ & High volatile bituminous coal \\
\hline Macropores & $\mathrm{D}>50 \mathrm{~nm}$ & Lignites + Sub-bituminous \\
\hline
\end{tabular}

A value of $692,000 \mathrm{psi}(4,770,000 \mathrm{kPa})$ for the elastic modulus and 0.3 for the porosity of the coal samples was used in the present study on the basis of literature (Palmer and Mansoori, 1996).

\subsection{RELEVANT PROPERTIES OF $\mathrm{CO}_{2}$ AND ARGON}

Carbon dioxide $\left(\mathrm{CO}_{2}\right)$ is the most predominant greenhouse gas that is produced by the combustion of coal or hydrocarbons. It changes its state to gaseous, liquid, or solid state depending on the temperature and pressure. Carbon dioxide sorption in coal can change the physical structure of coal (Larsen et al., 2004). The density and viscosity of $\mathrm{CO}_{2}$ change considerably with temperature and pressure, which is usually high at greater depths of the coal seams. 
Table 2.2 shows the compressibility values of $\mathrm{CO}_{2}$ used for performing the analyses for different pressures. Phase diagram for $\mathrm{CO}_{2}$ is shown in Figure 2.2 (Tang, 2006).

Table 2.2: Compressibility of Carbon dioxide (NIST: REFPROP, 2010)

\begin{tabular}{|c|c|c|c|c|}
\hline $\begin{array}{c}\text { Temperature } \\
\left({ }^{\circ} \mathbf{C}\right)\end{array}$ & $\begin{array}{c}\text { Pore } \\
\text { Pressure } \\
\mathbf{( M P a )}\end{array}$ & $\begin{array}{c}\text { Viscosity } \\
\mathbf{( P a}-\mathbf{s})\end{array}$ & $\begin{array}{c}\text { Adiabatic } \\
\text { Compressibility } \\
\mathbf{( 1 / P a )}\end{array}$ & $\begin{array}{c}\text { Adiabatic Bulk } \\
\text { Modulus } \\
\mathbf{( k P a})\end{array}$ \\
\hline 25 & 4.4 & 0.000016187 & $1.79 \mathrm{E}-07$ & $5.60 \mathrm{E}+03$ \\
\hline 25 & 6 & 0.000018316 & $1.27 \mathrm{E}-07$ & $7.89 \mathrm{E}+03$ \\
\hline 25 & 10 & 0.000073877 & $6.54 \mathrm{E}-09$ & $1.53 \mathrm{E}+05$ \\
\hline
\end{tabular}

Argon is an inert gas that was used to perform the experimental tests and the finite element modeling study. Argon exists both in gaseous and liquid forms. The compressibility of the Argon varies with the temperature and pore pressure. Table 2.3 shows the compressibility values for Argon at different pore pressures. The results obtained by using Argon and $\mathrm{CO}_{2}$ as the fluid mediums in the coal samples, are illustrated in this report. 
Table 2.3: Compressibility values of Argon at different pressures (NIST: REFPROP, 2010)

\begin{tabular}{|c|c|c|c|c|}
\hline $\begin{array}{c}\text { Temperature } \\
\left({ }^{\circ} \mathbf{C}\right)\end{array}$ & $\begin{array}{c}\text { Pore } \\
\text { Pressure } \\
\mathbf{( M P a})\end{array}$ & $\begin{array}{c}\text { Viscosity } \\
\mathbf{( P a}-\mathbf{s})\end{array}$ & $\begin{array}{c}\text { Adiabatic } \\
\text { Compressibility } \\
\mathbf{( 1 / P a )}\end{array}$ & $\begin{array}{c}\text { Adiabatic Bulk } \\
\text { Modulus } \\
\mathbf{( k P a )}\end{array}$ \\
\hline 25 & 3 & 0.0000232 & $1.93 \mathrm{E}-07$ & $5.18 \mathrm{E}+03$ \\
\hline 25 & 4 & 0.0000235 & $1.43 \mathrm{E}-07$ & $7.00 \mathrm{E}+03$ \\
\hline 25 & 4.4 & 0.0000236 & $1.30 \mathrm{E}-07$ & $7.72 \mathrm{E}+03$ \\
\hline 25 & 6 & 0.0000241 & $9.26 \mathrm{E}-08$ & $1.08 \mathrm{E}+04$ \\
\hline 25 & 10 & 0.0000255 & $5.20 \mathrm{E}-08$ & $1.92 \mathrm{E}+04$ \\
\hline
\end{tabular}

Phase Diagram - $\mathrm{CO}_{2}$

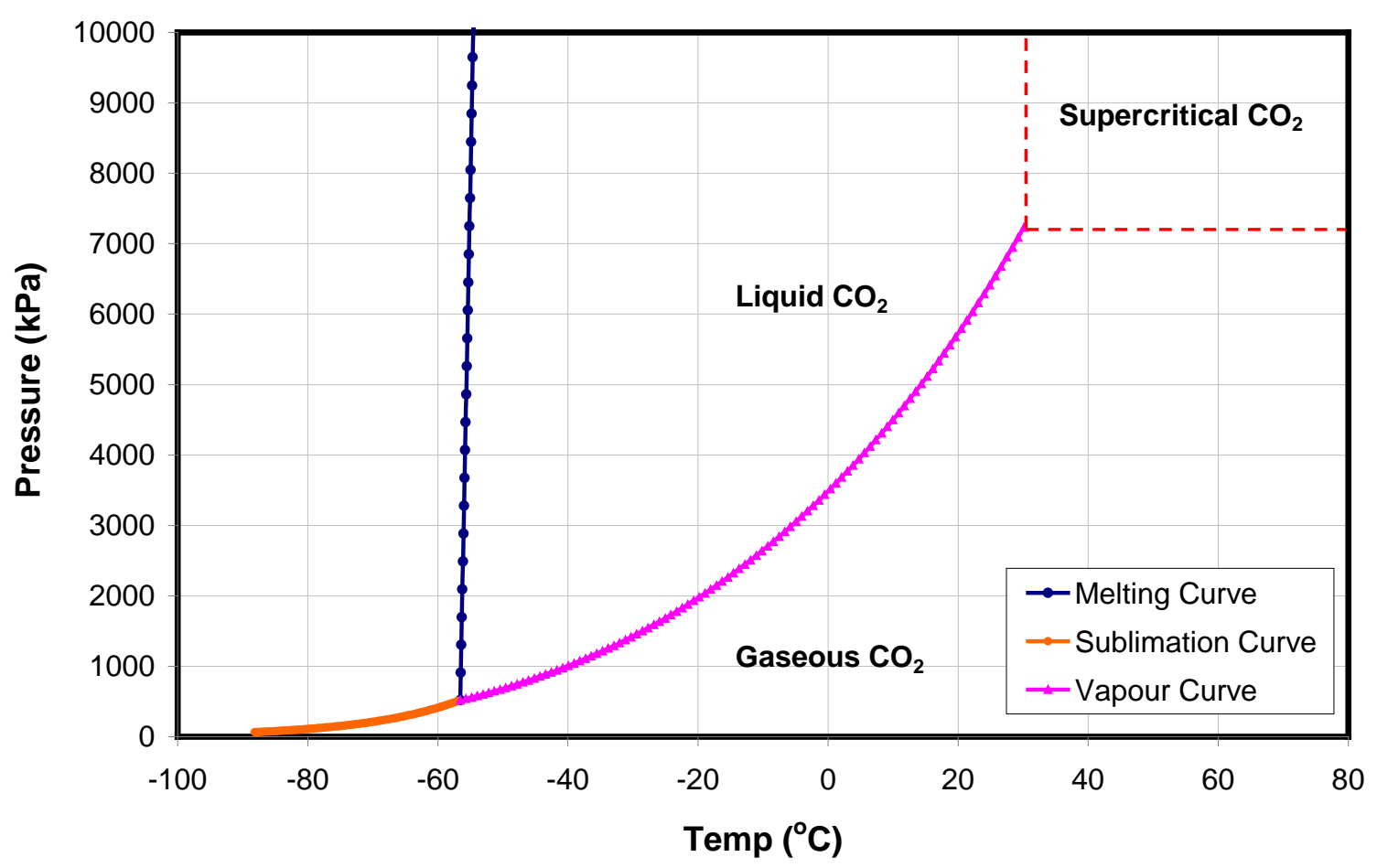

Figure 2.2: Temperature dependence of $\mathrm{CO}_{2}$ (Tang, 2006) 


\section{CHAPTER 3: EXPERIMENTAL RESULTS}

\subsection{METHODOLOGY}

The permeability of the coal sample can be determined only if the coal matrix is large and contains cleats. It is difficult to obtain coal samples which contain enough cleats for the laboratory tests and even if the samples are obtained for the laboratory tests, it takes an enormous amount of time to conduct the tests to determine the permeability of the coal matrix since the permeability values of coal are usually low (Haljasmaa et al., 2009). The permeability of the coal matrix should be determined in a short time since the sorption of carbon dioxide on coal is a time dependent process. Because of this time dependent process of sorption of carbon dioxide on the coal matrix, pressure transient methods are used to determine the permeability of the coal matrix much more quickly.

In a typical experiment, permeability is measured by the flow rate through a sample under a constant pressure gradient. Pressure and time are the two parameters that are easily measured in a high pressure experiment, rather than flow rate or velocity (Brace et al., 1968). In a pressure transient test, downstream pressure variation is measured for a known pressure pulse upstream.

Figure 3.1 shows a schematic diagram of a coal sample in a pressure transient test to determine the permeability of the coal matrix. Initially, the fluid reservoirs $V_{1}$ and $V_{2}$ at the ends of the coal matrix are maintained at nearly same pressures and the sample is subjected to a constant confining pressure. To measure the permeability of the coal, the pressure is rapidly changed in the upstream chamber and the recovery of this pressure, with respect to time, is observed as the fluid flows between the reservoirs of the coal matrix (Brace et al., 1968). 


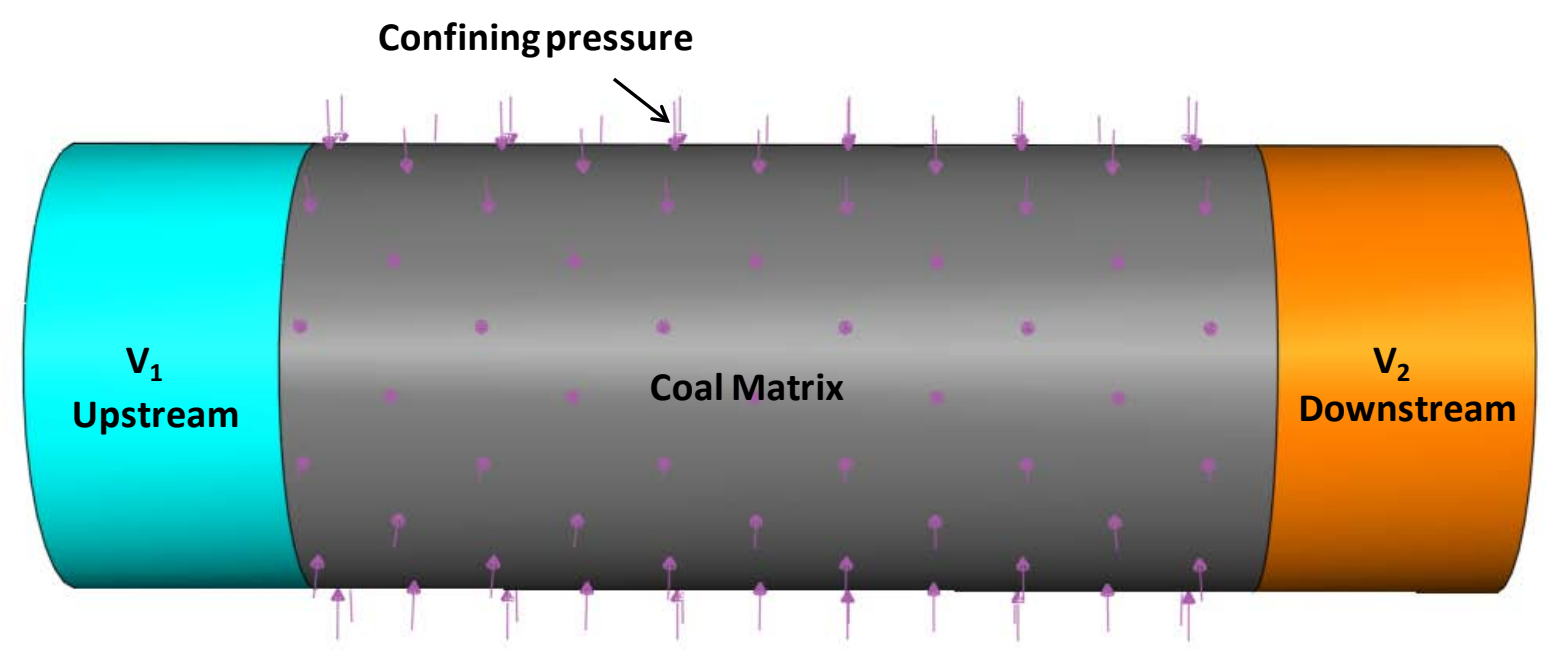

Figure 3.1: Schematics of the coal matrix

\subsection{EXPERIMENTAL TESTS}

The experimental data from fourteen different samples are available (Haljasmaa, Personal Communication).

The descriptions of all the samples are shown in Table 3.1. For the samples which do not have a natural cleat (S01 to S10) a fracture was created to perform the experimental tests. The samples from S11 through S14 contained a natural cleat (Haljasmaa et al, 2009). 
Table 3.1: Physical properties of the experimental samples

\begin{tabular}{|c|c|c|c|c|c|c|}
\hline Sample \# & $\begin{array}{l}\text { Diameter } \\
(\mathbf{m m})\end{array}$ & Length (mm) & Porosity & $\begin{array}{c}\text { Pore } \\
\text { Pressure } \\
\text { (MPa) }\end{array}$ & $\begin{array}{c}\text { Confining } \\
\text { Pressure } \\
\text { (MPa) }\end{array}$ & Comments \\
\hline S01 & 37.5 & 19.15 & $1.40 \%$ & 4.4 & 6.6 & Gaseous $\mathrm{CO}_{2}$ \\
\hline S02 & 37.7 & 51.1 & $0.63 \%$ & 10.0 & 20.0 & Liquid $\mathrm{CO}_{2}$ \\
\hline S03 & 37.47 & 80.1 & $0.52 \%$ & - & - & Failed Sample \\
\hline S04 & 37.5 & 80.1 & $0.71 \%$ & 10.0 & 20.0 & Liquid $\mathrm{CO}_{2}$ \\
\hline S05 & 37.45 & 79 & $0.62 \%$ & 10.0 & 20.0 & Liquid $\mathrm{CO}_{2}$ \\
\hline S06 & 37.65 & 67.6 & $0.78 \%$ & 10.0 & 20.0 & Liquid $\mathrm{CO}_{2}$ \\
\hline S07 & 37.45 & 75.25 & $0.42 \%$ & 4.0 & 8.0 & Gaseous $\mathrm{CO}_{2}$ \\
\hline S08 & 37.46 & 77.1 & $0.27 \%$ & 10.0 & 20.0 & Liquid $\mathrm{CO}_{2}$ \\
\hline S09 (T01) & 50.4 & 62.67 & $0.72 \%$ & - & - & Failed Sample \\
\hline S10 (T02) & 50.37 & 79.9 & $0.75 \%$ & 10.0 & 20.0 & Liquid $\mathrm{CO}_{2}$ \\
\hline S11 & 37.48 & 75.9 & $0.35 \%$ & 10.0 & 20.0 & Liquid $\mathrm{CO}_{2}$ \\
\hline S12 & 37.43 & 53.25 & $1.43 \%$ & 10.0 & 20.0 & Liquid $\mathrm{CO}_{2}$ \\
\hline S13 & 37.43 & 79.5 & $0.63 \%$ & 10.0 & 20.0 & Liquid $\mathrm{CO}_{2}$ \\
\hline S14 & 37.7 & 59.05 & $1.07 \%$ & 10.0 & 20.0 & Liquid $\mathrm{CO}_{2}$ \\
\hline
\end{tabular}




\section{Experimental Procedure:}

Pressure transient methods were used to determine the permeability of the coal samples (Haljasmaa et al., 2009). The porosity of each sample was measured and recorded before the test (Haljasmaa et al., 2009). Table 3.1 shows the porosity values for each sample. Figure 3.2 shows a typical CT scan image of a coal sample used for the experimental test. A constant confining pressure was maintained for each sample to simulate the actual field conditions. The details of each sample are shown in Table 3.1.

In a typical pressure transient test, a pressure pulse, $\mathrm{p}_{\mathrm{o}}$, is introduced in the upstream volume (Figure 3.3). The downstream pressure response, $\mathrm{p}(\mathrm{L}, \mathrm{t})$, is recorded in the downstream volume. The downstream volume, $\mathrm{V}$, is fixed.

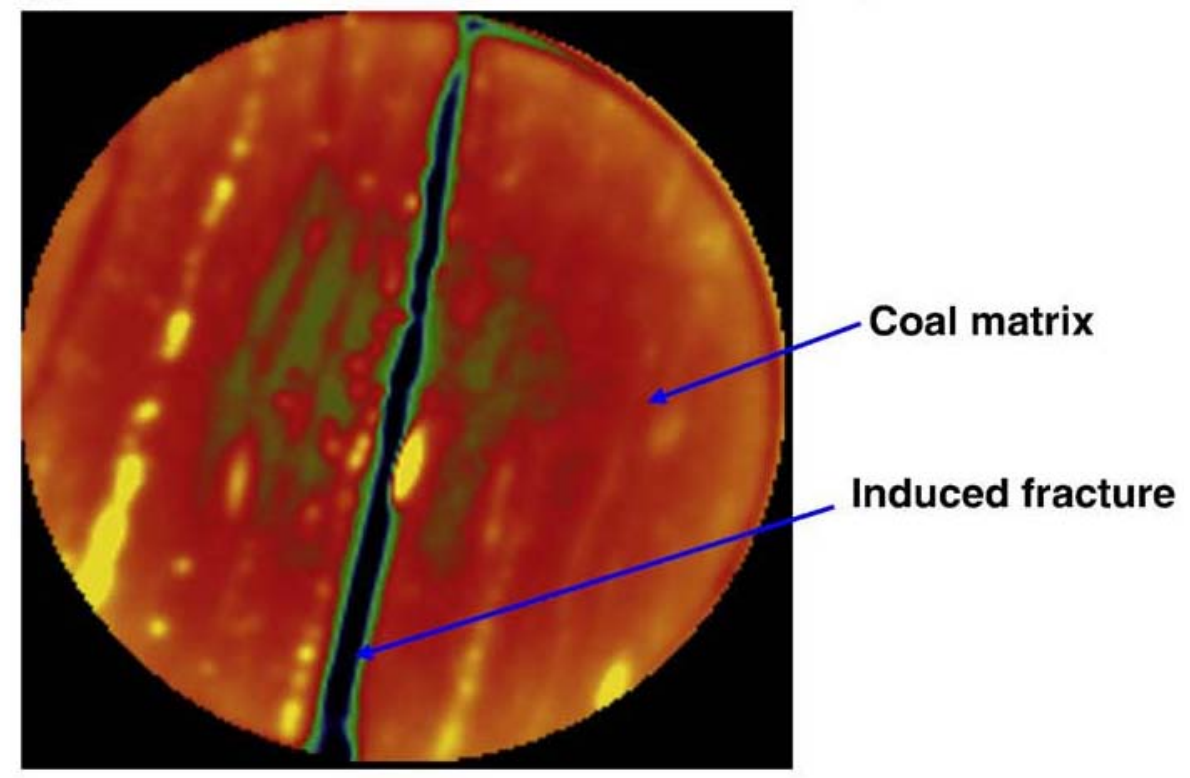

Figure 3.2: A CT Scan of a fractured coal matrix (Haljasmaa et al, 2009) 
Figure 3.3 shows the upstream and the downstream boundary conditions for the pressure transient method used to determine the permeability of the coal sample in this research study. The permeability of the coal sample was calculated based on the observations of the downstream pressure (Evans and Wong, 1992).

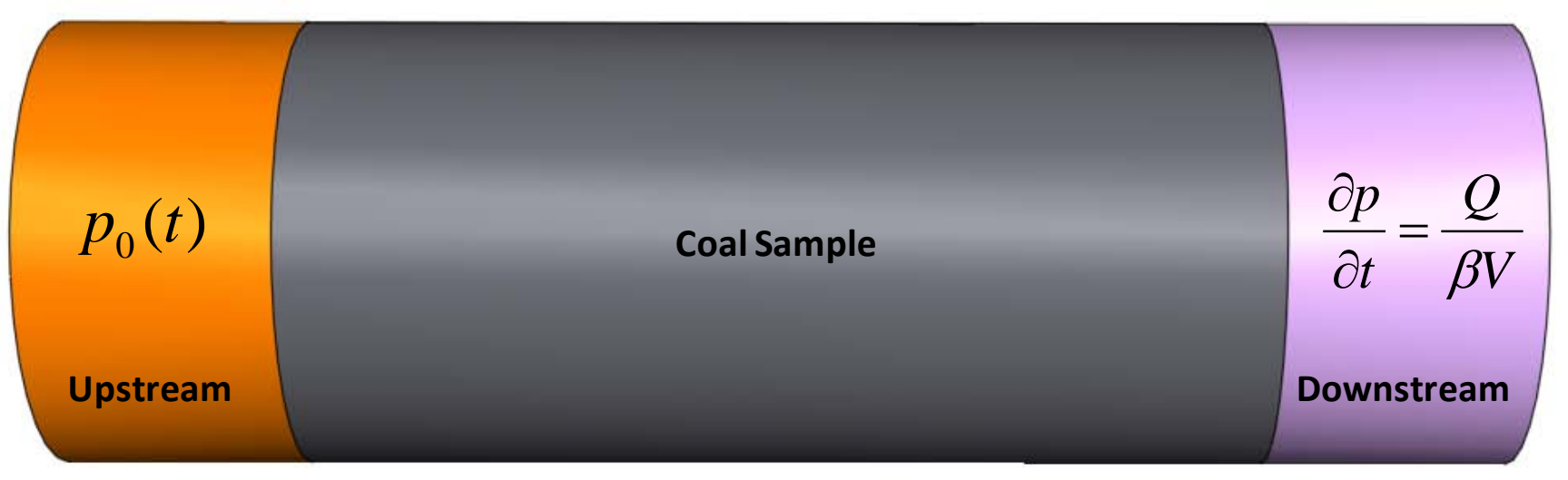

Figure 3.3: Upstream and Downstream boundary conditions

Where,

$$
\begin{aligned}
& \mathrm{P}_{0}(\mathrm{t})=\text { pre-defined pressure pulse, } \\
& \mathrm{L} \text { = length of the sample, } \\
& \mathrm{Q}=\text { flow rate through the sample, } \\
& \mathrm{V}=\text { downstream volume }
\end{aligned}
$$


The governing differential equation for a pressure pulse through the coal sample in a pressure transient method is given below (Haljasmaa et al., 2009; Brace et al., 1968; Evans and Wong, 1992).

$$
\left(\frac{k}{\eta}\right) \frac{\partial^{2} p}{\partial x^{2}}=(\alpha+\phi \beta) \frac{\partial p}{\partial t}
$$

Where,

$$
\begin{aligned}
& t=\text { time } \\
& x=\text { axial coordinate with the origin at the upstream face of the cylindrical } \\
& \text { sample } \\
& \alpha=\text { permeability of the sample, } \\
& \beta=\text { adiabatic compressibility of pore fluid, } \\
& \phi=\text { porosity of the sample and, } \\
& \eta=\text { dynamic viscosity of pore fluid }
\end{aligned}
$$

Two pressure transients, A-Spike pressure pulse and Sine-6 pressure pulse, were used in the present study. A typical upstream pressure pulse and its downstream pressure response for an A-Spike pressure pulse are shown in Figure 3.4. Figure 3.5 shows a typical downstream pressure response and the upstream pressure pulse for a Sine-6 pressure transient used in the study. 
S02: $\mathrm{CO}_{2}$ Event 147 Experimental Data

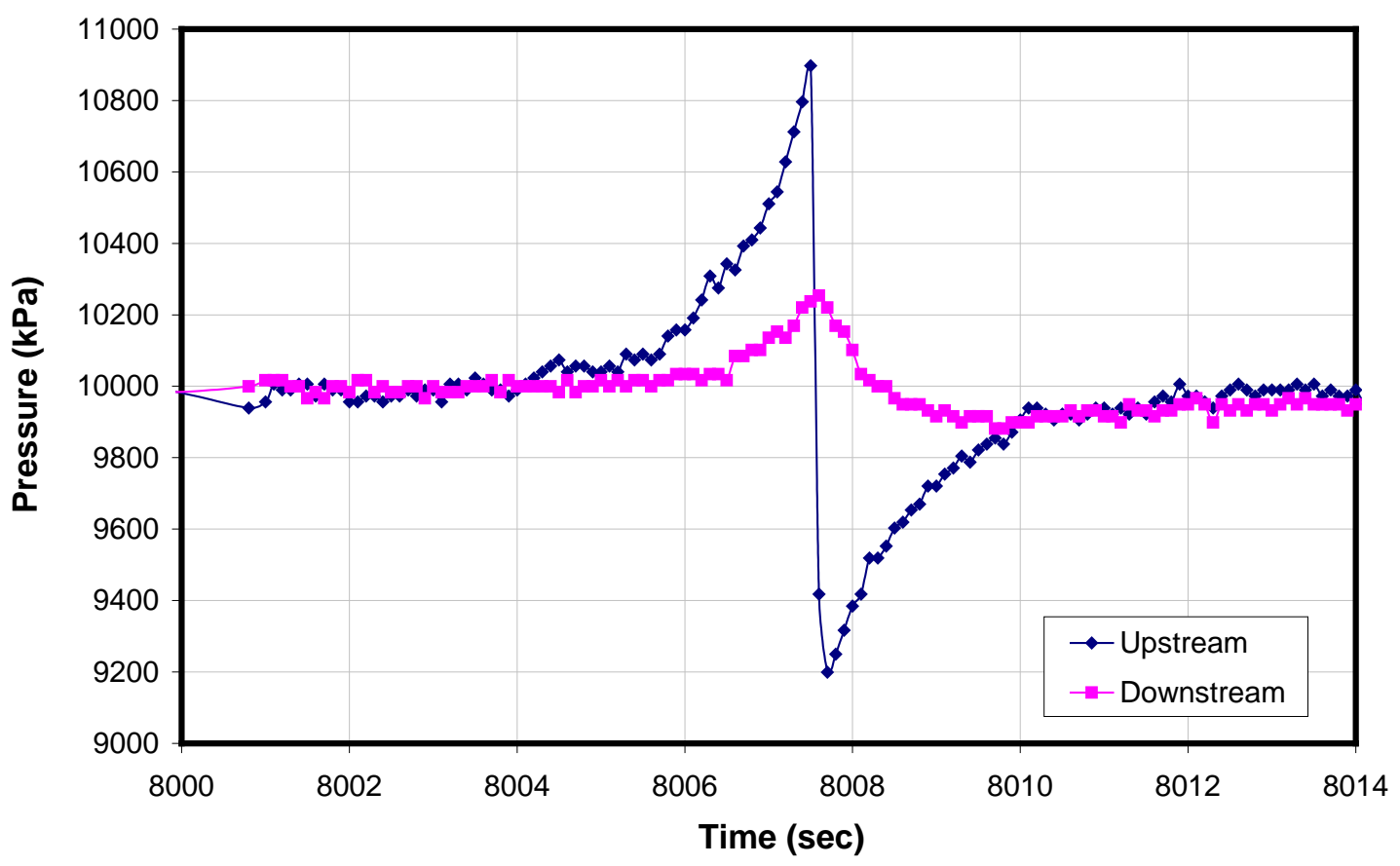

Figure 3.4: A typical A-Spike pressure pulse for experimental tests

S02: $\mathrm{CO}_{2}$ Event 147 Experimental Data

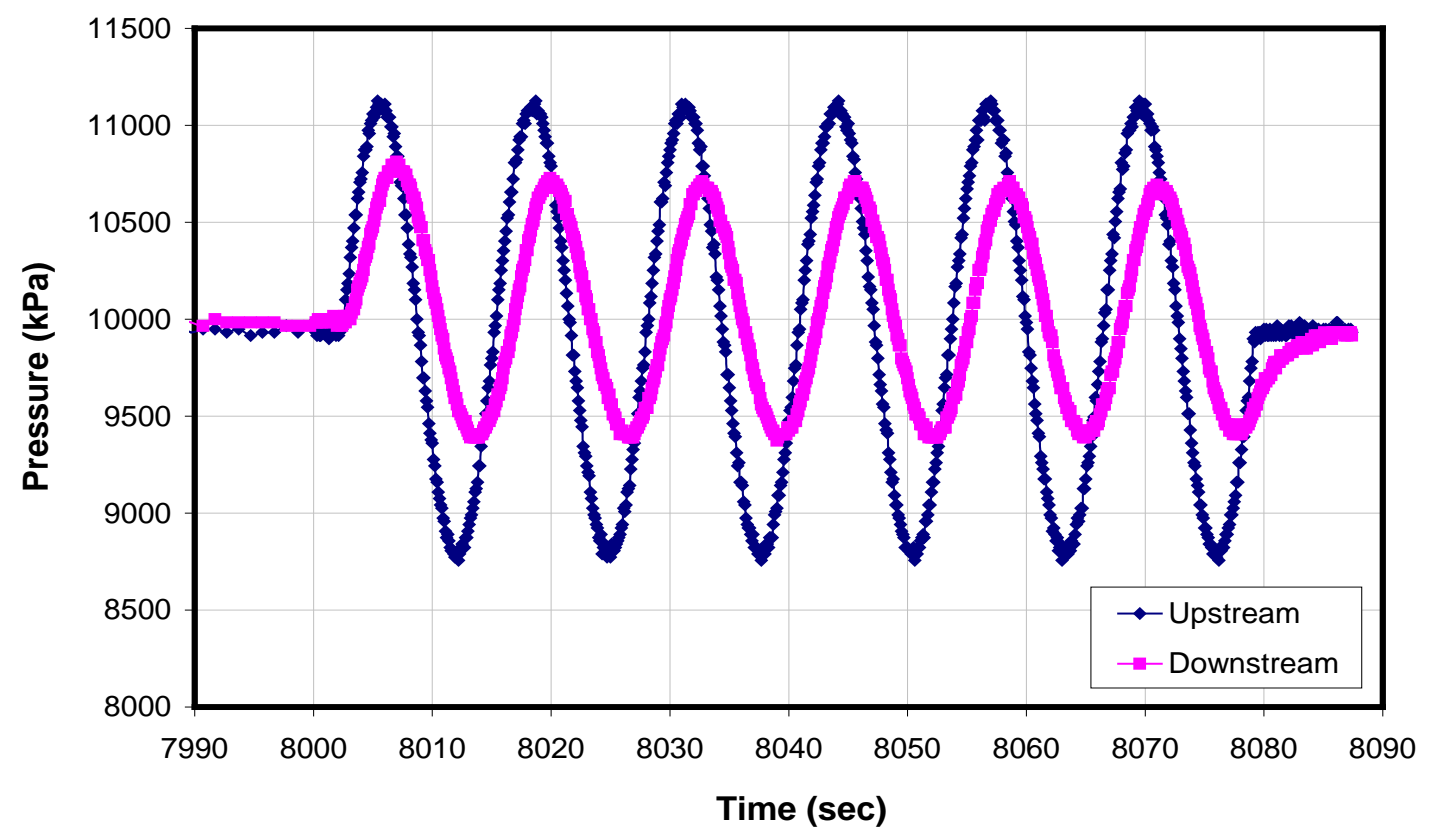

Figure 3.5: A typical Sine-6 pressure pulse for experimental tests 


\subsection{EXPERIMENTAL RESULTS}

Results from experimental tests conducted on fourteen coal samples are shown in Table 3.2 (Haljasmaa et al 2009). Of these fourteen samples, S03 and S09 were damaged during testing (Haljasmaa et al 2009). Each sample was tested using both pressure transients A-Spike and Sine-6 to determine the permeability of the coal matrix. For some samples, pressure rise and pressure decline responses were also observed at the downstream end. Permeability values of selected events for each coal sample are given in Table 3.2. Table 3.2, which shows a detailed summary of selected events and the permeability values obtained from the experimental apparatus. These experimental values of the permeability were compared with the results obtained from the numerical models for each sample in the later part of the report.

Table 3.2: Summary of experimental tests

\begin{tabular}{|c|c|c|c|c|c|c|c|}
\hline \multirow[b]{2}{*}{ Sample \# } & \multirow{2}{*}{$\begin{array}{c}\text { Data } \\
\text { Set } \\
\# \\
\end{array}$} & \multirow{2}{*}{$\begin{array}{l}\text { Pressure } \\
\text { Pulse }\end{array}$} & \multicolumn{2}{|c|}{ Duration } & \multirow{2}{*}{ Fluid } & \multirow{2}{*}{$\begin{array}{c}\text { Event } \\
\#\end{array}$} & \multirow{2}{*}{$\begin{array}{c}\text { Experimental } \\
\text { 'k' }\end{array}$} \\
\hline & & & $\mathbf{T}_{\mathbf{i}}(\mathrm{sec})$ & $\mathbf{T}_{\mathrm{f}}(\mathrm{sec})$ & & & \\
\hline S01 & - & - & - & - & - & - & - \\
\hline \multirow[t]{6}{*}{ S02 } & 1 & A-Spike & 537438.5 & 537465.9 & $\mathrm{CO}_{2}$ & 47 & $0.25 \mathrm{mD}$ \\
\hline & 1 & Sine - 6 & 537497.3 & 537594.8 & $\mathrm{CO}_{2}$ & 48 & $0.27 \mathrm{mD}$ \\
\hline & 2 & A-Spike & 1145063.9 & 1145098.8 & $\mathrm{CO}_{2}$ & 147 & $8 \mu \mathrm{D}$ \\
\hline & 2 & Sine - 6 & 1145176.6 & 1145279.3 & $\mathrm{CO}_{2}$ & 148 & $8 \mu \mathrm{D}$ \\
\hline & 3 & A-Spike & 1147713.7 & 1147779.9 & $\mathrm{CO}_{2}$ & 163 & $0.6 \mu \mathrm{D}$ \\
\hline & 3 & Sine - 6 & 1147888.5 & 1148094 & $\mathrm{CO}_{2}$ & 164 & $1.2 \mu \mathrm{D}$ \\
\hline S02 & 4 & $\begin{array}{l}\text { Transient } \\
\text { (Rising) }\end{array}$ & 0 & 4000 & Argon & - & - \\
\hline S03 & - & - Failed - & - & - & - & - & - \\
\hline \multirow[t]{2}{*}{ S04 } & 1 & Sine -6 & 8122.9 & 8279 & Argon & 4 & $2.4 \mathrm{mD}$ \\
\hline & 1 & A-Spike & 8303 & 8340 & Argon & 5 & $3.0 \mathrm{mD}$ \\
\hline
\end{tabular}


Table 3.2: Summary of experimental tests (continued...)

\begin{tabular}{|c|c|c|c|c|c|c|c|}
\hline \multirow[b]{2}{*}{ Sample \# } & \multirow{2}{*}{$\begin{array}{l}\text { Data } \\
\text { Set \# }\end{array}$} & \multirow{2}{*}{$\begin{array}{l}\text { Pressure } \\
\text { Pulse }\end{array}$} & \multicolumn{2}{|c|}{ Duration } & \multirow{2}{*}{ Fluid } & \multirow{2}{*}{$\begin{array}{c}\text { Event } \\
\#\end{array}$} & \multirow{2}{*}{$\begin{array}{c}\text { Experimental } \\
\text { ' } k \text { ' } \\
\end{array}$} \\
\hline & & & $T_{i}($ sec) & $T_{\text {f }}(\mathrm{sec})$ & & & \\
\hline \multirow[t]{6}{*}{ S04 } & 2 & A-Spike & 1295.6 & 1329.3 & $\mathrm{CO}_{2}$ & 0 & $36 \mu \mathrm{D}$ \\
\hline & 2 & Sine - 6 & 1415.6 & 1528.7 & $\mathrm{CO}_{2}$ & 1 & $29 \mu \mathrm{D}$ \\
\hline & 3 & Sine -6 & 1303402.2 & 1303598.4 & $\mathrm{CO}_{2}$ & 104 & $7.6 \mu \mathrm{D}$ \\
\hline & 3 & A-Spike & 1304022.2 & 1304089 & $\mathrm{CO}_{2}$ & 105 & $6.9 \mu \mathrm{D}$ \\
\hline & 4 & A-Spike & 1322869.4 & 1323028.5 & $\mathrm{CO}_{2}$ & 123 & $2.2 \mu \mathrm{D}$ \\
\hline & 4 & Sine - 6 & 1323147 & 1323397.5 & $\mathrm{CO}_{2}$ & 124 & $2.6 \mu \mathrm{D}$ \\
\hline \multirow[t]{2}{*}{ S05 } & 1 & A-Spike & 9147.7 & 9185.8 & Argon & 2 & $2.5 \mathrm{mD}$ \\
\hline & 1 & Sine - 6 & 9318.7 & 9452.0 & Argon & 3 & $3.2 \mathrm{mD}$ \\
\hline \multirow[t]{4}{*}{ S05 } & 2 & A-Spike & 1228.9 & 1261.2 & $\mathrm{CO}_{2}$ & 2 & $64 \mu \mathrm{D}$ \\
\hline & 2 & Sine - 6 & 1309.0 & 1409.9 & $\mathrm{CO}_{2}$ & 3 & $55 \mu \mathrm{D}$ \\
\hline & 3 & A-Spike & 172812.2 & 172961.1 & $\mathrm{CO}_{2}$ & 44 & $1.2 \mu \mathrm{D}$ \\
\hline & 3 & Sine - 6 & 173126.1 & 173354.7 & $\mathrm{CO}_{2}$ & 45 & $1.6 \mu \mathrm{D}$ \\
\hline \multirow[t]{2}{*}{ S06 } & 1 & A-Spike & 334.9 & 354.9 & Argon & 1 & $3.7 \mathrm{mD}$ \\
\hline & 1 & Sine - 6 & 393.8 & 495.8 & Argon & 2 & $4.9 \mathrm{mD}$ \\
\hline \multirow[t]{6}{*}{ S06 } & 2 & A-Spike & 332.8 & 358.7 & $\mathrm{CO}_{2}$ & 1 & $2.44 \mathrm{mD}$ \\
\hline & 2 & Sine - 6 & 401.5 & 503.5 & $\mathrm{CO}_{2}$ & 2 & $0.84 \mathrm{mD}$ \\
\hline & 3 & Sine -6 & 1143874.7 & 1144068.9 & $\mathrm{CO}_{2}$ & 122 & $2.5 \mu \mathrm{D}$ \\
\hline & 3 & A-Spike & 1144243.9 & 1144363.7 & $\mathrm{CO}_{2}$ & Bad! & - \\
\hline & 4 & A-Spike & 1144550.7 & 1144826.4 & $\mathrm{CO}_{2}$ & 123 & $2.1 \mu \mathrm{D}$ \\
\hline & 4 & Sine - 6 & 1145153.5 & 1146057.5 & $\mathrm{CO}_{2}$ & 124 & $2.1 \mu \mathrm{D}$ \\
\hline
\end{tabular}


Table 3.2: Summary of experimental tests (continued...)

\begin{tabular}{|c|c|c|c|c|c|c|c|}
\hline \multirow[b]{2}{*}{ Sample \# } & \multirow{2}{*}{$\begin{array}{c}\text { Data } \\
\text { Set } \\
\#\end{array}$} & \multirow{2}{*}{$\begin{array}{c}\text { Pressure } \\
\text { Pulse }\end{array}$} & \multicolumn{2}{|c|}{ Duration } & \multirow{2}{*}{ Fluid } & \multirow{2}{*}{$\begin{array}{c}\text { Event } \\
\#\end{array}$} & \multirow{2}{*}{$\begin{array}{c}\text { Experimental } \\
\text { 'k' }\end{array}$} \\
\hline & & & $T_{i}($ sec) & $T_{\mathrm{f}}(\mathrm{sec})$ & & & \\
\hline S07 & 1 & A-Spike & 90884.6 & 91915.7 & Argon & - & - \\
\hline \multirow[t]{4}{*}{ S08 } & 1 & A-Spike & 3997.5 & 4088.7 & $\mathrm{CO}_{2}$ & 2 & $1 \mu \mathrm{D}$ \\
\hline & 1 & Sine - 6 & 4163.2 & 4374.9 & $\mathrm{CO}_{2}$ & 3 & $1.2 \mu \mathrm{D}$ \\
\hline & 2 & Sine -6 & 4420.5 & 4881.9 & $\mathrm{CO}_{2}$ & 4 & $1.0 \mu \mathrm{D}$ \\
\hline & 2 & A-Spike & 5150.9 & 5308.8 & $\mathrm{CO}_{2}$ & 5 & $1.0 \mu \mathrm{D}$ \\
\hline S09 & - & - Failed - & - & - & - & - & - \\
\hline \multirow[t]{4}{*}{ S10 } & 1 & A-Spike & 17059.4 & 17094.3 & $\mathrm{CO}_{2}$ & 0 & $37 \mu \mathrm{D}$ \\
\hline & 1 & Sine - 6 & 17234.9 & 17353.7 & $\mathrm{CO}_{2}$ & 1 & $44 \mu \mathrm{D}$ \\
\hline & 2 & Sine -6 & 370815.1 & 372839.2 & $\mathrm{CO}_{2}$ & $\begin{array}{c}\text { Not } \\
\text { saved }\end{array}$ & - \\
\hline & 2 & A-Spike & 373368.8 & 373680.7 & $\mathrm{CO}_{2}$ & 66 & $0.2 \mu \mathrm{D}$ \\
\hline \multirow[t]{5}{*}{ S11 } & 1 & A-Spike & 2066.5 & 2668.2 & $\mathrm{CO}_{2}$ & 0 & $0.09 \mu \mathrm{D}$ \\
\hline & 1 & Sine - 6 & 3493.2 & 7708.2 & $\mathrm{CO}_{2}$ & 1 & $0.066 \mu \mathrm{D}$ \\
\hline & 2 & Sine -6 & 695357.1 & 705187.8 & $\mathrm{CO}_{2}$ & 18 & $0.027 \mu \mathrm{D}$ \\
\hline & 2 & A-Spike & 707891.8 & 709676.1 & $\mathrm{CO}_{2}$ & 19 & $0.025 \mu \mathrm{D}$ \\
\hline & 3 & $\begin{array}{l}\text { Transient } \\
\text { (Falling) }\end{array}$ & 0 & 4000 & $\mathrm{CO}_{2}$ & - & - \\
\hline \multirow[t]{2}{*}{ S12 } & 1 & A-Spike & 208.6 & 233.4 & $\mathrm{CO}_{2}$ & 0 & $0.127 \mathrm{mD}$ \\
\hline & 1 & Sine - 6 & 389.3 & 487.3 & $\mathrm{CO}_{2}$ & 1 & $0.121 \mathrm{mD}$ \\
\hline \multirow[t]{2}{*}{ S12 } & 2 & A-Spike & 489.6 & 520.0 & Argon & 0 & $0.11 \mathrm{mD}$ \\
\hline & 2 & Sine - 6 & 602.0 & 710.5 & Argon & 1 & $0.10 \mathrm{mD}$ \\
\hline S13 & 1 & Sine -6 & 4643.2 & 4846.0 & Argon & 1 & $2.8 \mu \mathrm{D}$ \\
\hline
\end{tabular}


Table 3.2: Summary of experimental tests (continued...)

\begin{tabular}{|c|c|c|c|c|c|c|c|}
\hline \multirow[b]{2}{*}{ Sample \# } & \multirow{2}{*}{$\begin{array}{l}\text { Data } \\
\text { Set \# }\end{array}$} & \multirow{2}{*}{$\begin{array}{c}\text { Pressure } \\
\text { Pulse }\end{array}$} & \multicolumn{2}{|c|}{ Duration } & \multirow{2}{*}{ Fluid } & \multirow{2}{*}{$\begin{array}{c}\text { Event } \\
\quad \#\end{array}$} & \multirow{2}{*}{$\begin{array}{c}\text { Experimental } \\
\text { 'k' }\end{array}$} \\
\hline & & & $\mathrm{T}_{\mathrm{i}}$ (sec) & $T_{f}(\mathrm{sec})$ & & & \\
\hline & 1 & A-Spike & 4925.6 & 5059.6 & Argon & 2 & $2.7 \mu \mathrm{D}$ \\
\hline & 2 & A-Spike & 25177.4 & 25381.0 & Argon & 9 & $2.1 \mu \mathrm{D}$ \\
\hline & 2 & Sine - 6 & 25643.0 & 26151.7 & Argon & 10 & $2.2 \mu \mathrm{D}$ \\
\hline & 3 & A-Spike & 270993.1 & 272400.2 & $\mathrm{CO}_{2}$ & 30 & $0.039 \mu \mathrm{D}$ \\
\hline & 3 & Sine - 6 & 273570.2 & 278236.5 & $\mathrm{CO}_{2}$ & 31 & $0.047 \mu \mathrm{D}$ \\
\hline & 4 & A-Spike & 430058.5 & 431647.0 & $\mathrm{CO}_{2}$ & 32 & $0.024 \mu \mathrm{D}$ \\
\hline & 4 & Sine - 6 & 433050.0 & 441710.5 & $\mathrm{CO}_{2}$ & 33 & $0.031 \mu \mathrm{D}$ \\
\hline \multirow[t]{4}{*}{$\mathrm{S} 14$} & 1 & A-Spike & 17764.1 & 17789.3 & Argon & 16 & $1.76 \mathrm{mD}$ \\
\hline & 1 & Sine - 6 & 17843.7 & 17948.1 & Argon & 17 & $1.38 \mathrm{mD}$ \\
\hline & 2 & A-Spike & 178717.6 & 178750.6 & $\mathrm{CO}_{2}$ & 63 & $195 \mu \mathrm{D}$ \\
\hline & 2 & Sine - 6 & 178802.5 & 178908.3 & $\mathrm{CO}_{2}$ & 64 & $127 \mu \mathrm{D}$ \\
\hline \multirow[t]{2}{*}{ Nat Cleat (no\#) } & 1 & A-Spike & 5543.4 & 5579.9 & $\mathrm{CO}_{2}$ & - & - \\
\hline & 1 & Sine - 6 & 5718.2 & 5817.5 & $\mathrm{CO}_{2}$ & - & - \\
\hline \multirow[t]{2}{*}{ New sample -782 } & 1 & Rising & 4700.1 & 5547.1 & Argon & - & - \\
\hline & 2 & Sine -6 & 7633.4 & 8025.9 & Argon & - & - \\
\hline \multirow[t]{4}{*}{ New sample - 762} & 1 & Rising & 10157.3 & 10536.3 & Argon & - & - \\
\hline & 1 & Sine - 6 & 10678.4 & 11063.4 & Argon & - & - \\
\hline & 1 & A-Spike & 11304.2 & 11379.2 & Argon & - & - \\
\hline & 1 & Falling & 15603.1 & 16427.1 & Argon & - & - \\
\hline New Sample - 169 & 1 & Rising & - & - & - & - & - \\
\hline
\end{tabular}


Table 3.2: Summary of experimental tests (continued...)

\begin{tabular}{|c|c|c|c|c|c|c|c|}
\hline \multirow[b]{2}{*}{ Sample \# } & \multirow{2}{*}{$\begin{array}{l}\text { Data } \\
\text { Set \# }\end{array}$} & \multirow{2}{*}{$\begin{array}{l}\text { Pressure } \\
\text { Pulse }\end{array}$} & \multicolumn{2}{|c|}{ Duration } & \multirow{2}{*}{ Fluid } & \multirow{2}{*}{$\begin{array}{c}\text { Event } \\
\#\end{array}$} & \multirow{2}{*}{$\begin{array}{c}\text { Experimental } \\
\text { ' } k \text { ' }\end{array}$} \\
\hline & & & $T_{i}(\mathrm{sec})$ & $T_{f}(\sec )$ & & & \\
\hline & 1 & Sine - 6 & 6766.1 & 7532.1 & $\mathrm{CO}_{2}$ & - & - \\
\hline
\end{tabular}

These permeability values reported in Table 3.2 for the coal matrix were obtained from the experimental results based on the assumption that there is no fracture in the coal matrix. This is because the apparatus determines the permeability by considering the matrix and the fracture as one homogeneous medium. In other words, the fracture permeability alone cannot be determined from the apparatus. The permeability determined in the apparatus is an average value of the permeabilities of the matrix and the fracture. Obviously, the fracture permeability is much higher than the matrix permeability. The mathematical theory used in the apparatus assumes on value of the permeability for the medium.

In the present study, the permeability of the fracture is assumed to be different from that of the matrix. This assumption requires the solutions to be obtained by using numerical methods. In the present study, finite element method was used in computing the pressure transient behavior of the fractured coal samples. 


\section{CHAPTER 4: FINITE ELEMENT ANALYSIS}

\subsection{METHODOLOGY}

Finite element analysis was performed on the coal samples to determine permeability. Various coal samples (Table 3.2) were selected to perform the computer modeling study. The physical properties used to perform the numerical analyses for each sample are different and are shown in Table 3.1. Available experimental results (Haljasmaa et al., 2009) were compared with those obtained from computer models. Fluid compressibility values of $\mathrm{CO}_{2}$ and Argon were used to perform the finite element analyses. These values are shown in Table 2.2 and Table 2.3. A value of $692,000 \mathrm{psi}(4,770,000 \mathrm{kPa})(\mathrm{Eo})$ for the elastic modulus of the coal samples was used on the basis of literature (Palmer and Mansoori, 1996).

A typical fractured coal sample used in an experiment is shown in Figure 4.1. A flexible rubber sleeve was placed around the sample to keep the sample intact during the experimental tests. Figure 4.2 shows the schematic diagram of a fracture induced in a coal sample.

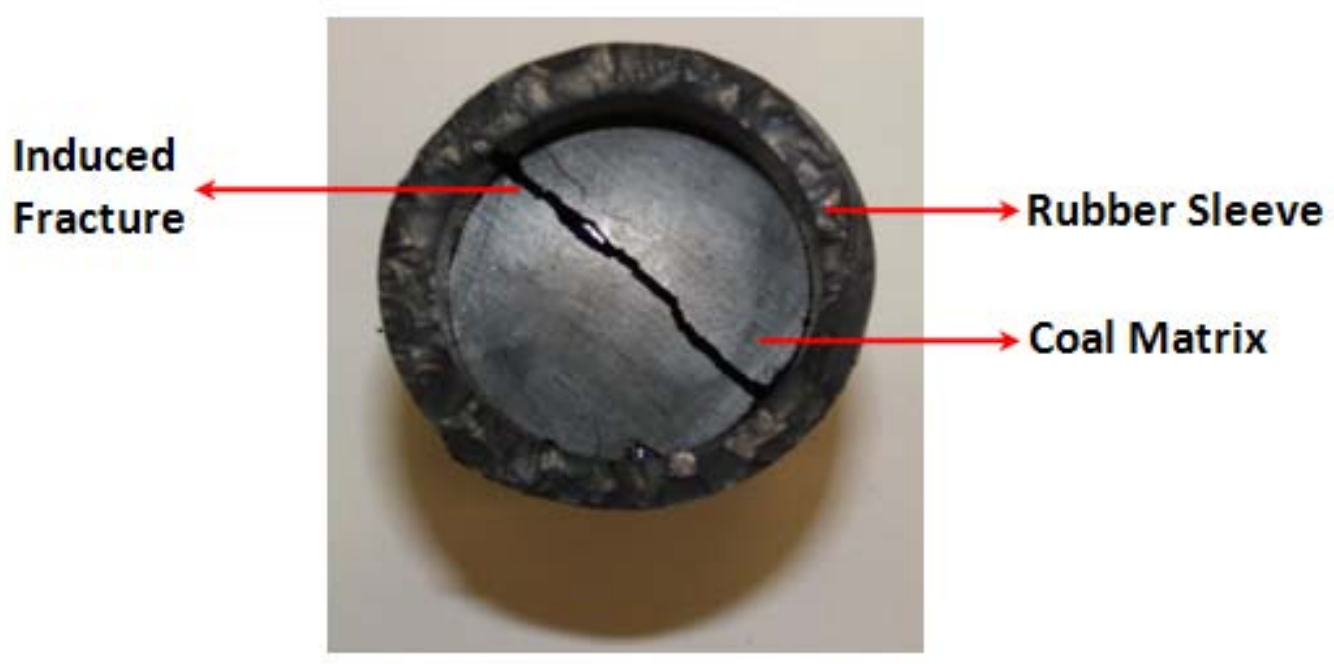

Figure 4.1: A typical fractured coal sample used in an experiment test 


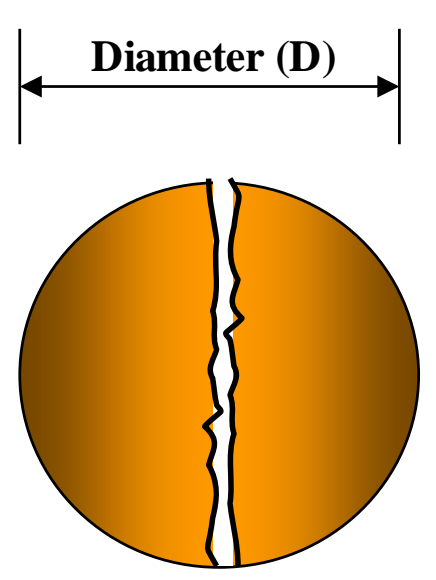

Refer: Table 3.1

Diameter (D) $<50.5 \mathrm{~mm}$

Length (L) $<80.2 \mathrm{~mm}$

Fracture width $\left(\mathrm{t}_{\mathrm{w}}\right)=1 \mathrm{~mm}$

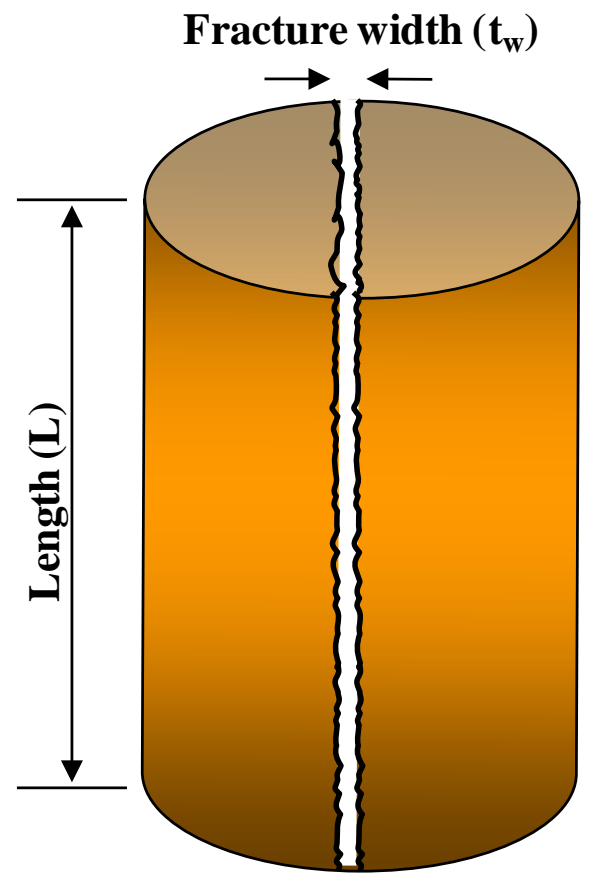

Figure 4.2: Schematic of a coal sample with a fracture

\subsection{PROCEDURE FOR NUMERICAL MODELING}

In the present research, Finite element models were generated for each coal sample using ABAQUS. Finite element analyses on each sample were performed to compare the computer model results with the available experimental results for various events that were identified (Table 3.2). The analysis for each sample was performed using different pressure transients: Sine-6 pressure transient and A-Spike pressure transient. For some samples the downstream response of pressure rise and pressure decline curves were also compared with the numerical results. Figure 4.3 shows the finite element mesh for sample S10 with a fracture that was used in the computer model study.

The analyses were performed in two ways:

1. Considering a fracture width of $1 \mathrm{~mm}$.

2. Considering that there is no fracture. 
The range of values of matrix permeability and matrix porosity for each coal sample were reported elsewhere (Haljasmaa et al, 2009). For each sample, the fracture porosity was determined using equation (4.1) assuming the matrix permeability value of $100 \mathrm{nD}$ or $200 \mathrm{nD}$ for an event.

$$
\phi_{f}=\left(\frac{k_{f}}{k_{m}}\right)^{1 / 3} * \phi_{m}
$$

Where,

$$
\begin{aligned}
& \phi_{f}=\text { Porosity of fracture } \\
& \phi_{m}=\text { Porosity of matrix } \\
& k_{f}=\text { Fracture permeability } \\
& k_{m}=\text { Matrix permeability }
\end{aligned}
$$
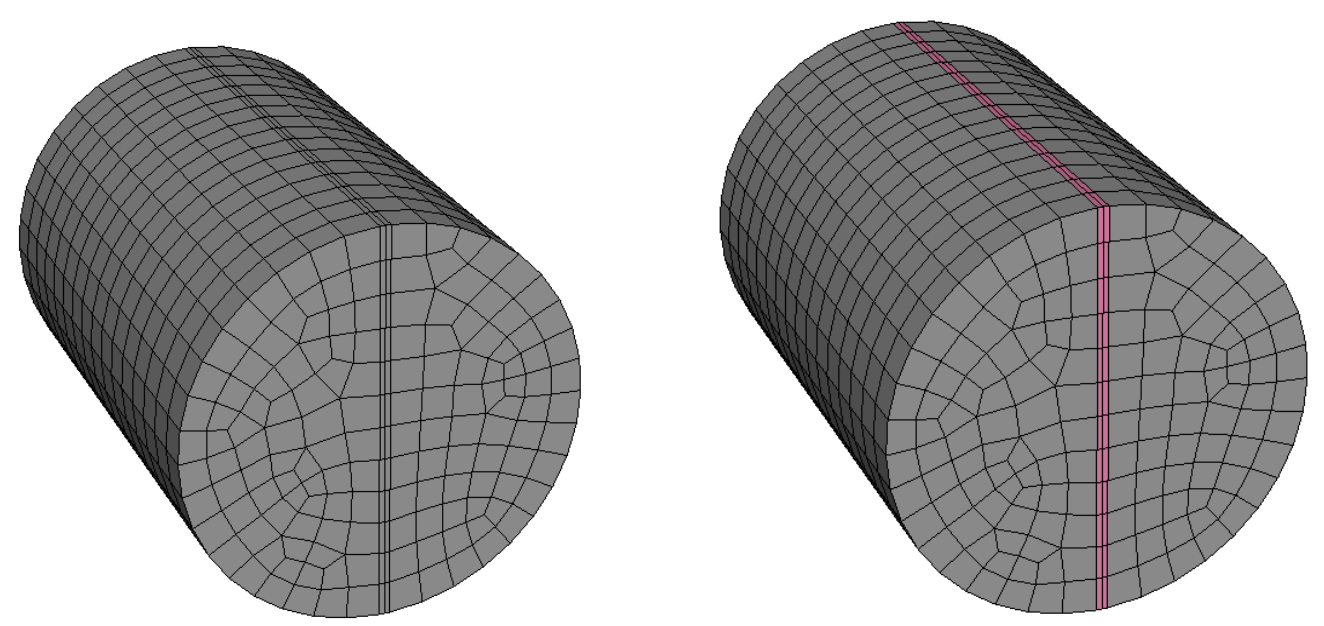

Figure 4.3: Finite element mesh for rock sample S10 with a $1 \mathrm{~mm}$ fracture 
The pore volume of the upstream chamber and downstream chamber were considered as 14.92 cc and 0.8 cc, respectively (Haljasmaa et al, 2009). The length of the upstream chamber was calculated by using equation (4.2). In the computer model that was generated for each coal sample the length of the downstream chamber was considered to be equal to that of upstream chamber length.

$$
V_{\text {chamber }}=\frac{\pi D^{2}}{4} * L
$$

The porosity of downstream chamber used in the porosity for computer model was calculated by using equation (4.3). The downstream pore volume is equal to $0.8 \mathrm{cc}$, as reported earlier.

$$
V_{\text {porevolume }}=\phi \times V_{\text {chamber }}
$$

Each test was performed in three different stages as shown in Figure 4.4 and Figure 4.5. In the first stage of the test, upstream fluid pressure was maintained at 4.0 or $10.0 \mathrm{MPa}$ depending on the event for which the analysis was being performed. In the second stage of the experiment, the fluid pressure at the upstream chamber of the sample was modified by applying a sine-6 pressure pulse or A-spike pressure pulse. The upstream pressure pulses (ASpike pressure pulse and sine-6 pressure pulse) are shown in Figure 4.4 and Figure 4.5, respectively. In the final stage of the experiment, the upstream pressure was reduced to zero.

Specifically the following pressure changes were made in the upstream chamber.

Stage 1: Pressure increase (See Table 3. 1)

Stage 2: Pressure Transient (Sine-6 and A-Spike)

Stage 3: Pressure release 
The permeability ratio is defined as the ratio of fracture permeability $\left(\mathrm{k}_{\mathrm{f}}\right)$ to matrix permeability $\left(\mathrm{k}_{\mathrm{m}}\right)$ as given in equation (4.4).

$$
\text { Permeability Ratio, } \lambda=\frac{k_{f}}{k_{m}}
$$

Various values for the permeability ratio $(\lambda)$ were used to match the computer model results with the available experimental results for each event of the samples. This approach involved a several analyses for each coal sample. The $\lambda$ value that provided a reasonable overall match with experimental data which was selected in determining fracture permeability on the basis of equation 4.4. 
$\mathrm{S} 10: \mathrm{CO}_{2}$ Event $\mathrm{O}$

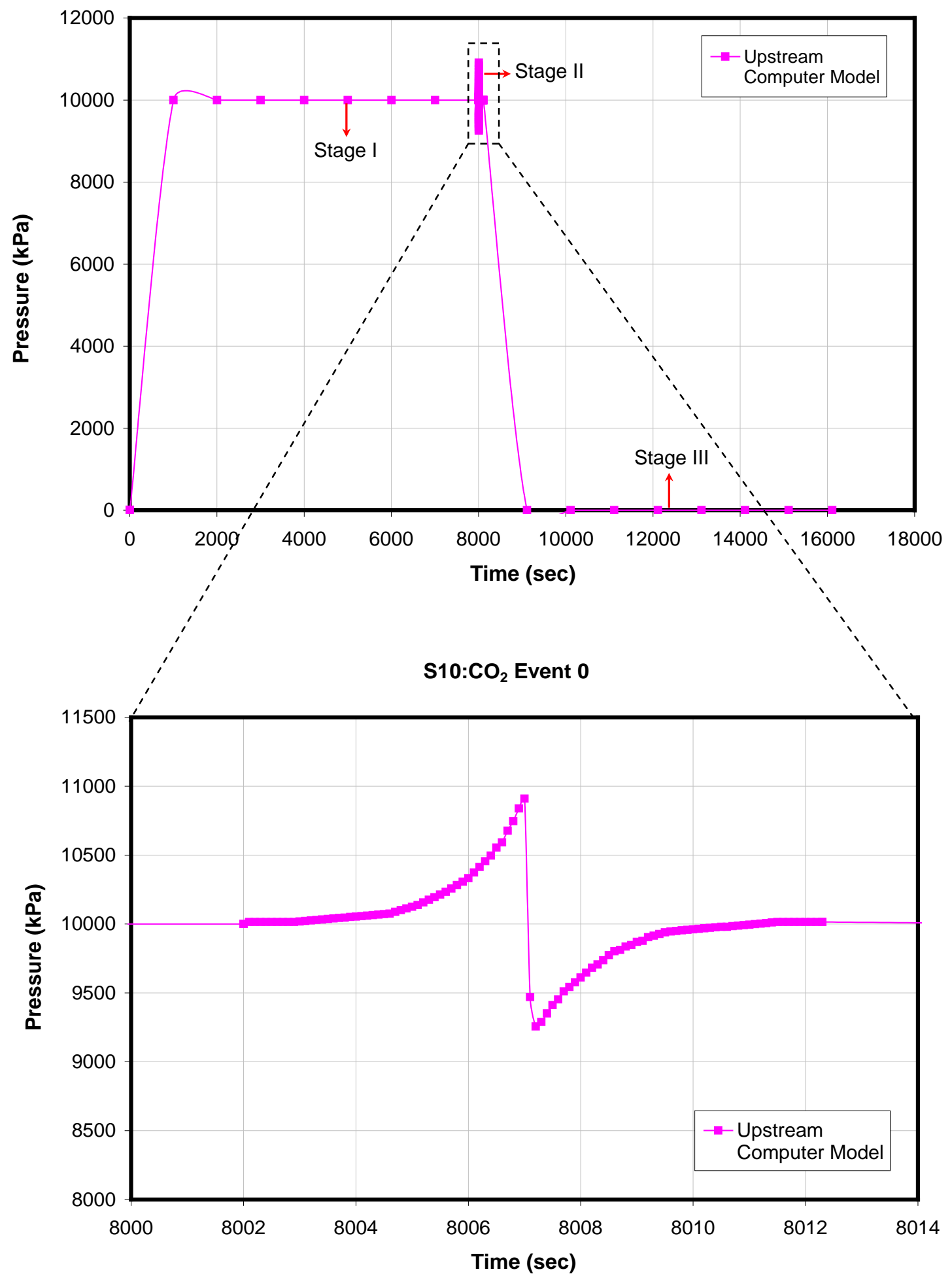

Figure 4.4: Upstream pressure pulse (A-Spike) 
S10: $\mathrm{CO}_{2}$ Event 1

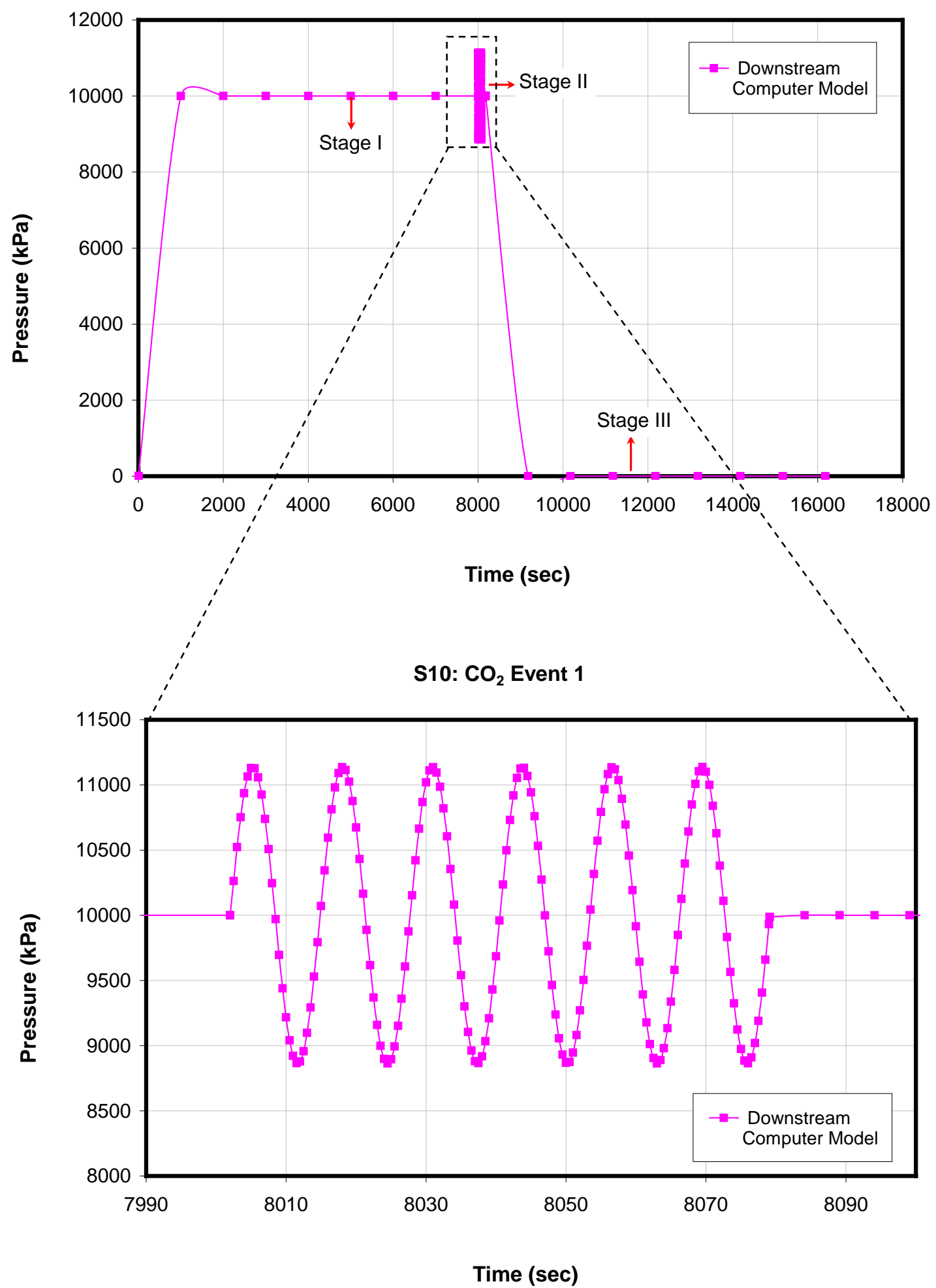

Figure 4.5: Upstream pressure pulse (Sine - 6) 
A comprehensive study was conducted to the check the influence of the physical properties such as elastic modulus, porosity, fracture width, and fluid compressibility. The results for each physical property mentioned above are shown below. Figure 4.6 shows downstream pressure response when the elastic modulus of the coal sample was varied from $0.1 \mathrm{E}_{\mathrm{o}}$ to $10 \mathrm{E}_{\mathrm{o}}$. The elastic modulus of coal seems to have a significant influence on the pressure response. To investigate the influence of the fracture width, fracture widths of $1 \mathrm{~mm}$ and $2 \mathrm{~mm}$ were used in the models. The value of permeability for rock was assumed to be 100 $\mathrm{nD}$ (Haljasmaa et al, 2009). For $1 \mathrm{~mm}$ fracture width, the fracture permeability value of 3.2 $\mathrm{mD}$ was considered as the base case and the fracture permeability value of $2 \mathrm{~mm}$ fracture width was $25.6 \mathrm{mD}$ which was calculated using equation (4.5) (Carmen, 1937). The influence of fracture width on the downstream pressure is shown in Figure 4.7. Figure 4.8 shows the downstream pressure responses for fracture permeability values of $0.064 \mathrm{mD}$ and $0.52 \mathrm{mD}$ for fracture widths of $1 \mathrm{~mm}$ and $2 \mathrm{~mm}$, respectively. As can be seen from this figure, the fracture width in the range of $1 \mathrm{~mm}$ to $2 \mathrm{~mm}$ has a significant influence on the downstream pressure response.

$$
\frac{k_{f_{1}}}{k_{f_{2}}}=\left(\frac{t_{1}}{t_{2}}\right)^{3}
$$

Where,

$$
\begin{aligned}
& k_{f_{1}}=\text { fracture permeability } \\
& k_{f_{2}}=\text { fracture permeability } \\
& \mathrm{t}_{1}=\text { fracture thickness } \\
& \mathrm{t}_{2}=\text { fracture thickness }
\end{aligned}
$$


$\mathrm{S} 10: \mathrm{CO}_{2}$ Event 0 Downstream Experimental Data Vs Model Data

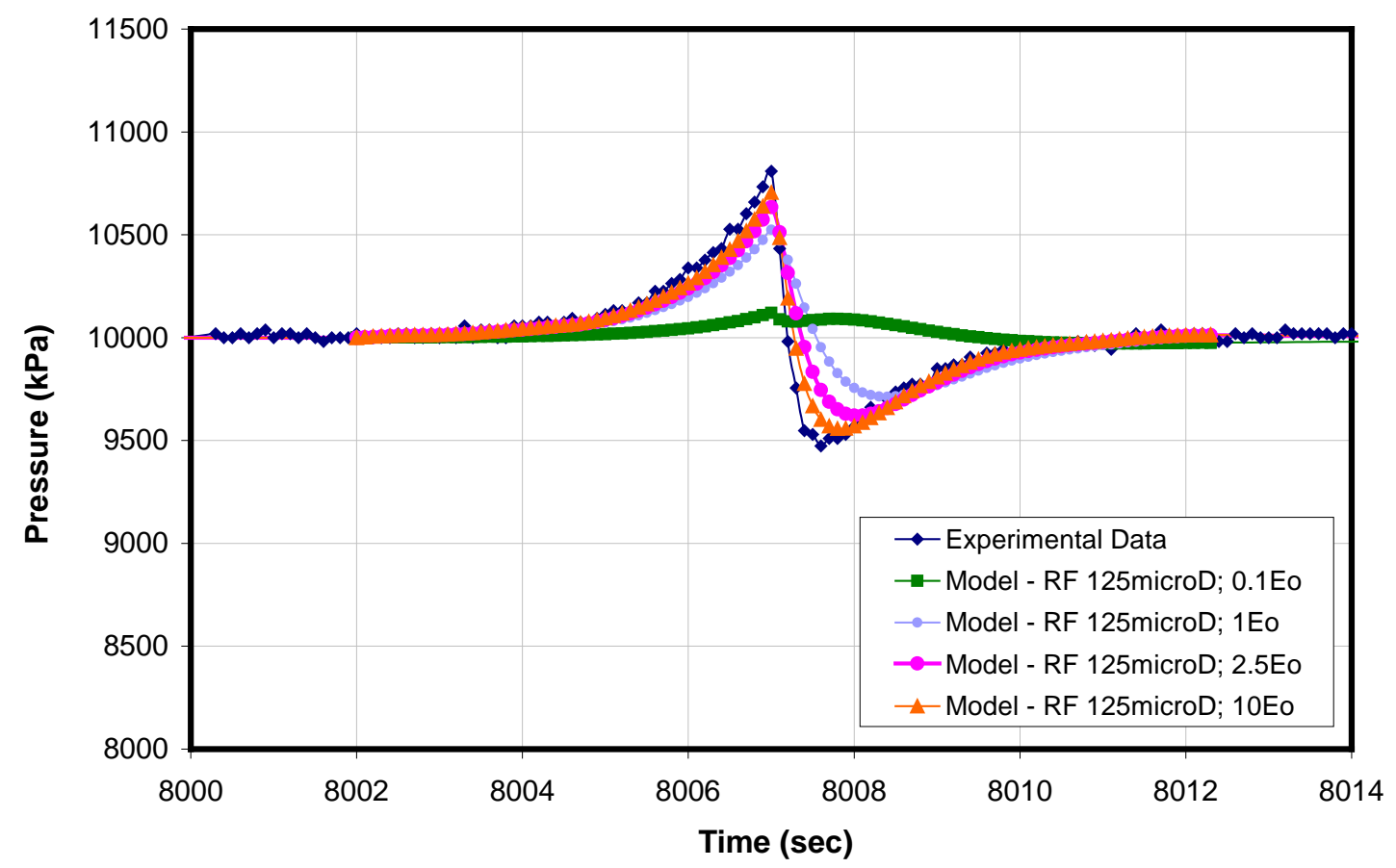

Figure 4.6: Influence of elastic modulus of the coal matrix 
S05:CO2 Event 2

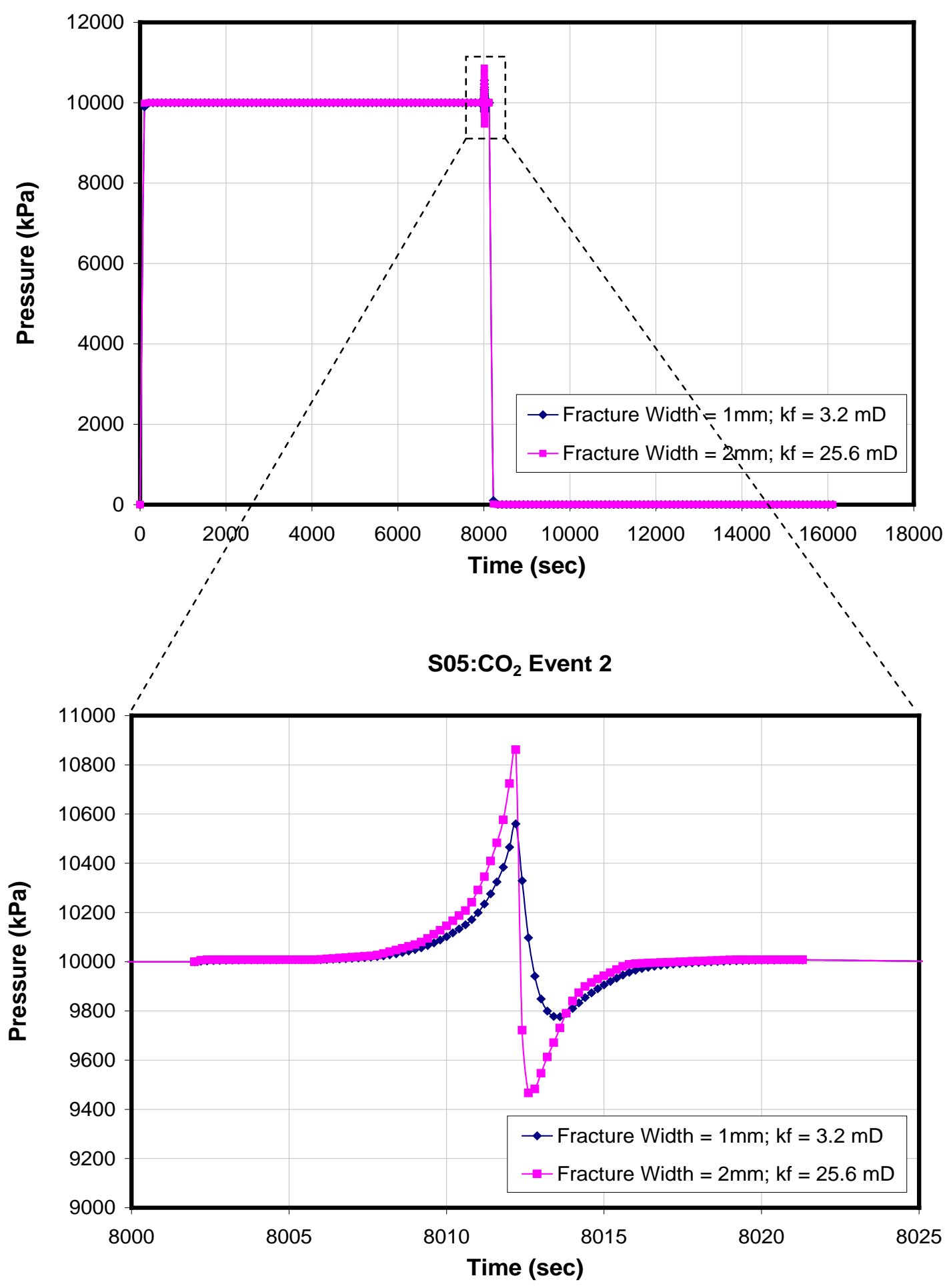

Figure 4.7: Influence of fracture width of the coal matrix 
S05:CO2 Event 2

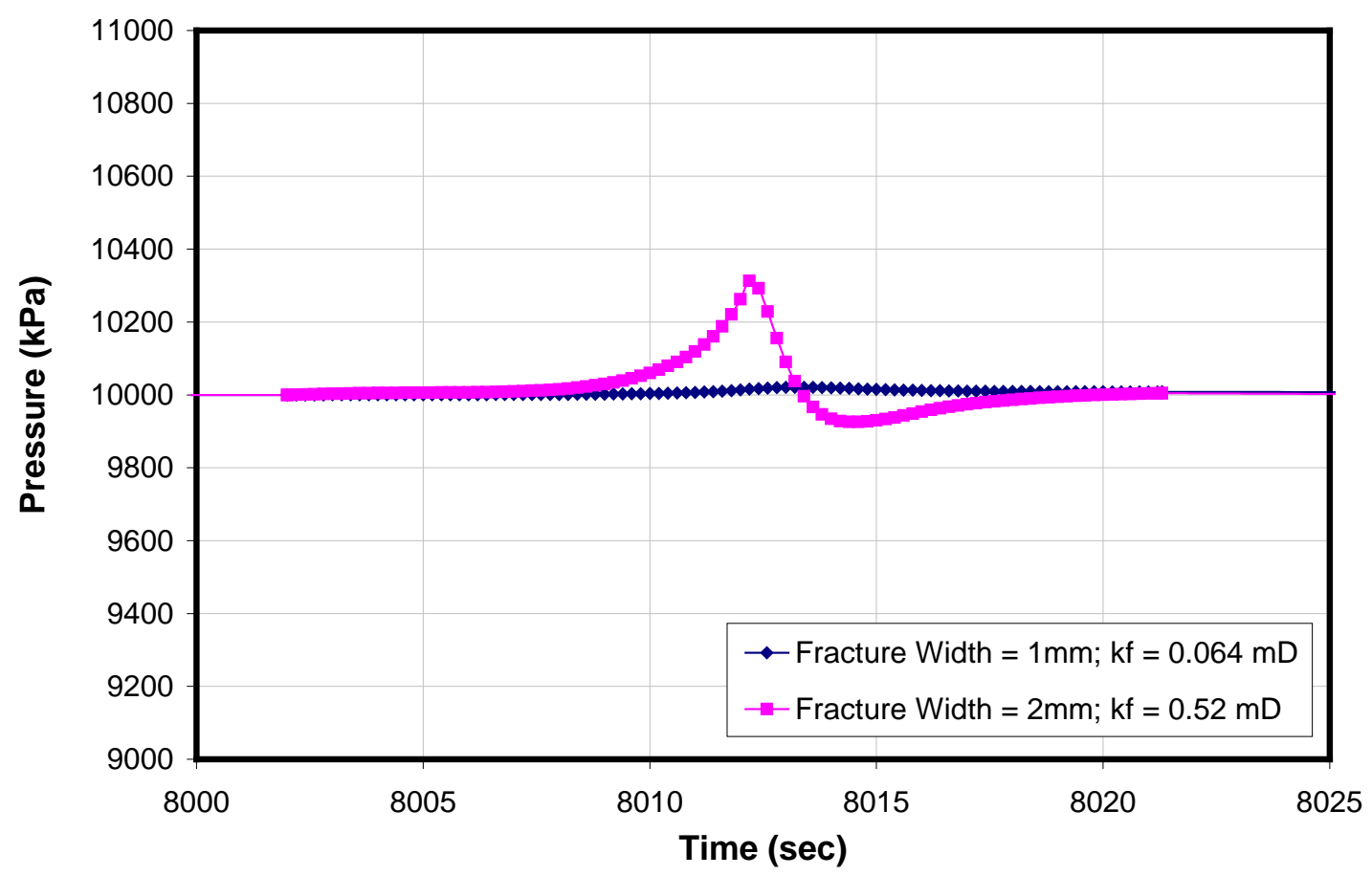

Figure 4.8: Influence of fracture width of the coal matrix 
The effect of fluid compressibility for sample S14 was computed. Figure 4.9 and Figure 4.10 show the upstream pressure variation and the downstream pressure response of sample S14 Event 64. To check the influence of fluid compressibility $\mathrm{CO}_{2}$, Argon, and Water were considered as the fluid media. The fluid compressibility has a significant influence on the downstream pressure response. Figure 4.11 shows that the amplitude of the downstream pressure response increases as the fluid compressibility value decreases.

Figure 4.12 shows the influence of fracture porosity. To investigate the influence of fracture porosity, the porosity value of $0.63 \%$ as reported in the Table 3.1 was used to perform the computer model analyses. In Figure 4.12 the fracture porosity values were changed from $0.63 \%$ to $10 \%$, keeping porosity of rock as $0.63 \%$ (Table 3.1 ). The fracture permeability values were obtained by using equation 4.6.

Where,

$$
k_{f i}=k_{f o}\left(\frac{\phi_{f i}}{\phi_{f o}}\right)^{3}
$$

$$
\begin{aligned}
& \mathrm{k}_{\mathrm{fi}}=\text { variable fracture porosity } \\
& \mathrm{k}_{\mathrm{fo}}=\text { constant fracture porosity } \\
& \phi_{f i}=\text { variable fracture porosity } \\
& \phi_{f o}=\text { constant fracture porosity }
\end{aligned}
$$


S14 : Event - 64 (Upstream)

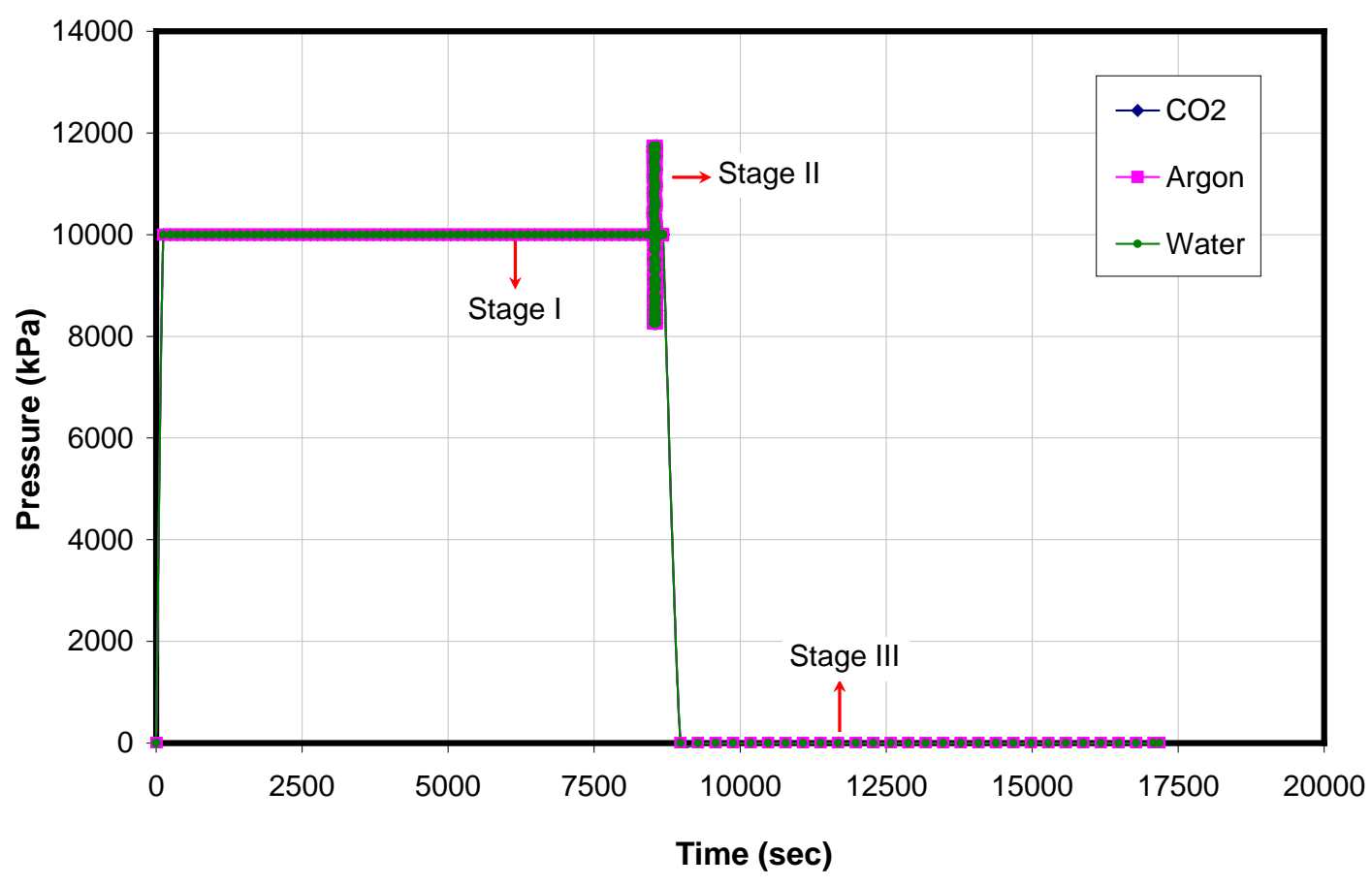

Figure 4.9: Influence of fluid compressibility - upstream pressure pulse

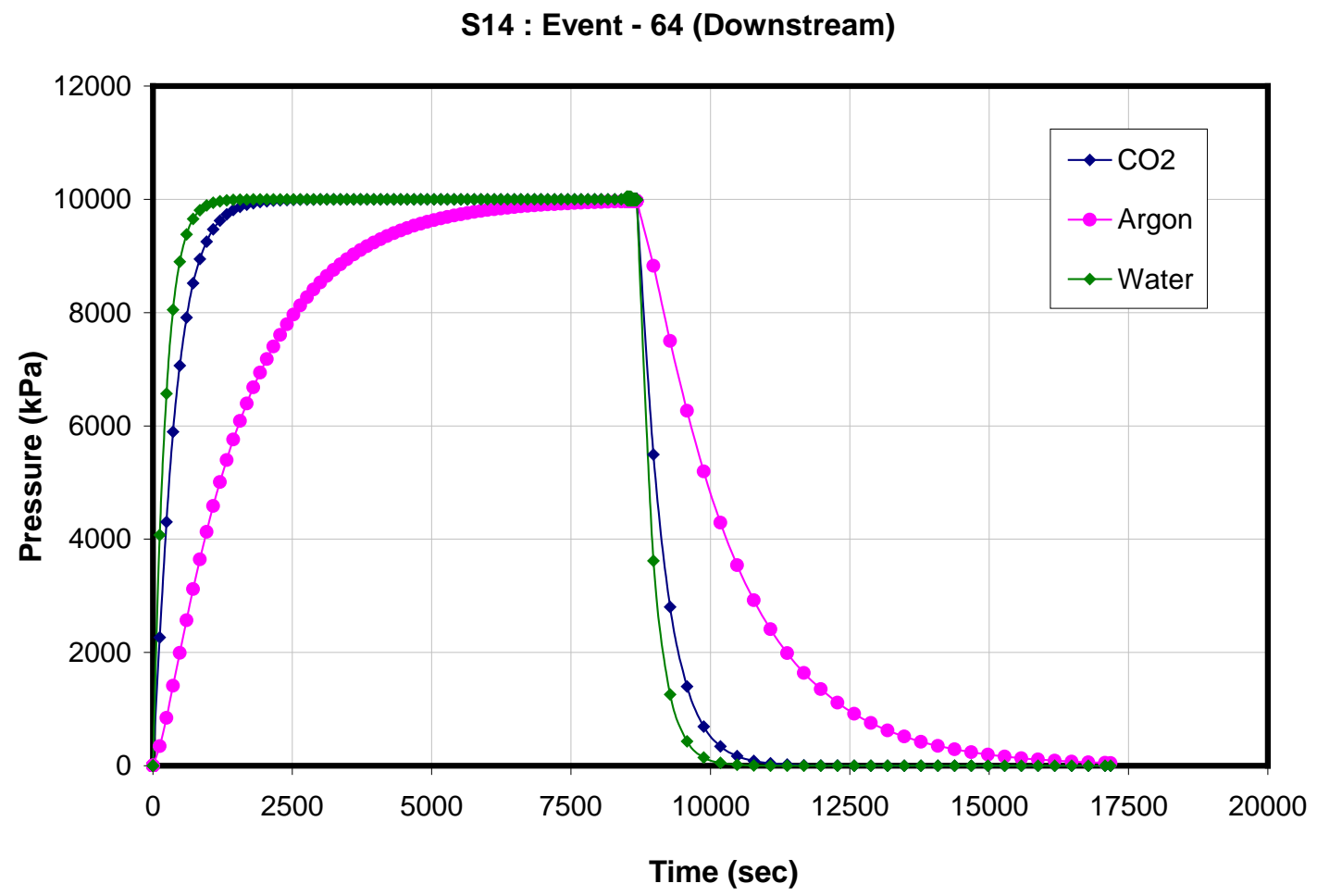

Figure 4.10: Influence of fluid compressibility - downstream pressure response 


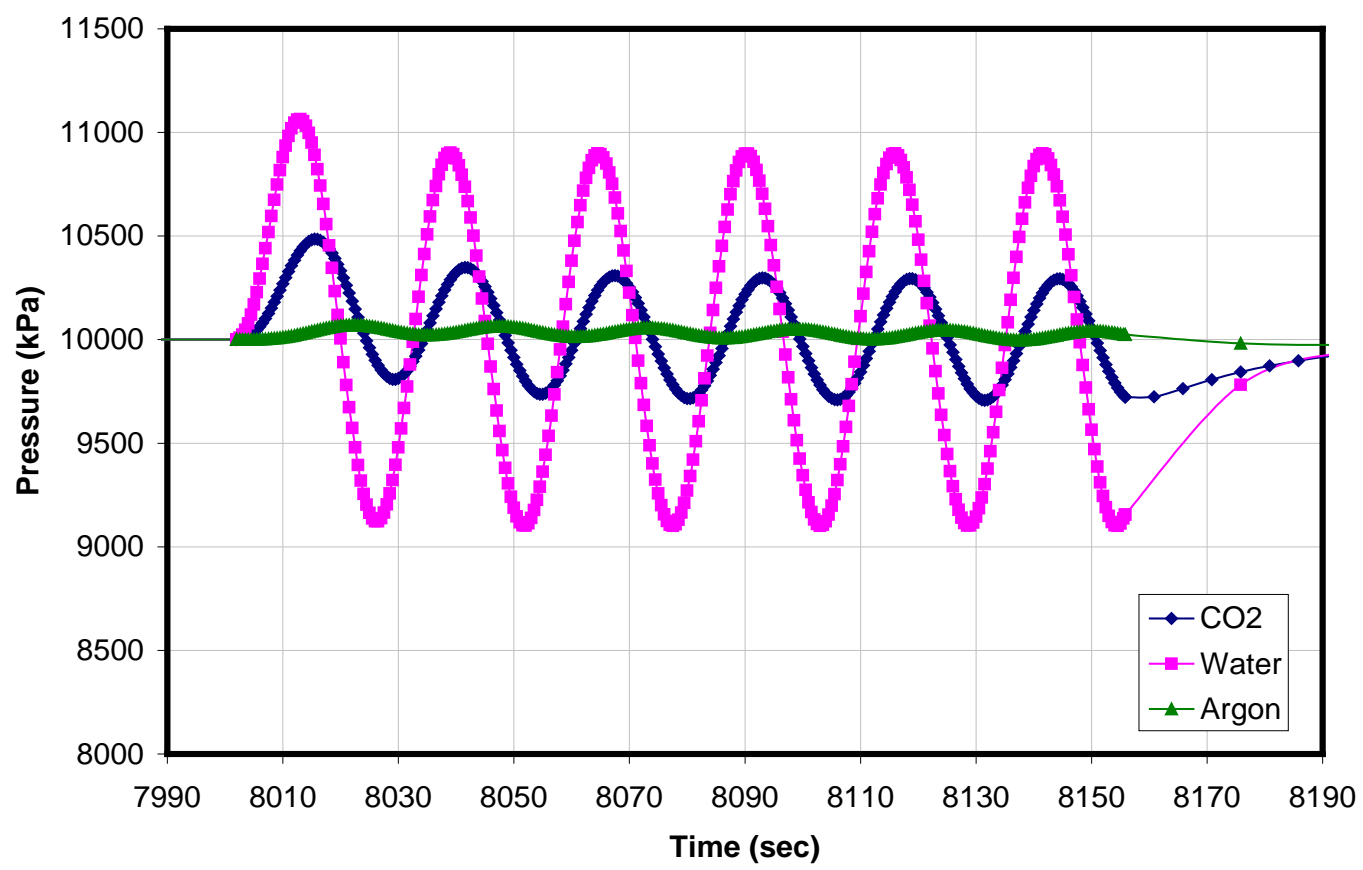

Figure 4.11: Influence of fluid compressibility - downstream pressure response

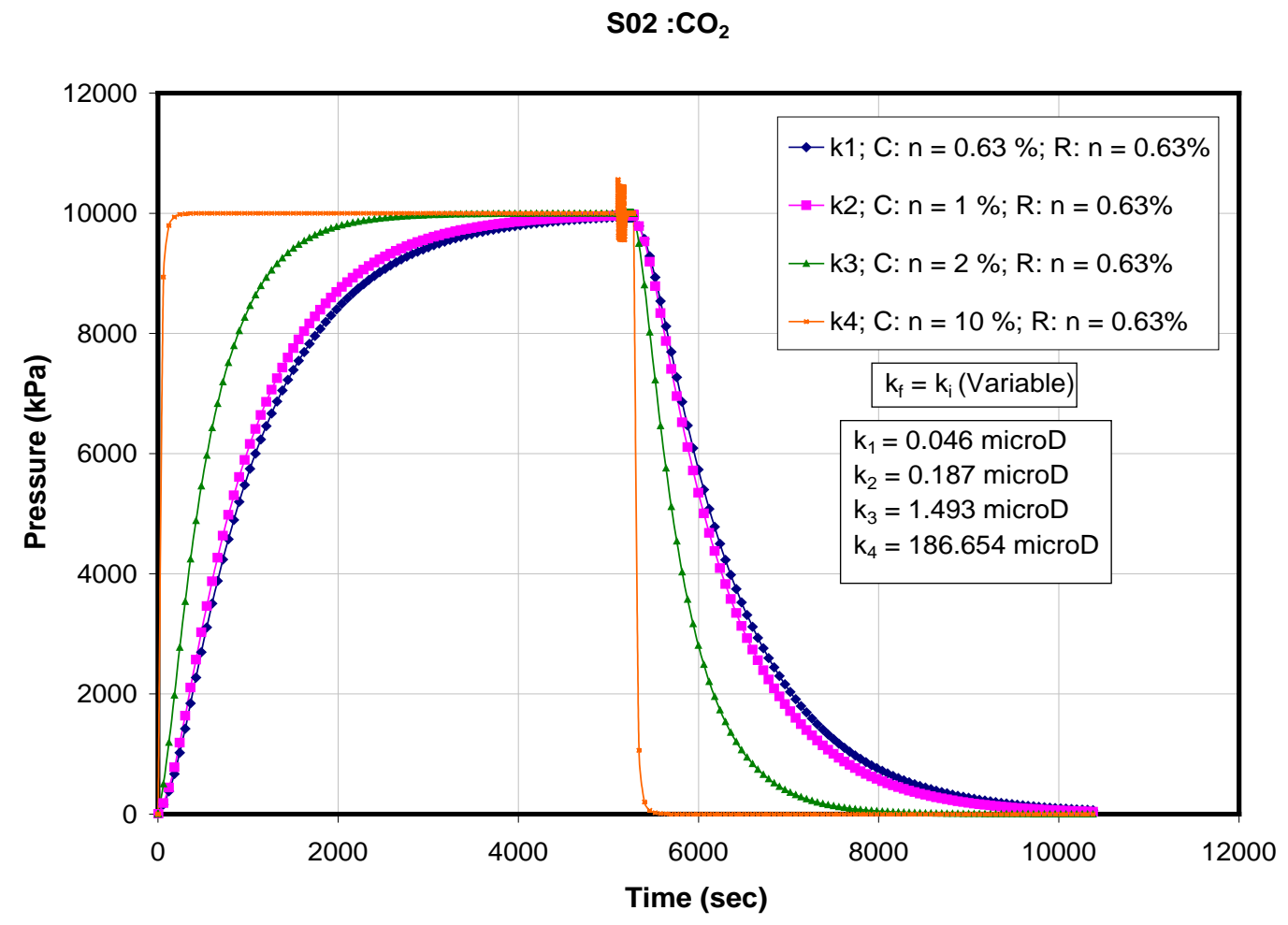

Figure 4.12: Downstream end - fracture porosity not equal to matrix porosity 


\subsection{SUMMARY}

Permeability values of each coal sample were determined using computer models. The physical properties shown in Table 3.1 were used to perform the analyses of each coal sample. Each test was conducted in three pressure changes, namely pressure increase, pressure transient and pressure release. Two pressure transients: A-Spike and Sine-6 were used to perform the computer model analyses. Influence of different physical properties such as elastic modulus, porosity, fracture width and fluid compressibility was also studied. Results show that there is no significant influence of the fracture width on the downstream pressure response. Elastic modulus, fluid compressibility and fracture porosity have a significant response on the downstream pressure variation. 


\section{CHAPTER 5: RESULTS AND DISCUSSION}

\subsection{NUMERICAL MODELING RESULTS}

Results obtained from computer modeling were compared with the available experimental results for several coal samples. To perform the analyses, the confining pressure on the coal matrix was changed from $8 \mathrm{MPa}, 20 \mathrm{MPa}$ to $40 \mathrm{MPa}$ depending on the event for each sample which was analyzed. The experimental results are available for all the samples except samples S01, S03 and S09, which were damaged during the tests (Haljasmaa et al, 2009).

The results obtained for certain experiments (i;e events) of samples S02, S04, S10, and S14 are shown in this chapter. For sample S02 events, $\mathrm{CO}_{2}-$ Rising, $\mathrm{CO}_{2}-$ Event 47 (ASpike), $\mathrm{CO}_{2}$ - Event 48 (Sine-6), $\mathrm{CO}_{2}$ - Event 147 (A-Spike), and $\mathrm{CO}_{2}-$ Event 148 (Sine-6) were selected to perform the numerical analysis. To perform the finite element analyses for sample S04 events, Argon - Event 4 (Sine-6), Argon - Event 5 (A-Spike), $\mathrm{CO}_{2}$ - Event 0 (ASpike) and $\mathrm{CO}_{2}$ - Event 1 (Sine-6) were selected. For sample S10, events $\mathrm{CO}_{2}$ - Event 0 (ASpike), and $\mathrm{CO}_{2}$ - Event 1 (Sine-6) were selected, and for sample S14 events Argon - Event 16 (A-Spike), and Argon - Event 17 (Sine-6) were selected to perform the finite element analyses.

\subsection{RESULTS AND DISCUSSION}

The experimental results for the sample S02 were compared with the obtained computer model results. Figure 5.1 shows the downstream pressure response of the pressure rise curve for sample S02. For the pressure rise curve the fluid compressibility value of Argon was considered in the finite element analyses. To match this pressure rise experimental curve, the value of the elastic modulus of the coal matrix was assumed to be 2.5Eo, where Eo is $692,000 \mathrm{psi}(4,770,000 \mathrm{kPa})$. Also, for the case with the fracture, the matrix permeability was assumed to be $100 \mathrm{nD}$. For the case with no fracture, it was assumed that matrix permeability was equal to the fracture permeability of $2 \mu \mathrm{D}$. The comparison of modeling results with experimental data can be considered as excellent. 
Since there are many results, the following notations are used in the results shown below.

R F - Rock and Fracture

Elastic Modulus, Eo $=4,770,000 \mathrm{kPa}$

$\mathrm{R}$ - Rock

F - Fracture

$\mathrm{kf}$ - fracture permeability

$\mathrm{kr}$ - rock permeability

C: $\mathrm{n}$ - Fracture porosity

$\mathrm{R}: \mathrm{n}$ - Rock porosity 
S02: Argon Downstream End - Rising (Experimental Data Vs Model Results)

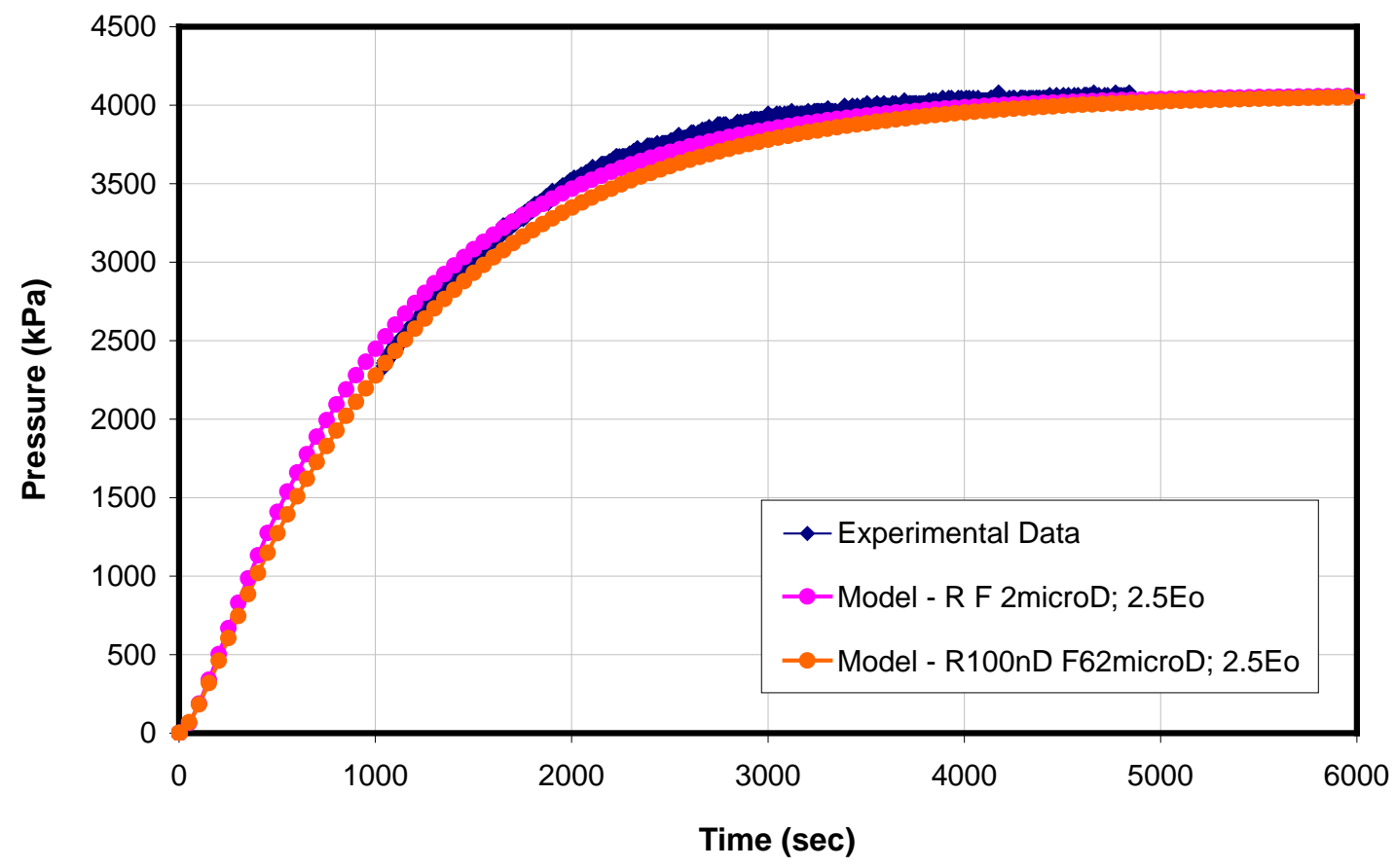

Figure 5.1: S02 - pressure rise curve (downstream end)

Figure 5.2 shows the downstream response of sample S02 event 47 (A-Spike). The experimental permeability for this event was determined as $0.25 \mathrm{mD}$. The laboratory determination was based on the assumption that there was no fracture in the coal matrix. In the first trial for this event, the analysis was performed using an elastic modulus of Eo, to obtain a permeability value of the matrix. The fracture permeability of $0.5 \mathrm{mD}$ was observed to match the experimental downstream pressure response, which is higher than the experimental value. The analysis was carried out again by taking the elastic modulus of the coal matrix as 2.5Eo. The numerical result obtained from this trail for the permeability of the matrix and the fracture was $0.28 \mathrm{mD}$, which is close to the experimental result. 
S02: $\mathrm{CO}_{2}$ Event 47 Downstream End (Experimental Data Vs Model Results)

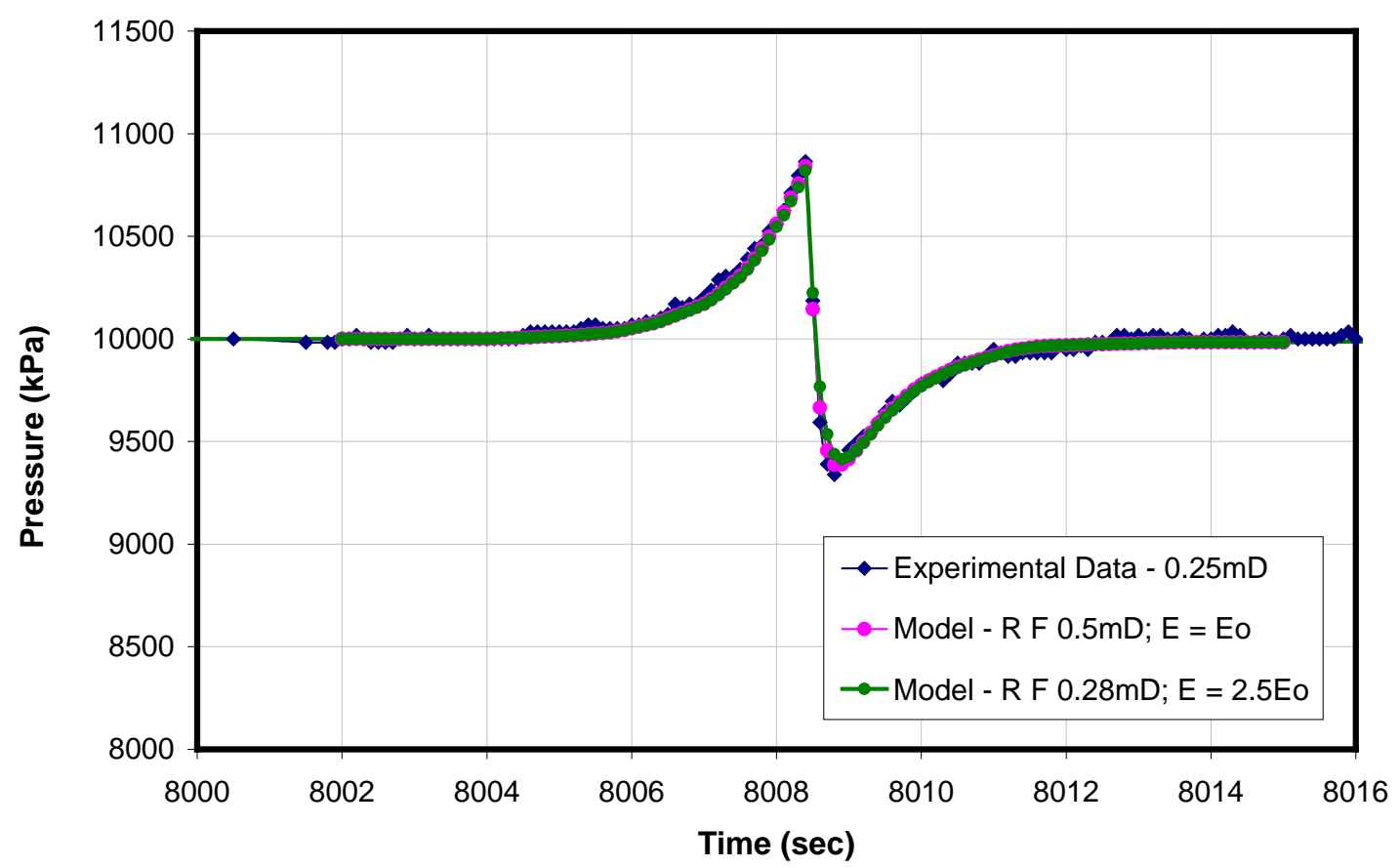

Figure 5.2: S02 - Downstream pressure response A-Spike (without fracture)

In the analysis for which the fracture was considered in the coal matrix for the same events mentioned above, the matrix permeability was considered to be $100 \mathrm{nD}$. This value of matrix permeability (100 nD) was determined from the experimental tests performed elsewhere (Haljasmaa et al, 2009). In this analysis the fracture permeability value was varied to match the experimental observations of pressure transient behavior. The numerical result obtained by considering the elastic modulus of the coal matrix as Eo is $8 \mathrm{mD}$. The value of the fracture permeability decreased to $4.8 \mathrm{mD}$ when the elastic modulus was changed to 2.5Eo. Figure 5.3 shows the comparison of experimental result and the results from the numerical model for the event 47 (A-Spike) for sample S02. 
S02: $\mathrm{CO}_{2}$ Event 47 Downstream End (Experimental Data Vs Model Results)

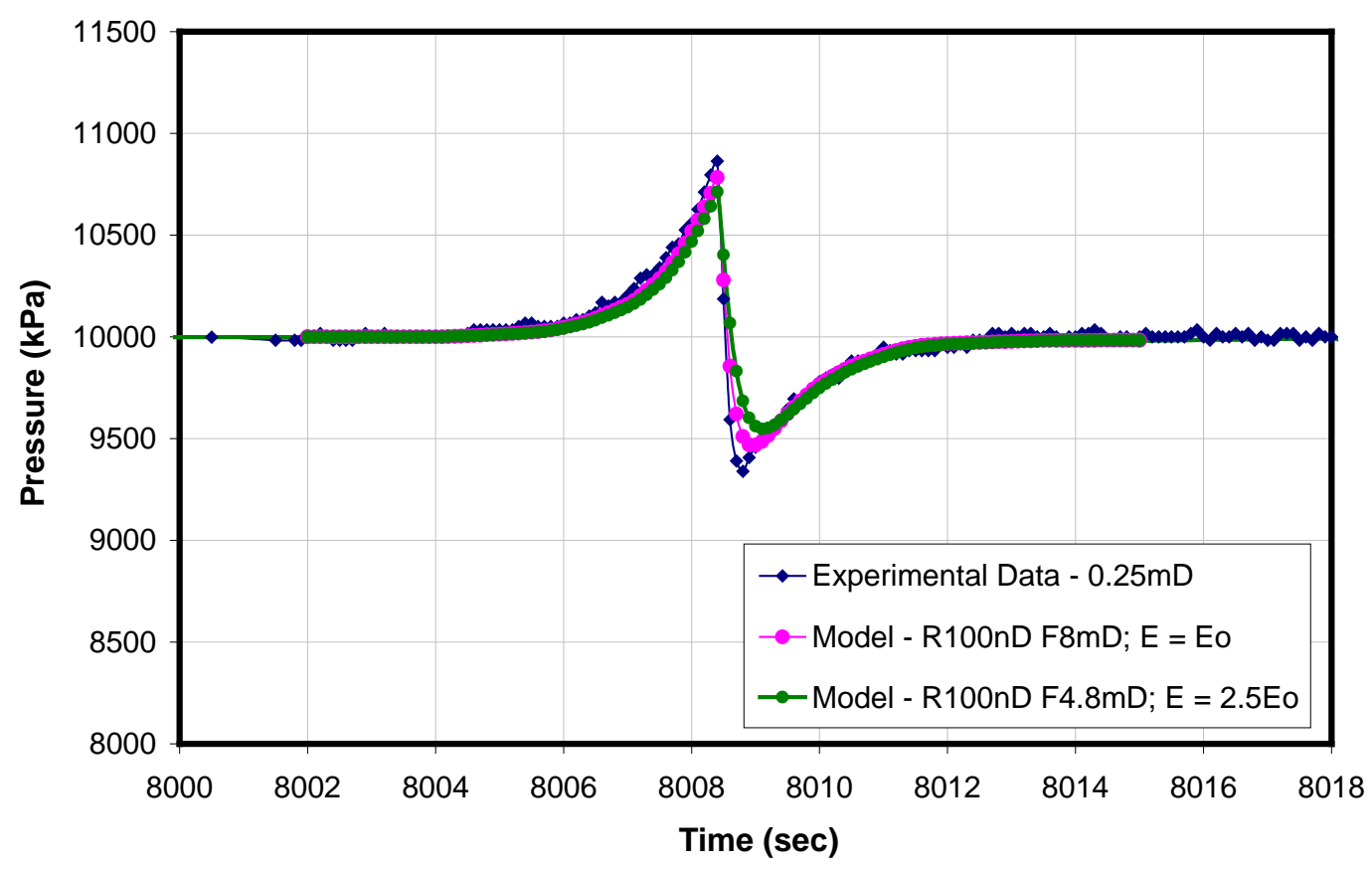

Figure 5.3: S02 - Downstream pressure response A-Spike (with fracture)

Figure 5.4 shows the downstream pressure response for sample S02 event 48 (Sine-6) for the case with no fracture condition. A permeability value of $5 \mathrm{mD}$ was considered when the elastic modulus of the coal matrix was taken as Eo. This value decreased to $0.3 \mathrm{mD}$, when the elastic modulus of 2.5Eo was assumed in the numerical model. This value is close to the experimental result of $0.27 \mathrm{mD}$. Similarly Figure 5.5 shows the comparison of result obtained from the laboratory experimental and the numerical model for sample S02 event 48 (Sine-6) for the case with a fracture. The confining pressure for the events 47 and 48 was $20 \mathrm{MPa}$. The pore pressure in the sample was maintained at $10 \mathrm{MPa}$. The comparison of numerical results with experimental data can be considered as excellent. 
S02: $\mathrm{CO}_{2}$ Event 48 Downstream End (Experimental Data Vs Model Results)

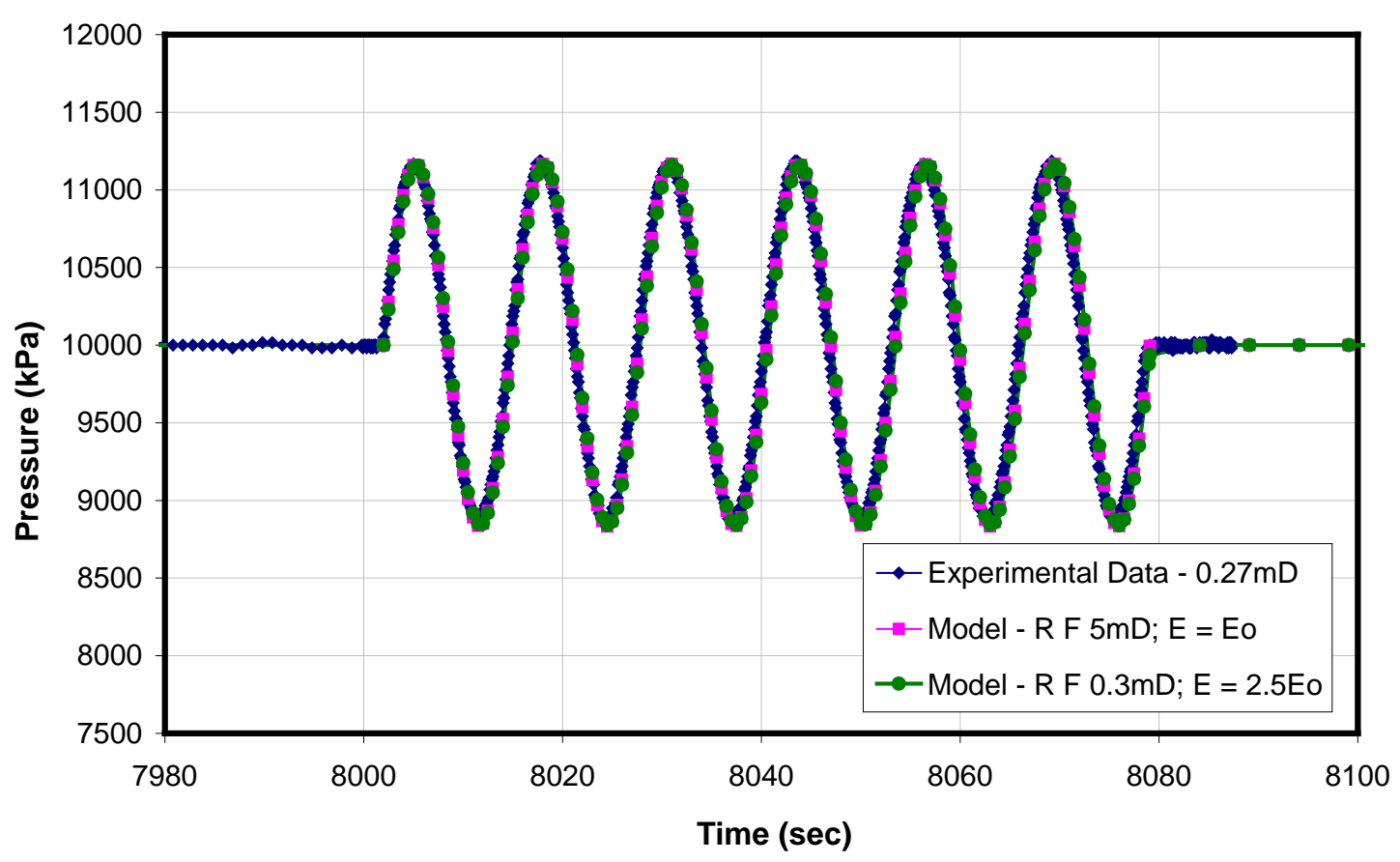

Figure 5.4: S02 - Downstream pressure response Sine-6 (without fracture)

S02: $\mathrm{CO}_{2}$ Event 48 Downstream End (Experimental Data Vs Model Results)

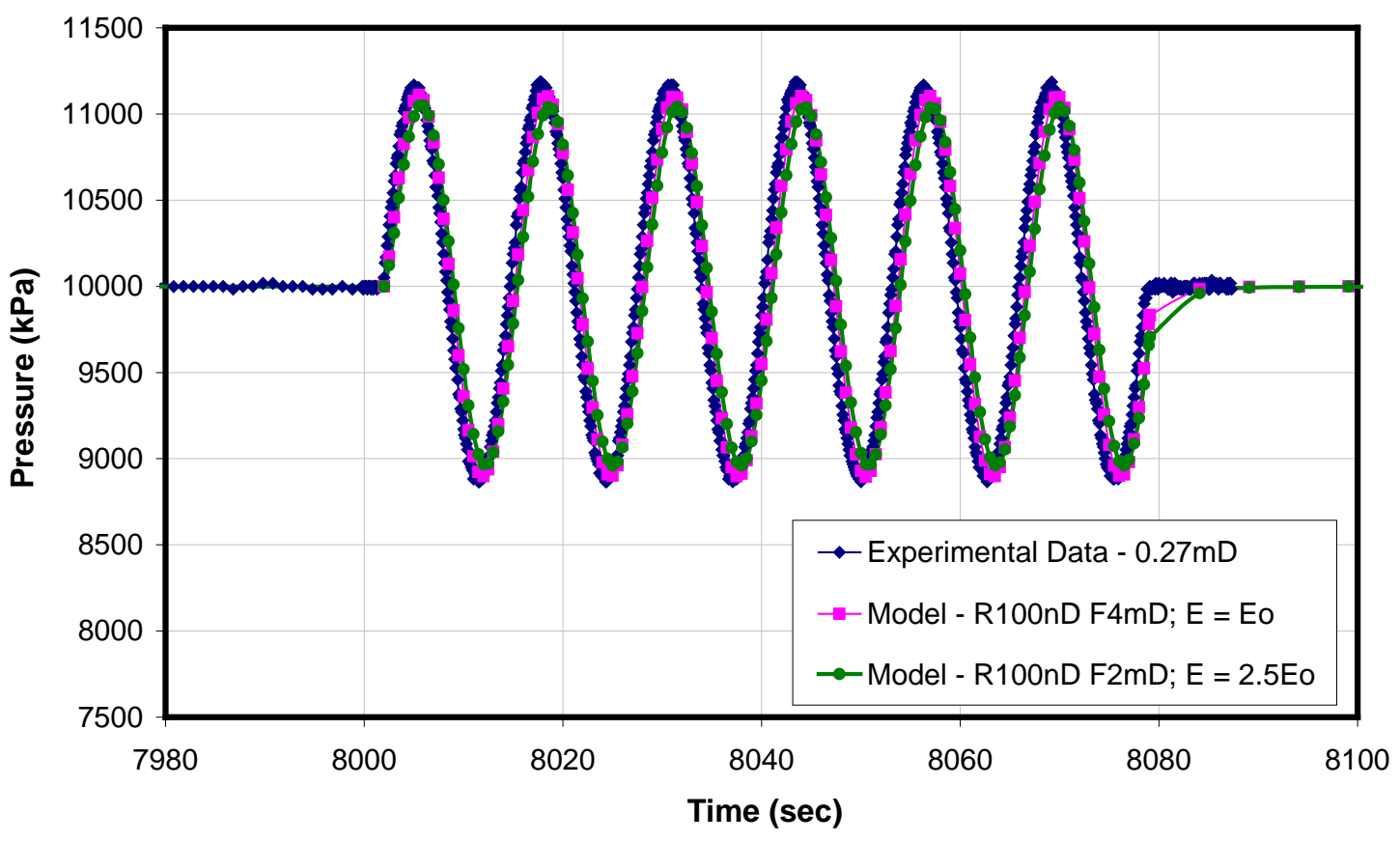

Figure 5.5: S02 - Downstream pressure response Sine-6 (with fracture) 
Figure 5.6 and Figure 5.7 show pressure response for event 147 for sample S02 corresponding to the cases with and without a fracture. When the permeability value of the fracture and the coal matrix was maintained at $12 \mu \mathrm{D}$ in the computer model, the computed downstream pressure response, matched well with the available experimental data on downstream pressure response. The permeability of the coal matrix was found to be $8 \mu \mathrm{D}$ in the experimental test. Figure 5.6 shows that the downstream pressure response from the computer model matched fairly well with the experimental downstream response when the elastic modulus of the coal matrix E was taken as 2.5Eo.

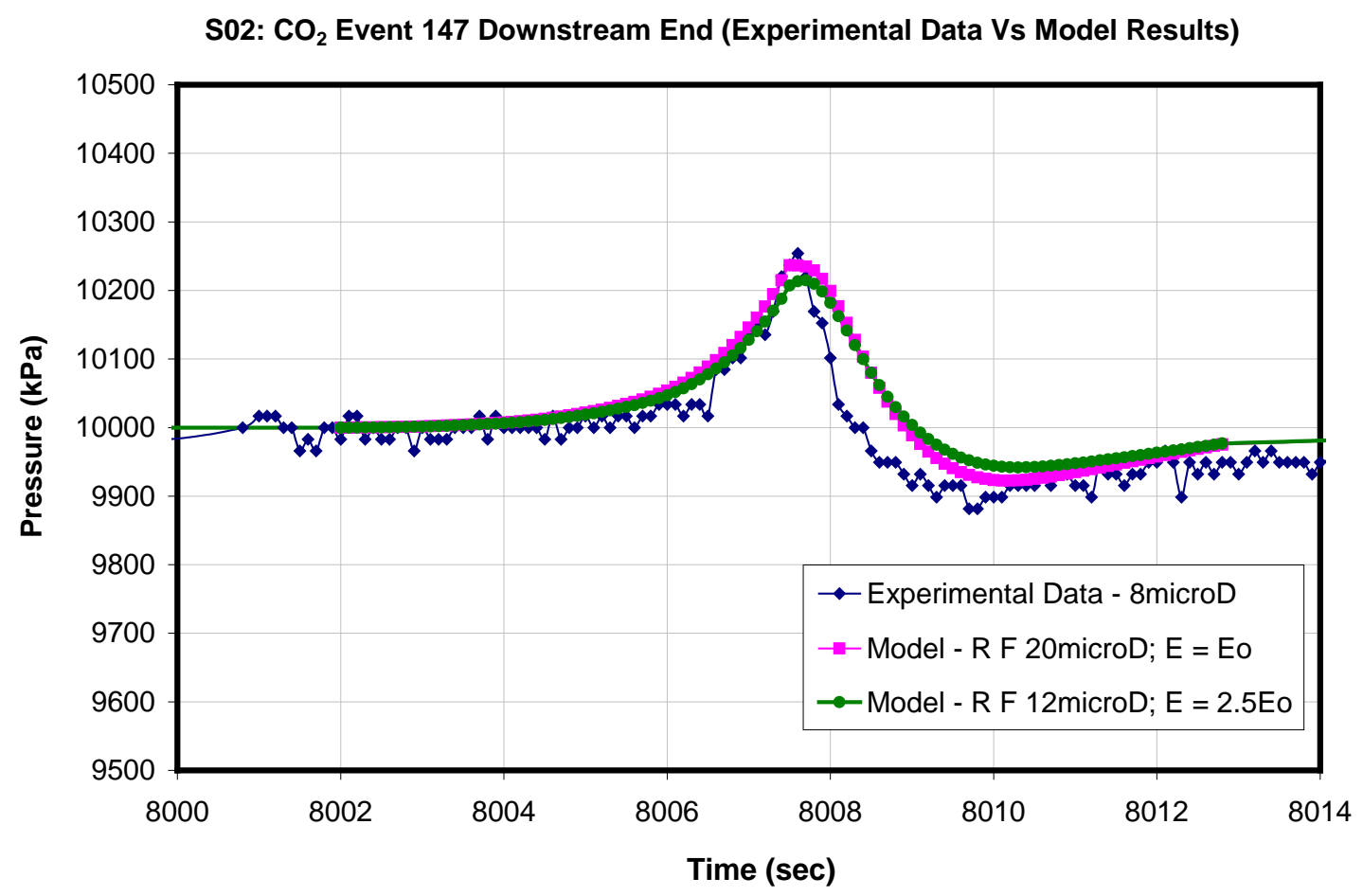

Figure 5.6: Downstream pressure response for sample S02 - event 147 A-Spike (without fracture)

Similarly Figure 5.8 and Figure 5.9 show the comparison of computed downstream pressure response with the experimental data for event 148. For these events the pore pressure of the coal matrix was maintained at $10 \mathrm{MPa}$. The comparison of model predictions with experimental data can be considered as excellent for this event. 
S02: $\mathrm{CO}_{2}$ Event 147 Downstream End (Experimental Data Vs Model Results)

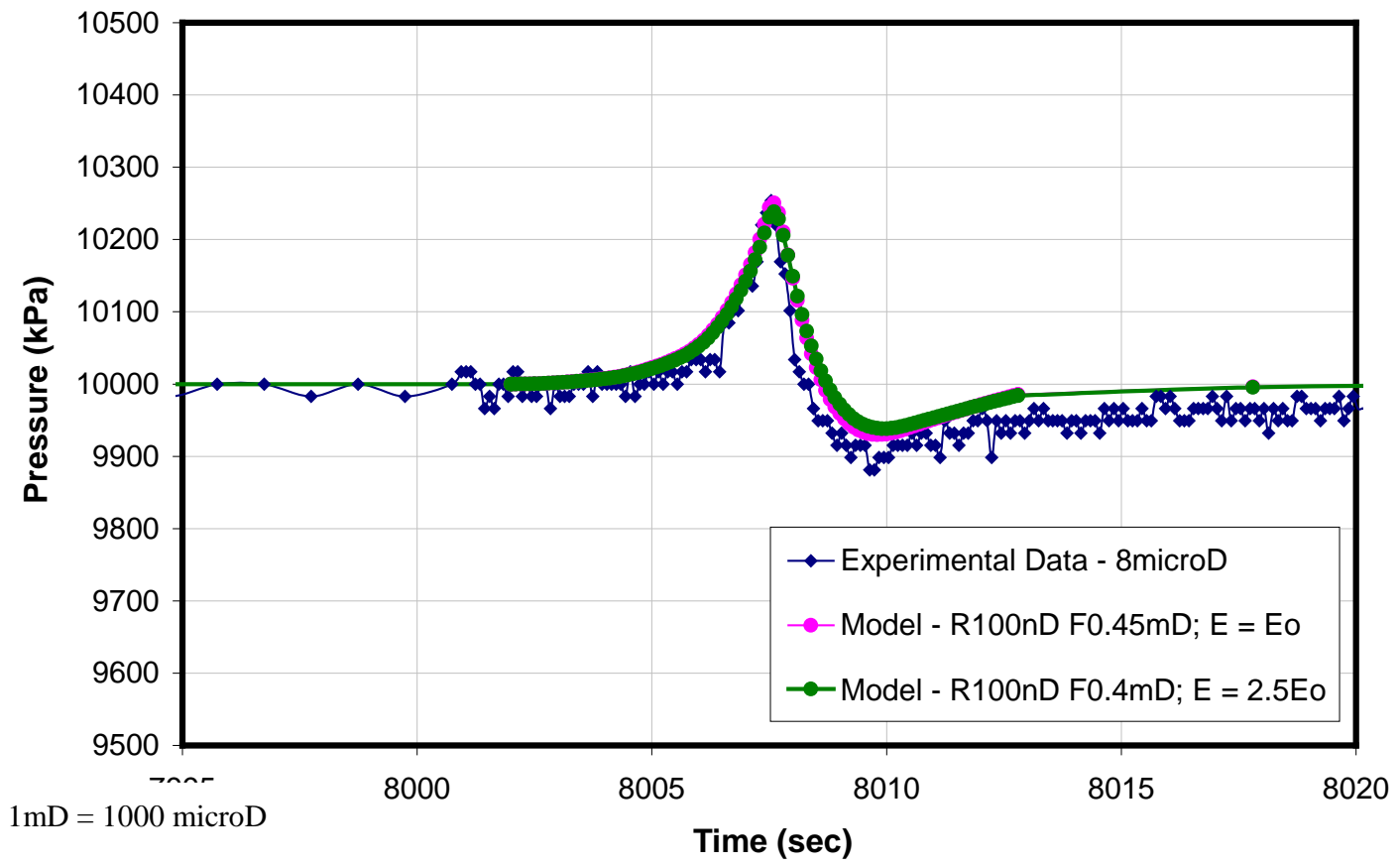

Figure 5.7: Downstream pressure response S02 - event 147 A-Spike (with fracture)

S02: CO2 Event 148 Downstream End (Experimental Data Vs Model Results)

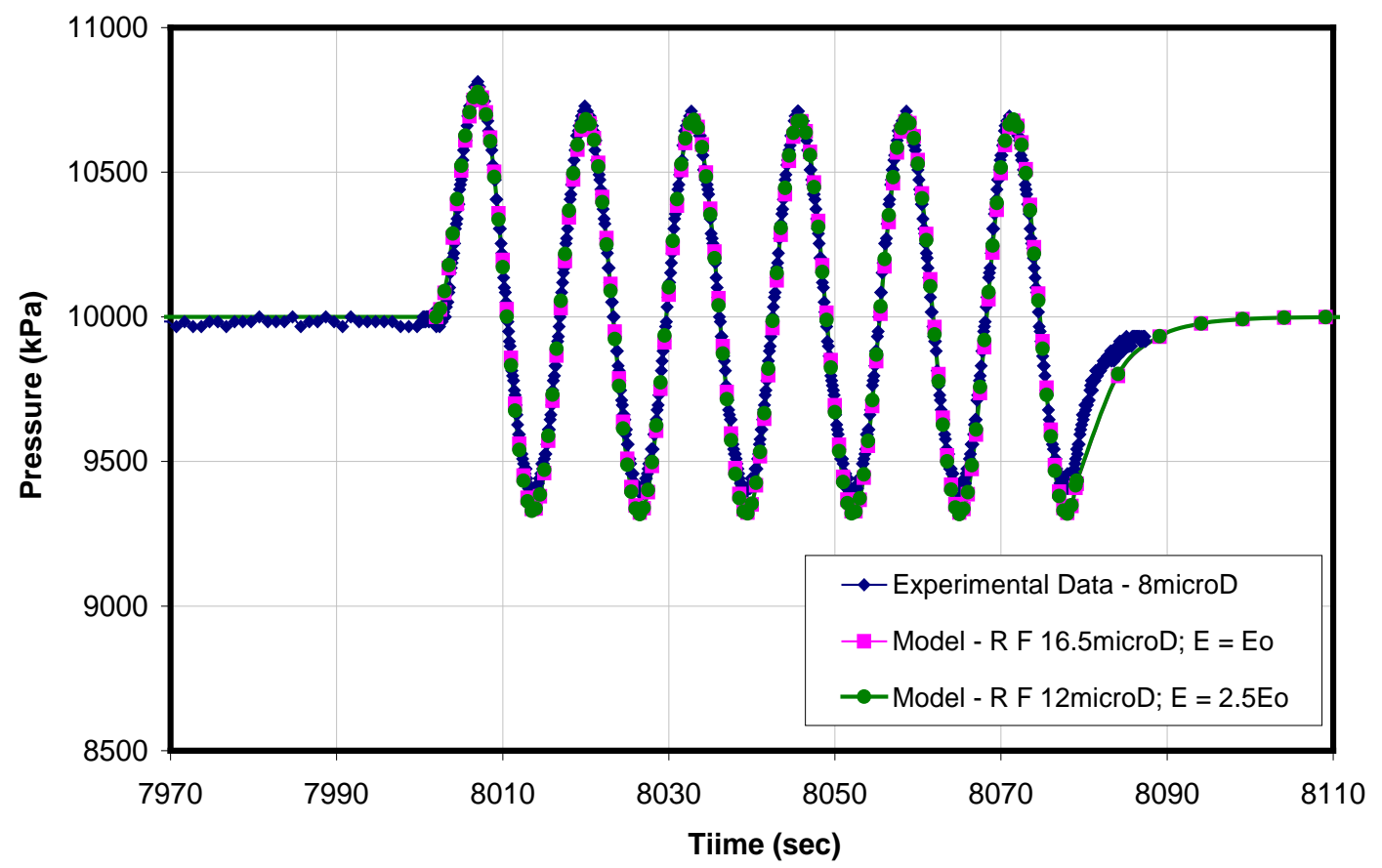

Figure 5.8: Downstream pressure response S02 - event 148 Sine-6 (without fracture) 
S02: $\mathrm{CO}_{2}$ Event 148 Downstream End (Experimental Data Vs Model Results)

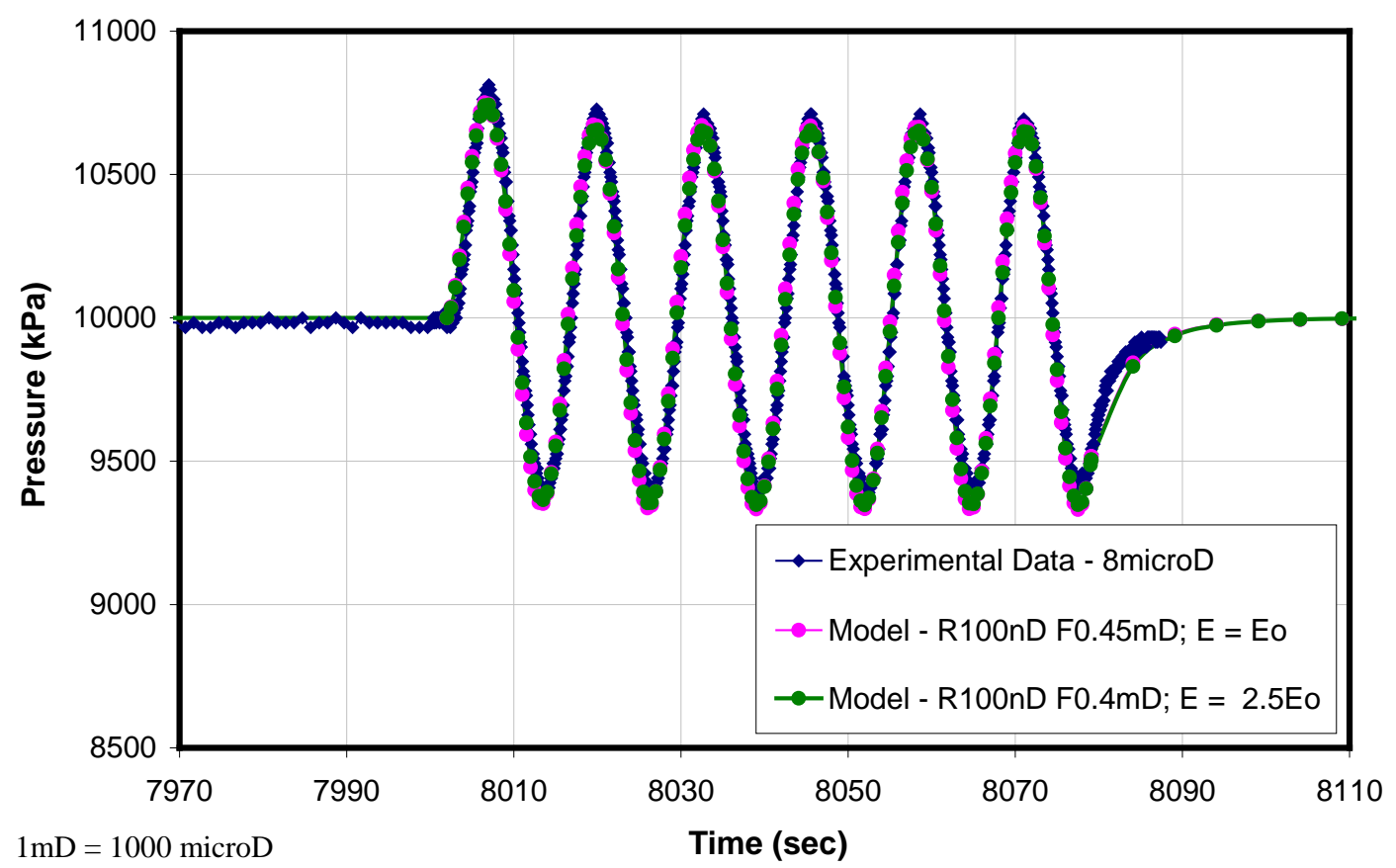

Figure 5.9: Downstream pressure response S02 - event 148 Sine-6 (with fracture)

In the numerical analyses of pressure transient behavior for sample S04, the matrix permeability was assumed to be $200 \mathrm{nD}$, since the value of $100 \mathrm{nD}$ for the matrix permeability resulted in pressure transient curves that did not fit well with the experimental data. Figure 5.10 and Figure 5.11 shows a comparison of downstream pressure responses of the available experimental data and obtained computer model results for the cases with and without a fracture in the sample S04 for events 4 and 5, respectively. The fluid compressibility value of Argon was used and the confining pressure of the sample was maintained at $8 \mathrm{MPa}$ to perform the numerical analyses for these particular events for sample S04. The pore pressure for these events was considered to be $4.0 \mathrm{MPa}$. 
S04: Argon Event 4 Downstream End (Experimental Data Vs Model Results)

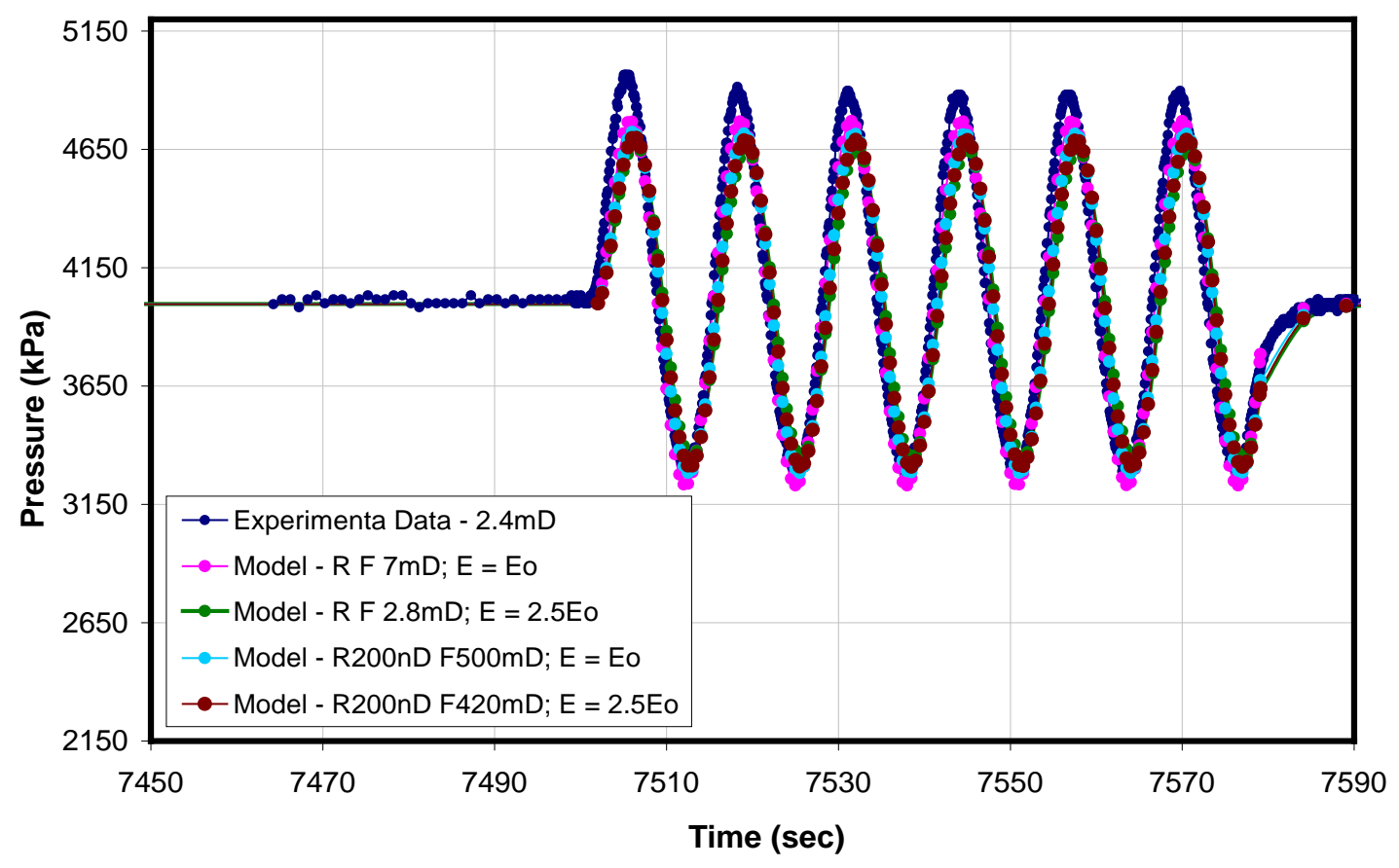

Figure 5.10: Downstream pressure pulses for S04 - Argon event 4 Sine- 6

S04: Argon Event 5 Downstream End (Experimental Data Vs Model Results)

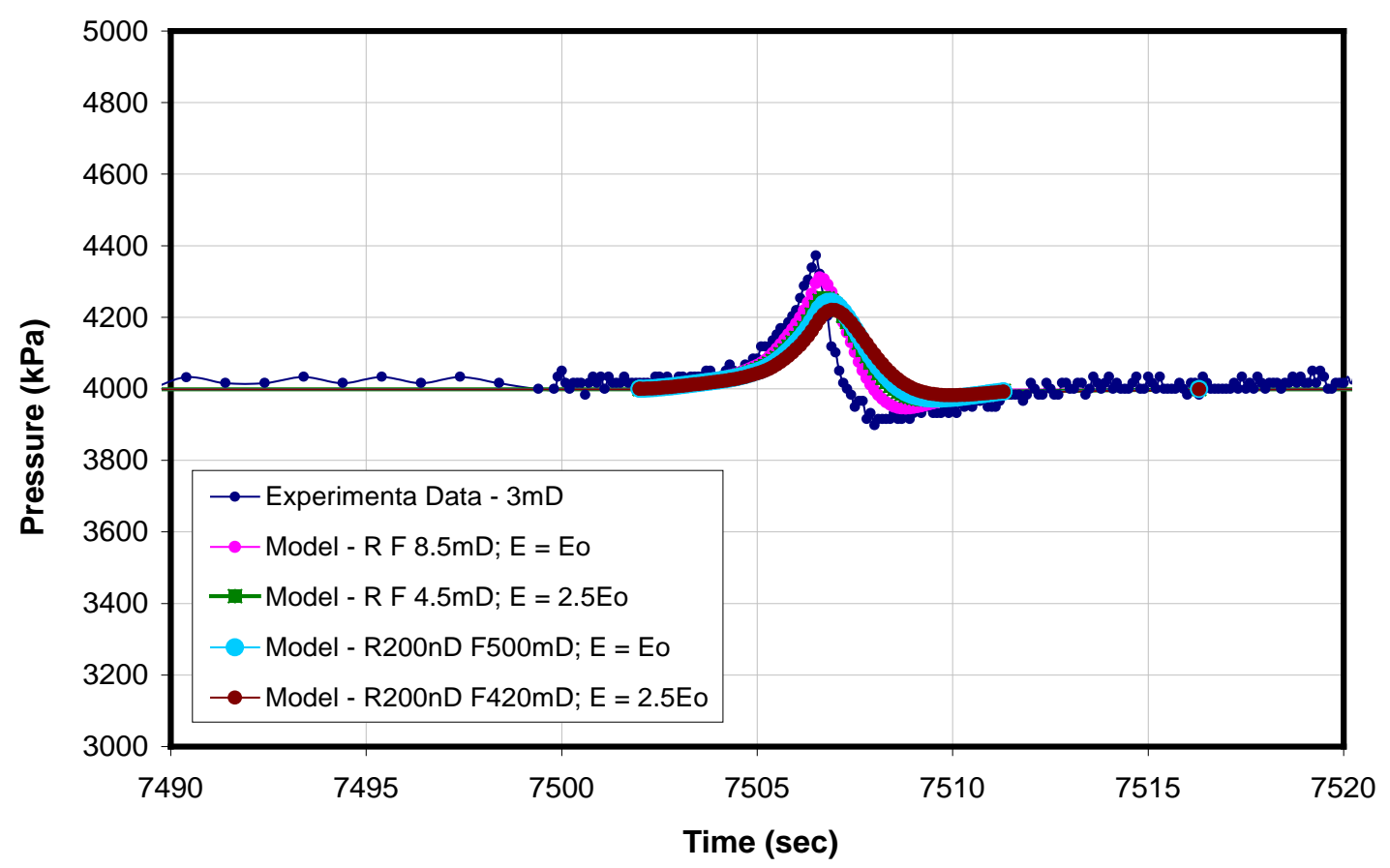

Figure 5.11: Downstream pressure pulses for S04 - Argon event 5 A-Spike 
Figure 5.12 and Figure 5.13 show the comparison of the experimental downstream pressure response with the numerical model downstream pressure response for event 0 for sample S04. The results for the case with no fracture condition are shown in Figure 5.12. Figure 5.13 shows the results for the case with a fracture. Figure 5.14 shows a comparison of the downstream pressure responses of the experimental test and the numerical model for sample S04 - event 1 for the case with no fracture condition. Results for the fractured condition are shown in Figure 5.15 for the same event. $\mathrm{CO}_{2}$ was considered as the fluid media to determine the permeability for these events. The confining pressure and the pore pressure of the sample for these events (event 0 and event 1) were $20 \mathrm{MPa}$ and $10 \mathrm{MPa}$, respectively.

S04: $\mathrm{CO}_{2}$ Event 0 Downstream End (Experimental Data Vs Model Results)

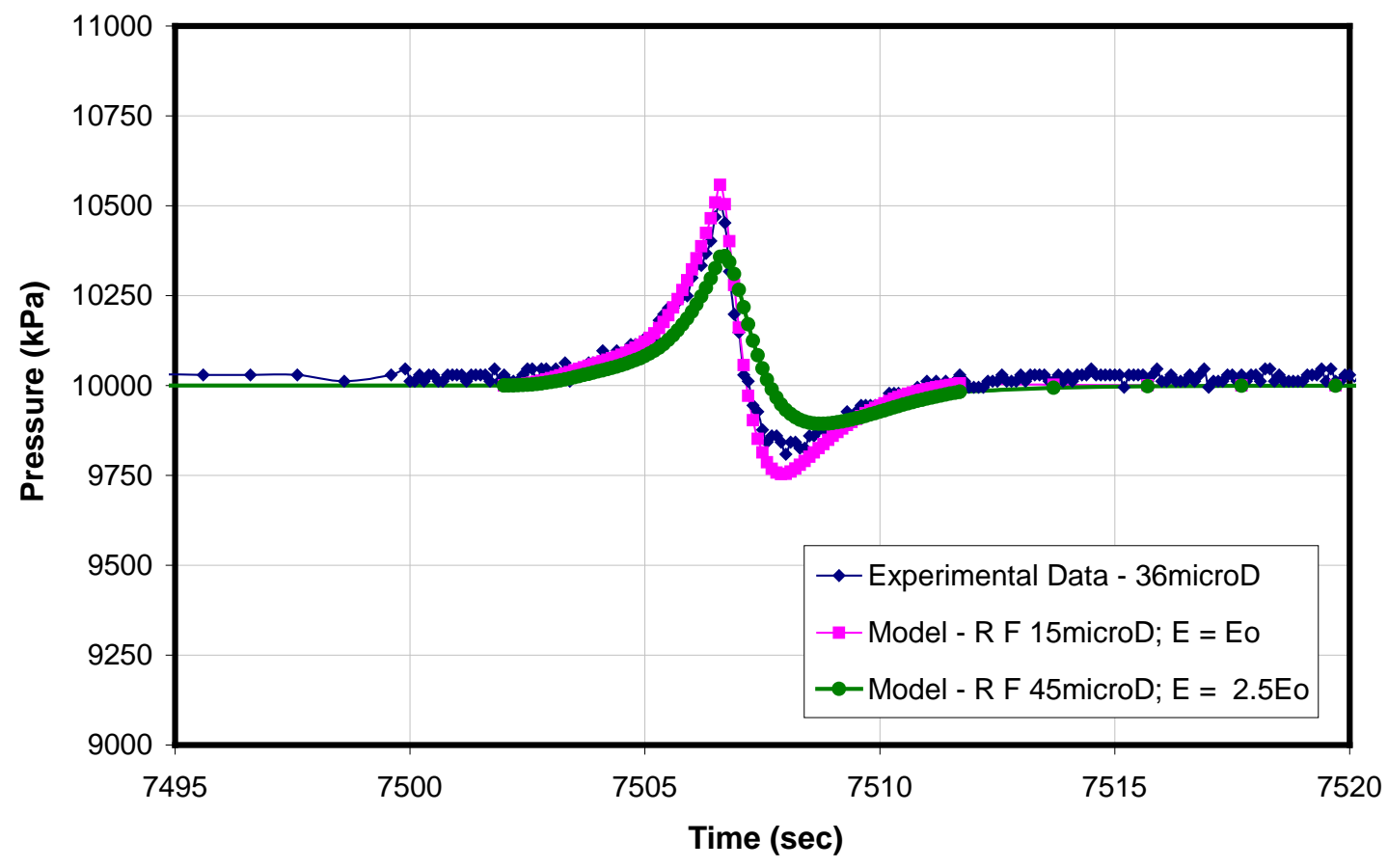

Figure 5.12: Downstream pressure pulses for sample S04 - event 0 A-Spike (without fracture) 
S04: $\mathrm{CO}_{2}$ Event 0 Downstream End (Experimental Data Vs Model Results)

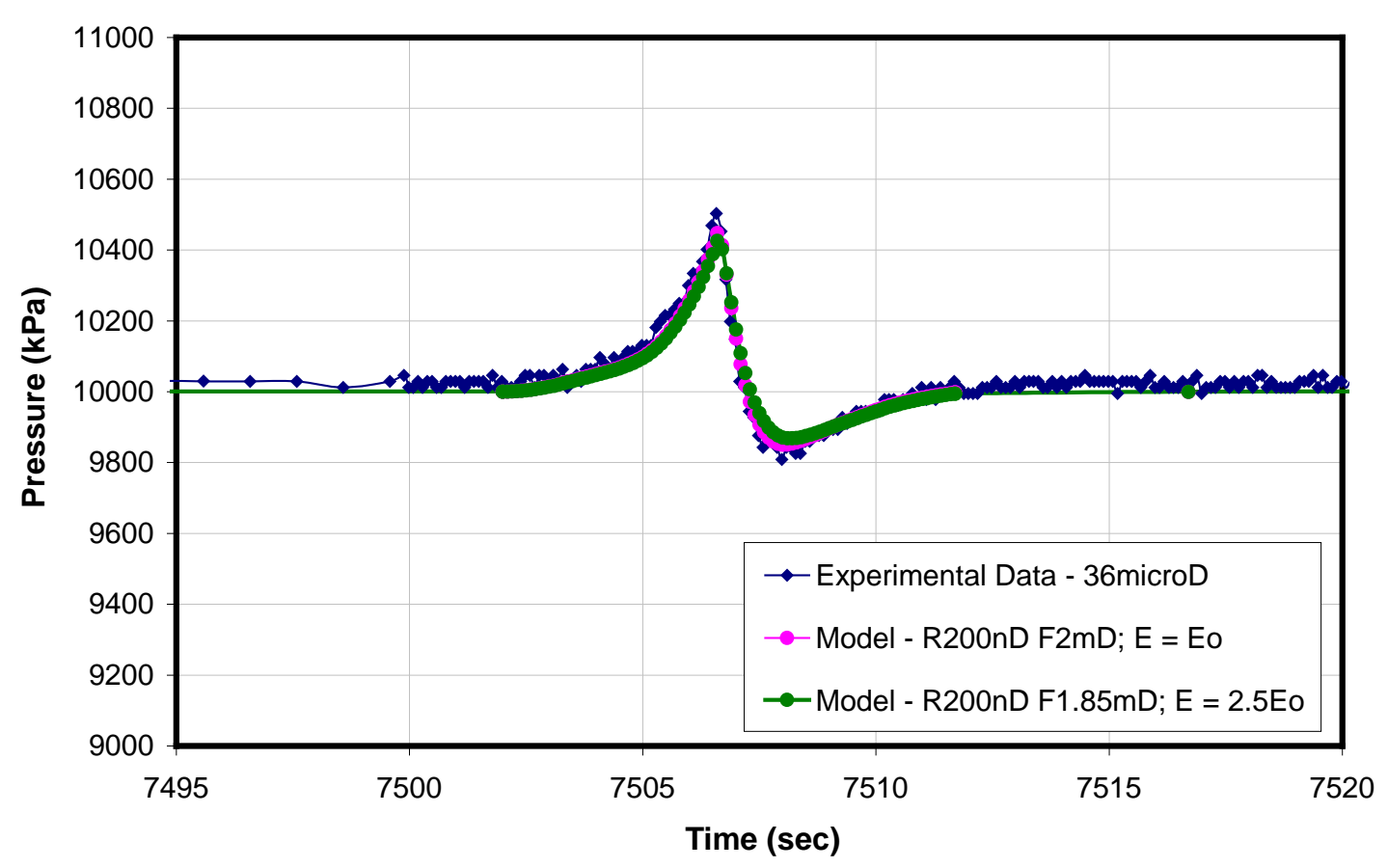

$1 \mathrm{mD}=1000$ microD

Figure 5.13: Downstream pressure pulses for sample S04 - event 0 A-Spike (with fracture)

S04: $\mathrm{CO}_{2}$ Event 1 Downstream End (Experimental Data Vs Model Results)

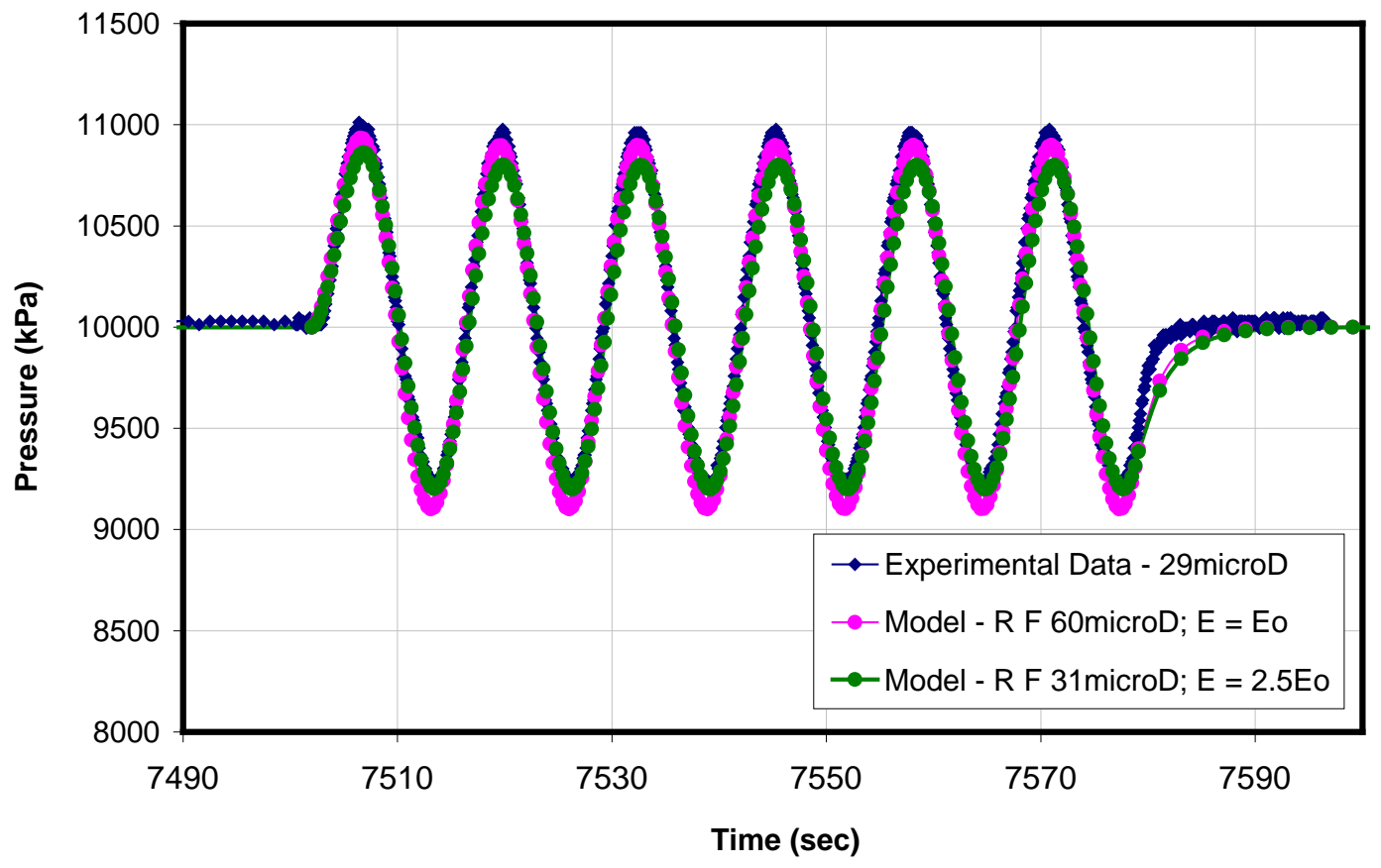

Figure 5.14: Downstream pressure pulses for sample S04 - event 1 Sine-6 (without fracture) 
S04: $\mathrm{CO}_{2}$ Event 1 Downstream End (Experimental Data Vs Model Results)

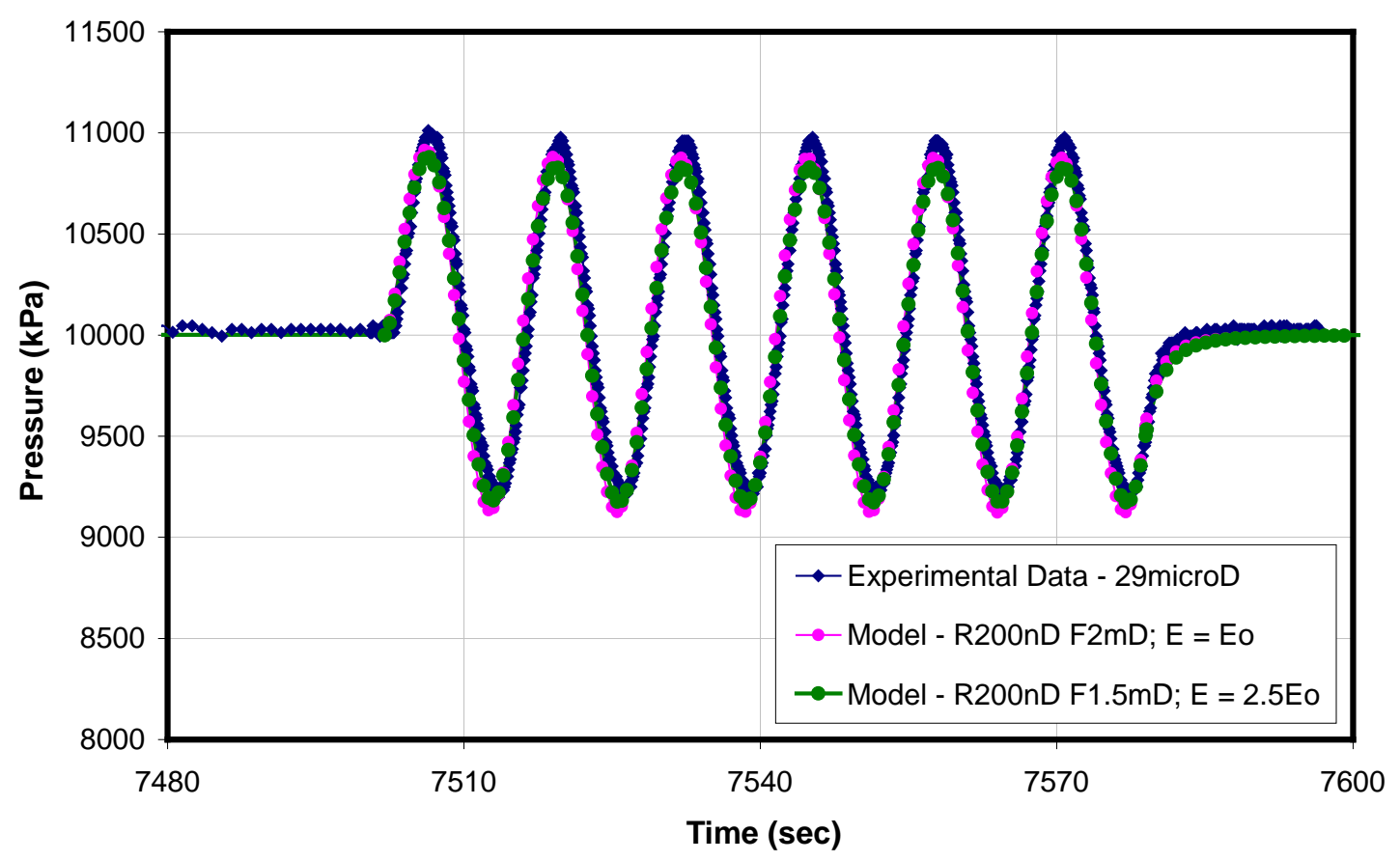

$1 \mathrm{mD}=1000$ microD

Figure 5.15: Downstream pressure pulses for sample S04 - event 1 Sine-6 (with fracture)

For sample S10, the numerical results for event 0 and event 1 are shown in this report. For these events the fluid compressibility value of Argon was used. The confining pressure and the pore pressure were maintained at $20 \mathrm{MPa}$ and $10 \mathrm{MPa}$, respectively. Figure 5.16 shows the experimental upstream pressure pulse and numerical upstream pressure pulse used to obtain the downstream pressure response shown in Figure 5.17 for the case with no fracture condition.

Similarly, the upstream pressure pulse for event 1 of sample S10 is shown in Figure 5.18. The downstream pressure response of this upstream pressure pulse is shown in Figure 5.19. For this analysis no fracture condition was considered. 
S10: $\mathrm{CO}_{2}$ Event 0 Upstream End (Experimental Data Vs Model Results)

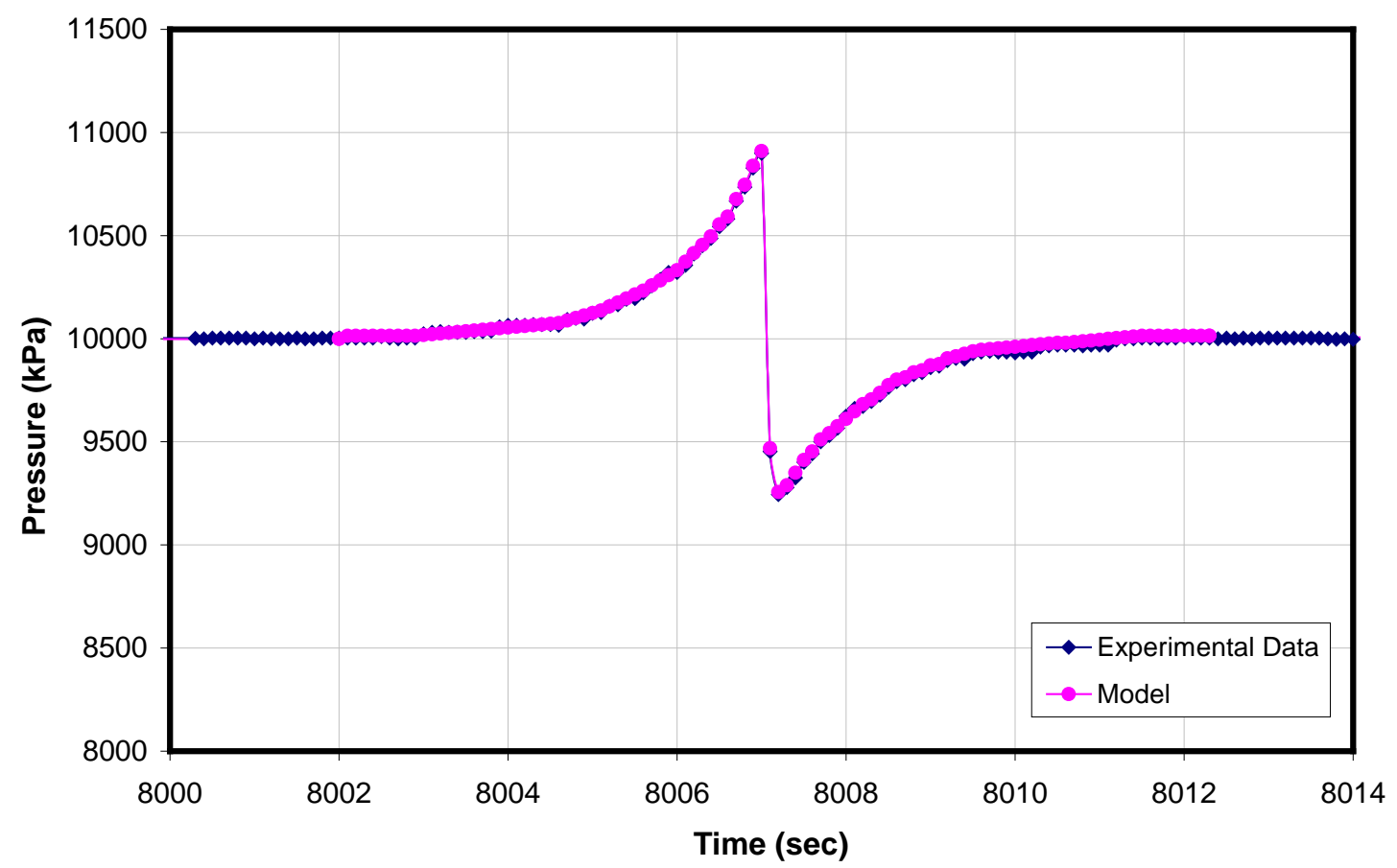

Figure 5.16: Upstream pressure pulse for sample S10 - event 0 A-Spike

S10: $\mathrm{CO}_{2}$ Event 0 Downstream End (Experimental Data Vs Model Results)

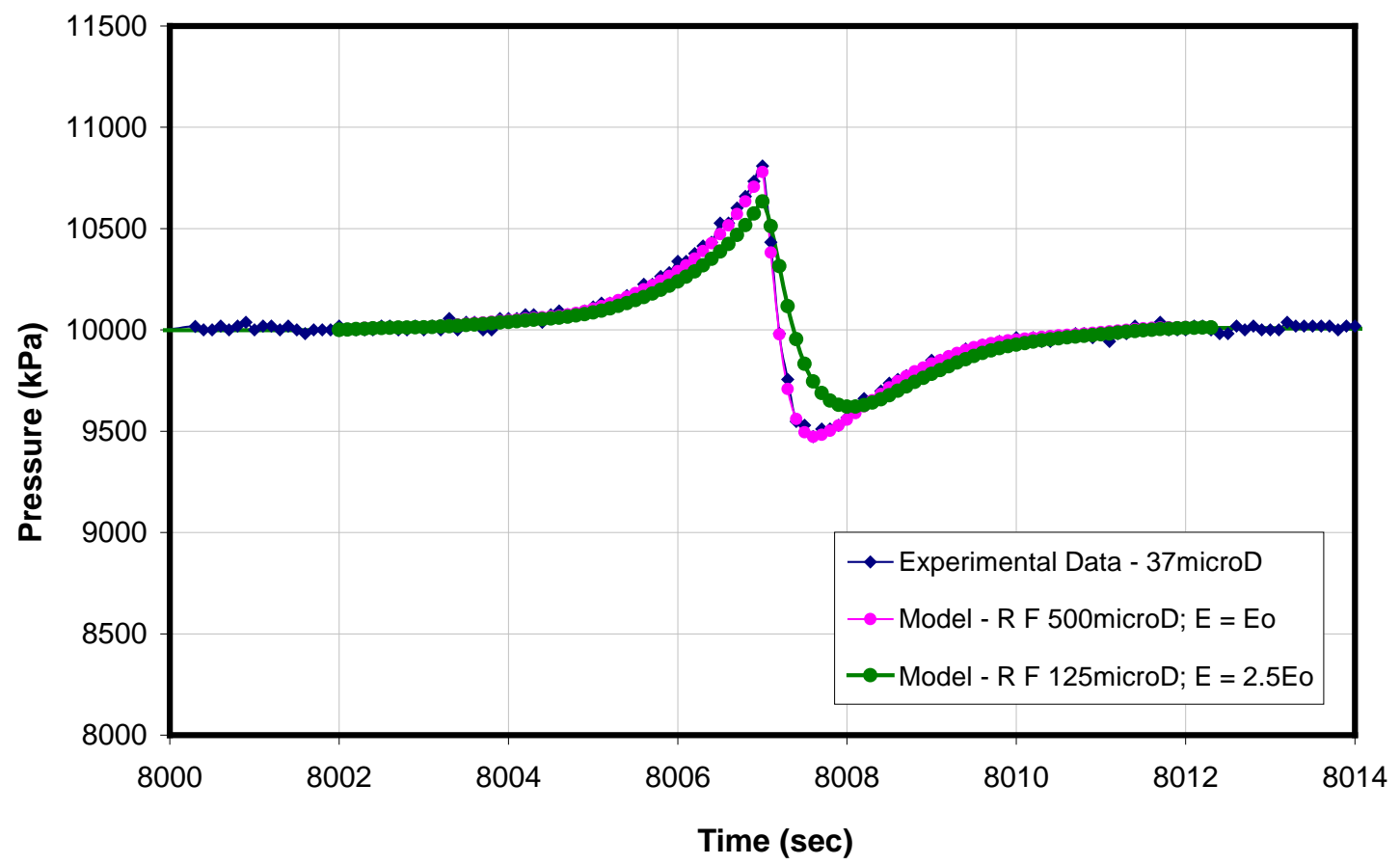

Figure 5.17: Downstream pressure response of sample S10 - event 0 A-Spike (without fracture) 
S10: $\mathrm{CO}_{2}$ Event 1 Upstream End (Experimental Data Vs Model Results)

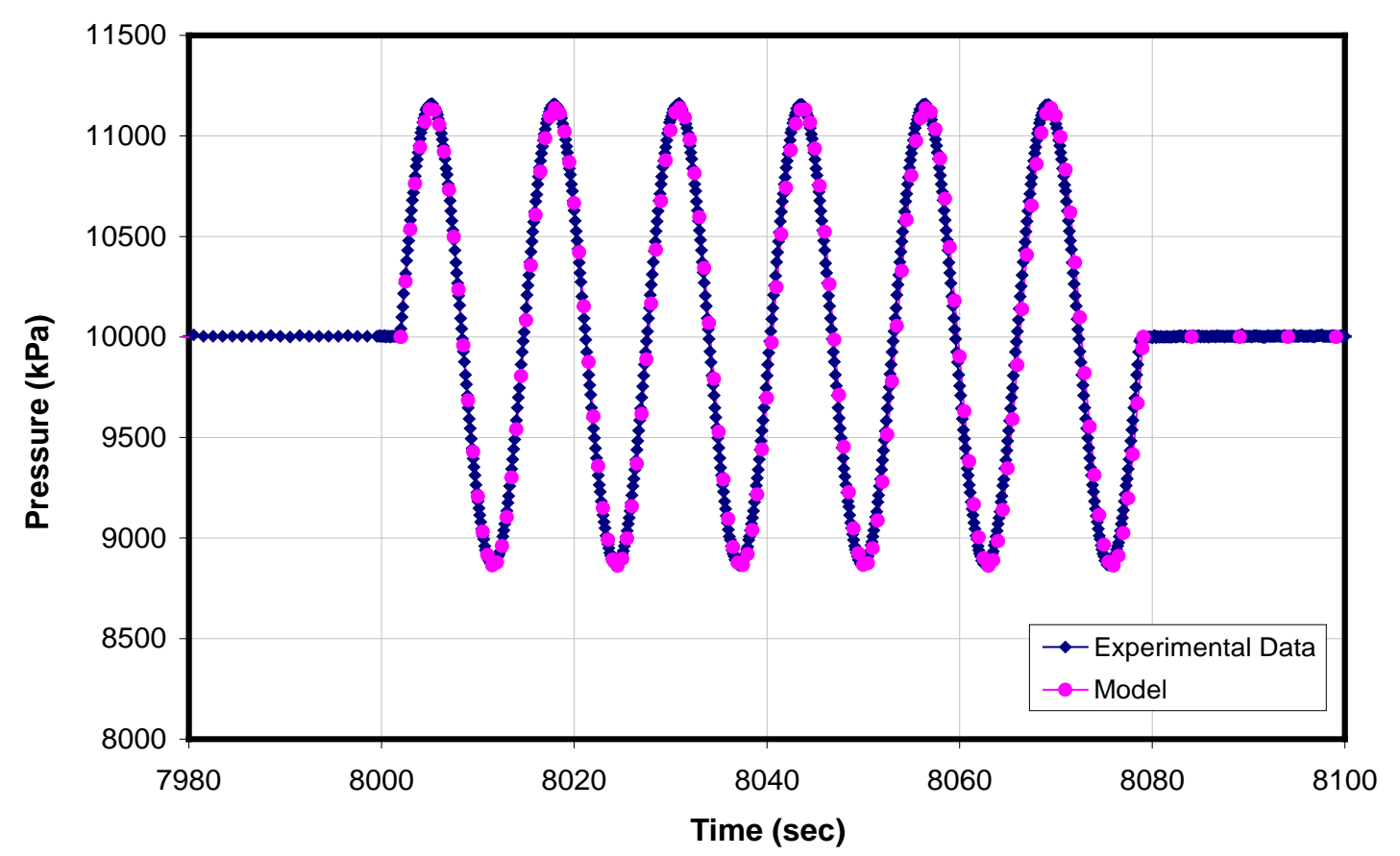

Figure 5.18: Upstream pressure pulse for sample S10 - event 1 Sine-6

S10: $\mathrm{CO}_{2}$ Event 1 Downstream End (Experimental Data Vs Model Results)

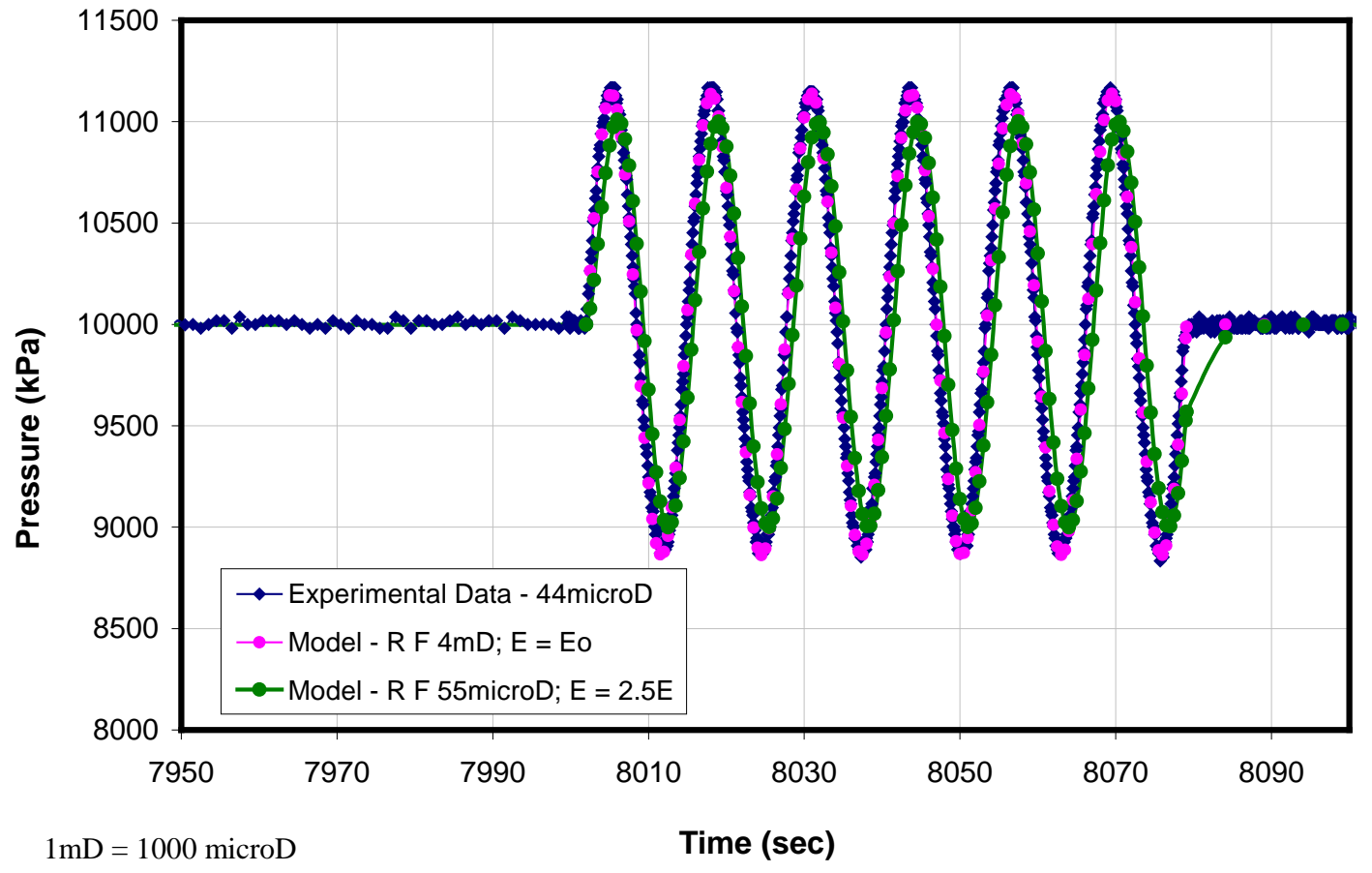

Figure 5.19: Downstream pressure response of sample S10 - event 1 Sine-6 (without fracture) 
Figures 5.20 and 5.21 show the results for events 0 and 1 for sample S10 for the case with fracture condition. Model results compare well with experimental observations.

S10: $\mathrm{CO}_{2}$ Event 0 Downstream End (Experimental Data Vs Model Results)

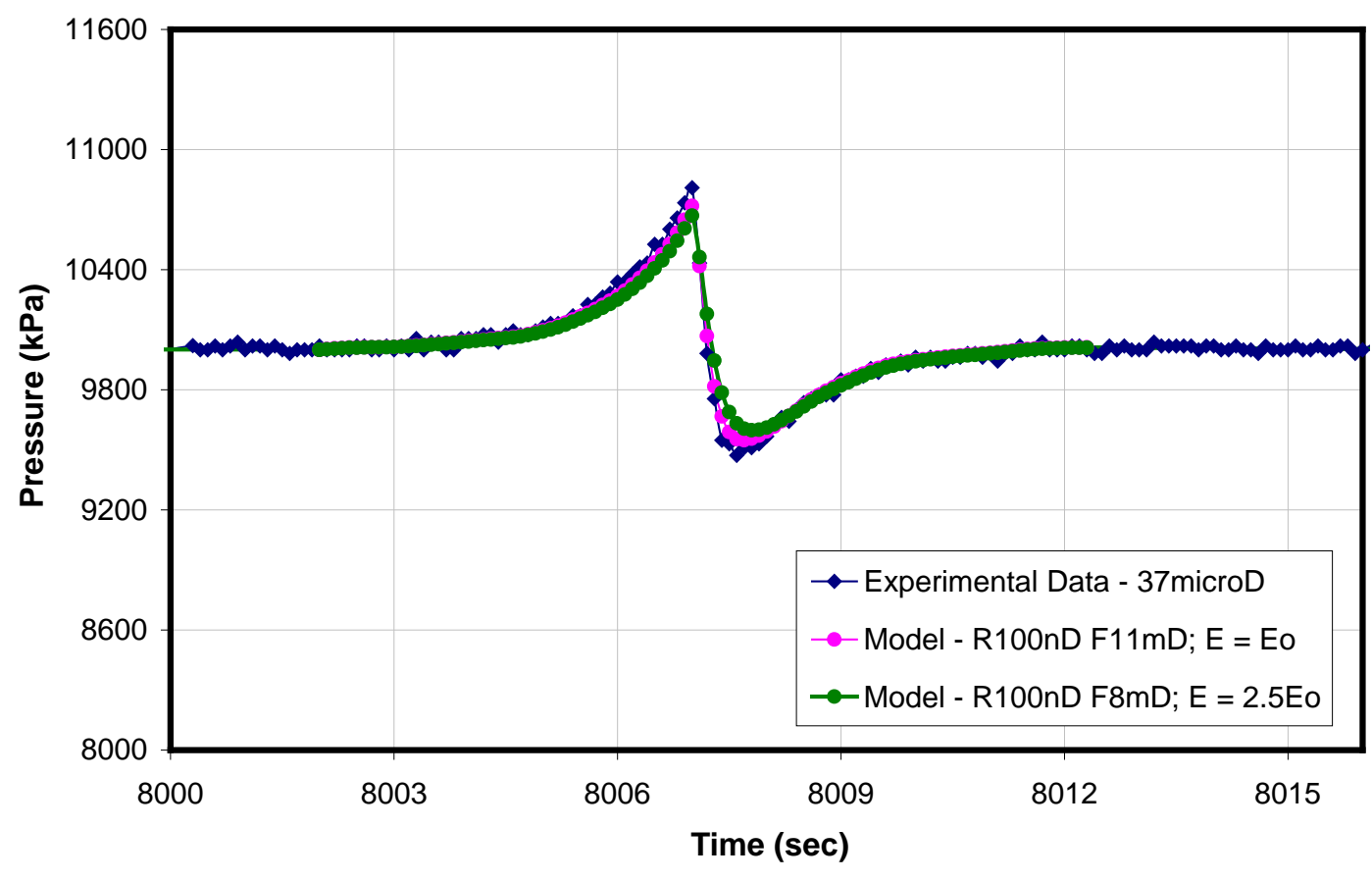

$1 \mathrm{mD}=1000$ microD

Figure 5.20: Downstream pressure response of sample S10 - event 1 A-Spike (with fracture) 
S10: $\mathrm{CO}_{2}$ Event 1 Downstream End (Experimental Data Vs Model Results)

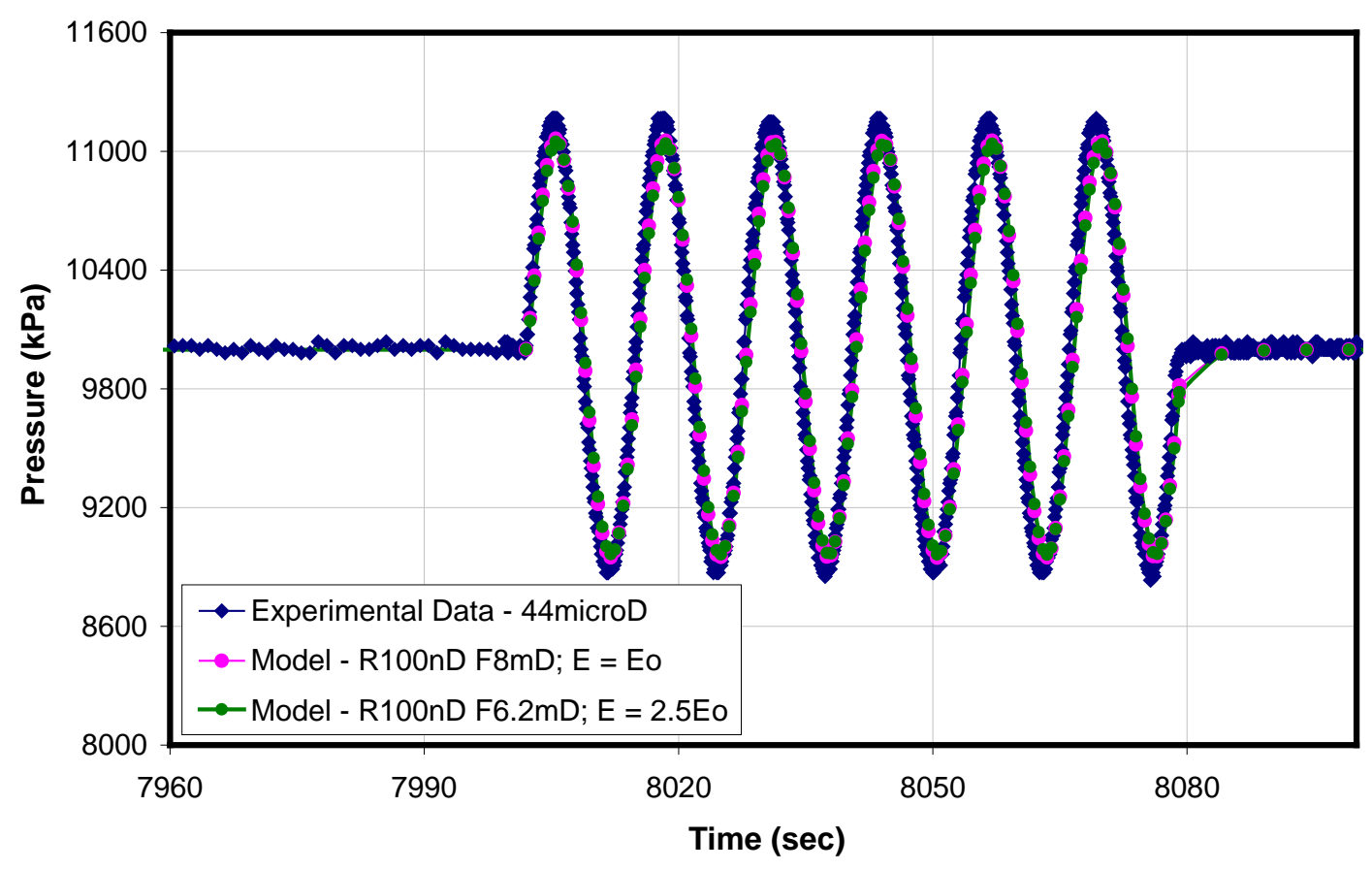

$1 \mathrm{mD}=1000$ microD

Figure 5.21: Downstream pressure response of sample S10 - event 1 Sine-6 (with fracture)

Downstream pressure response obtained from an upstream pressure pulse for sample S14 event 16 is shown in Figure 5.22. To perform this analyses no fracture condition was considered and the fluid compressibility value of Argon was used to match the experimental results. The permeability values obtained from the numerical analysis for this event show a value higher than that obtained from experimental results and can be seen in Table 5.1. Similarly, Figure 5.23 shows the upstream and the downstream pressure pulses for event 17 for the case with no fractured condition. Figure 5.24 and Figure 5.25 show the comparison of the downstream pressure obtained from the experimental test with the response obtained from the numerical model for sample S14 events 16 and 17, respectively for the case with fracture condition. For this sample, the confining pressure was maintained at $20 \mathrm{MPa}$ and the pore pressure of the sample was maintained at $10 \mathrm{MPa}$. Numerical model results compare well with available experimental data. 
S14: Argon - Event 16 (Experimental Data Vs Model Results )

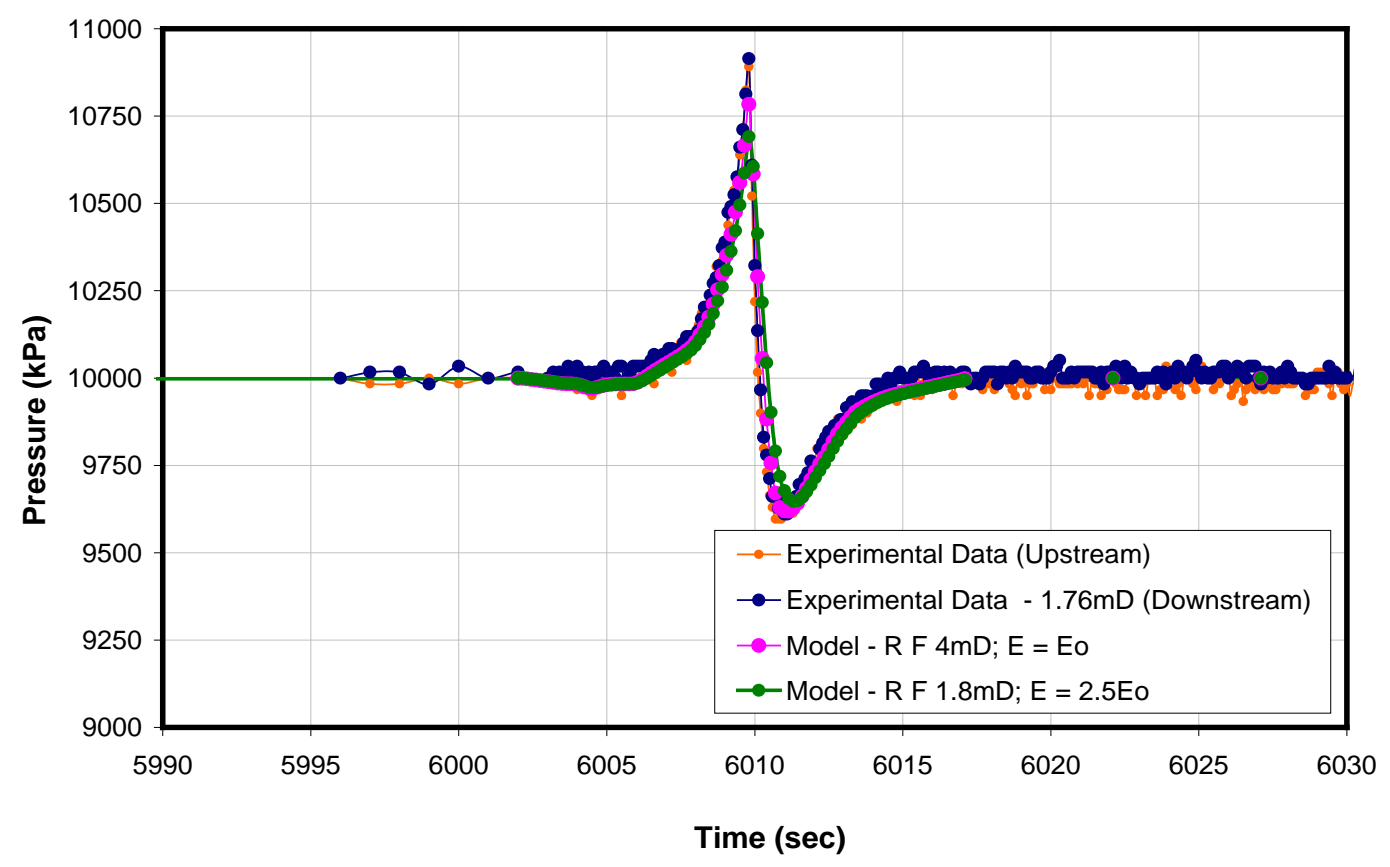

Figure 5.22: Upstream and downstream pressure pulses of sample S14 - event 16 A-Spike (without fracture) 
S14: Argon - Event 17 (Experimental Data Vs Model Results)

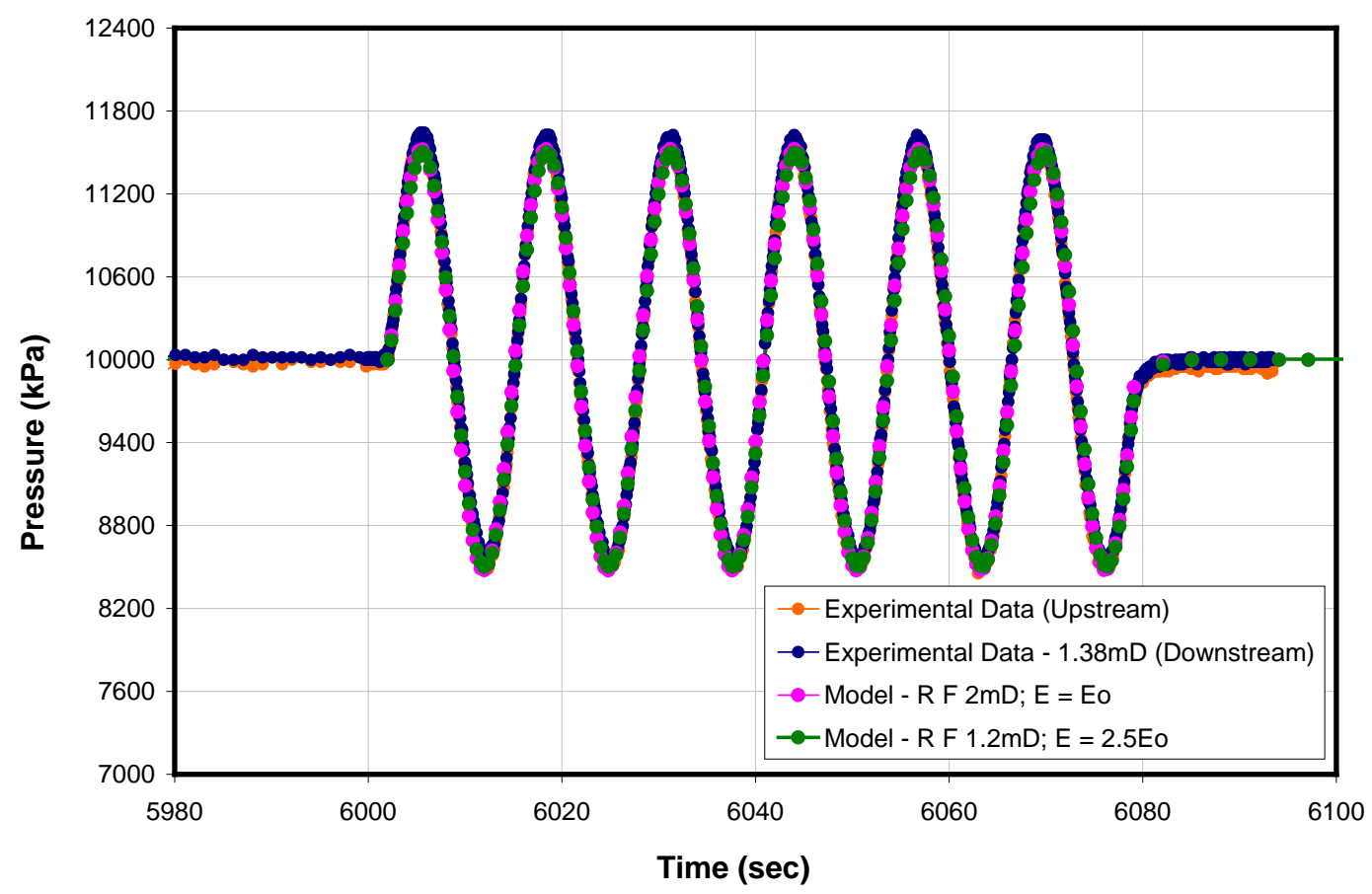

Figure 5.23: Upstream and downstream pressure pulses of sample S14 - event 16 A-Spike (without fracture) 
S14: Argon - Event 16 Downstream End (Experimental Data Vs Model Results)

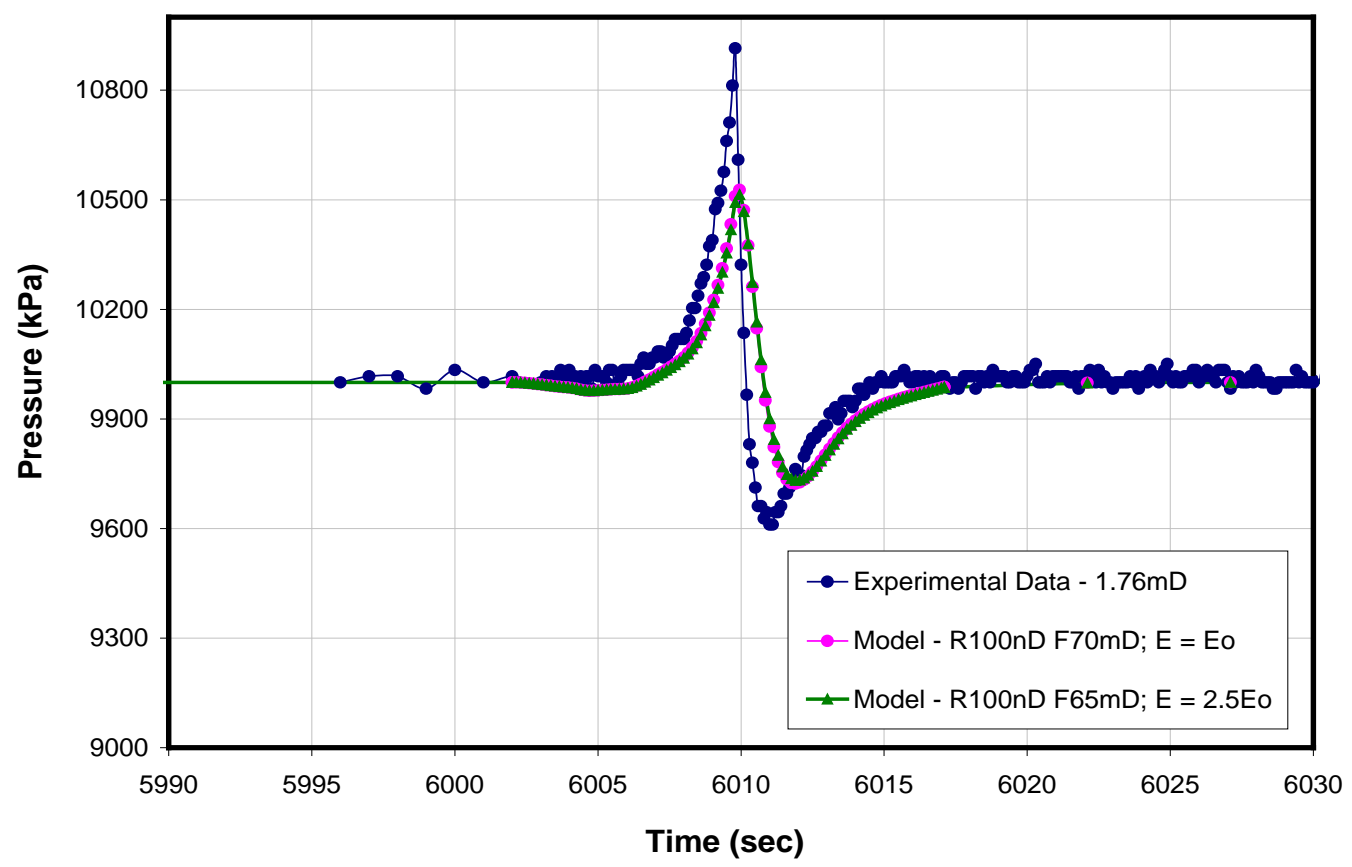

Figure 5.24: Downstream pressure response of sample S14 event 16 A-Spike (with fracture) S14: Argon - Event 17 Downstream End (Experimental Data Vs Model Results)

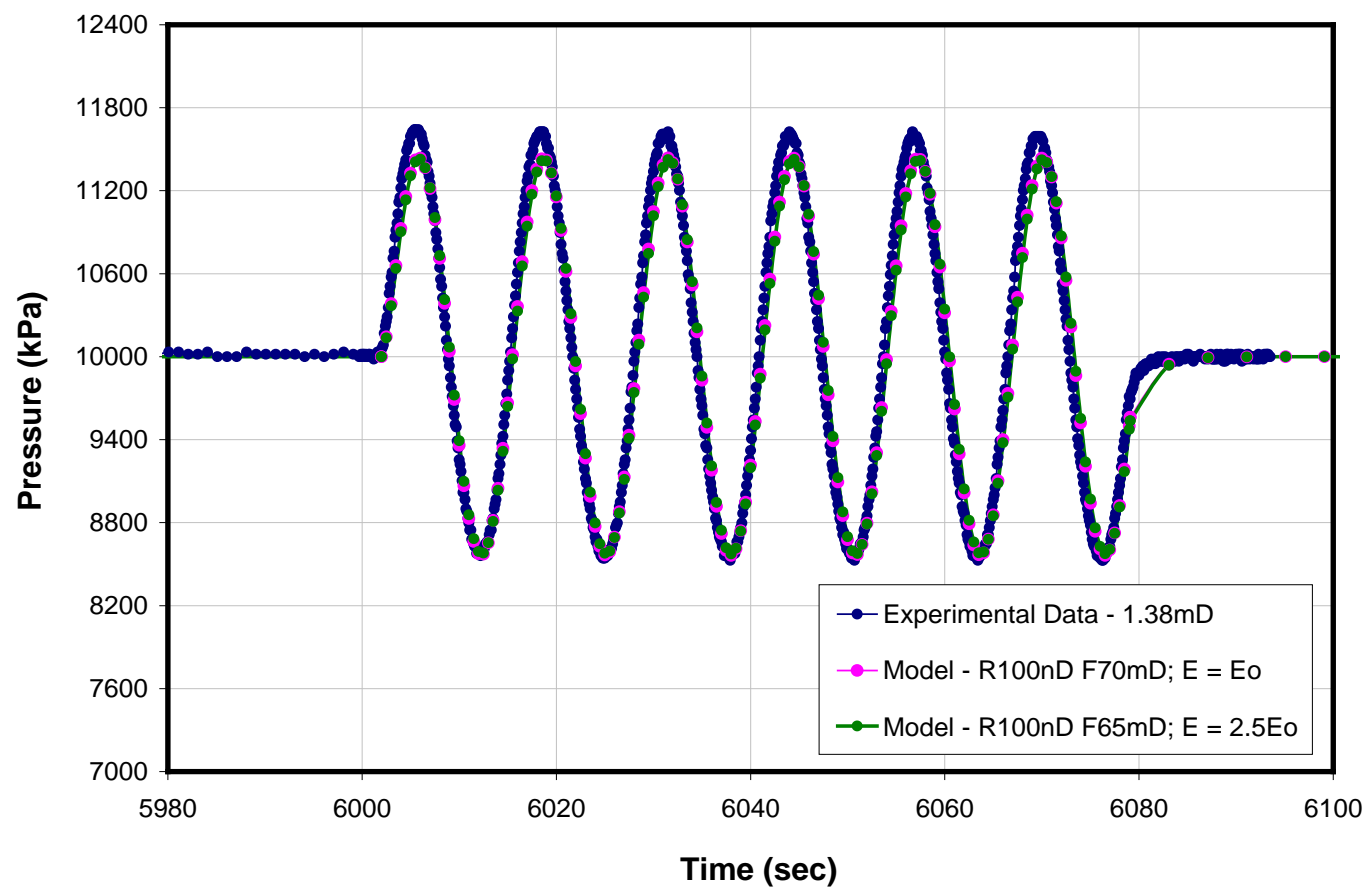

Figure 5.25: Downstream pressure response of sample S14 event 17 A-Spike (with fracture) 
All the numerical model results were compared with the experimental results. A summary of this comparison is shown in Table 5.1 . 
Table 5.1: Comparison of experimental results with computer model results

\begin{tabular}{|c|c|c|c|c|c|c|c|c|}
\hline \multirow{2}{*}{ Sample \# } & \multirow{2}{*}{ Event } & \multirow{2}{*}{$\begin{array}{l}\text { Pressure } \\
\text { pulse }\end{array}$} & \multirow{2}{*}{ Fluid } & \multirow{2}{*}{$\begin{array}{l}\text { Permeability } \\
\text { (Experimental } \\
\text { results) }\end{array}$} & \multicolumn{2}{|c|}{$\begin{array}{c}\text { Permeability (Model results) } \\
\text { E = Eo }\end{array}$} & \multicolumn{2}{|c|}{$\begin{array}{c}\text { Permeability (Model results) } \\
E=2.5 E 0\end{array}$} \\
\hline & & & & & $\begin{array}{l}\text { Without } \\
\text { fracture }\end{array}$ & With fracture & $\begin{array}{l}\text { Without } \\
\text { fracture }\end{array}$ & With fracture \\
\hline S01 & - & - & - & - & - & - & - & - \\
\hline \multirow[t]{6}{*}{ S02 } & 47 & A-Spike & $\mathrm{CO}_{2}$ & $0.25 \mathrm{mD}$ & $\mathrm{RF} 0.5 \mathrm{mD}$ & R100nD F8mD & RF $0.28 \mathrm{mD}$ & R100nD F4.8mD \\
\hline & 48 & Sine - 6 & $\mathrm{CO}_{2}$ & $0.27 \mathrm{mD}$ & $\mathrm{RF} 5 \mathrm{mD}$ & R100nD F4mD & RF 0.3mD & R100nD F2mD \\
\hline & 147 & A-Spike & $\mathrm{CO}_{2}$ & $8 \mu \mathrm{D}$ & $\mathrm{RF} 20 \mu \mathrm{D}$ & R100nD F0.45mD & $\mathrm{RF} 12 \mu \mathrm{D}$ & R100nD F0.4mD \\
\hline & 148 & Sine - 6 & $\mathrm{CO}_{2}$ & $8 \mu \mathrm{D}$ & RF $16.5 \mu \mathrm{D}$ & R100nD F0.45mD & $\mathrm{RF} 12 \mu \mathrm{D}$ & R100nD F0.4mD \\
\hline & 163 & A-Spike & $\mathrm{CO}_{2}$ & $0.6 \mu \mathrm{D}$ & $\mathrm{RF} 3 \mu \mathrm{D}$ & R100nD F60 $\mu D$ & $\mathrm{RF} 1 \mu \mathrm{D}$ & R100nD F55 $\mu D$ \\
\hline & 164 & Sine - 6 & $\mathrm{CO}_{2}$ & $1.2 \mu \mathrm{D}$ & $\mathrm{RF} 2.4 \mu \mathrm{D}$ & R100nD F70 $\mu D$ & $\mathrm{RF} 1.5 \mu \mathrm{D}$ & R100nD F55 $\mu \mathrm{D}$ \\
\hline S02 & & $\begin{array}{l}\text { Transient } \\
\text { (Rising) }\end{array}$ & Argon & - & $\mathrm{RF} 2 \mu \mathrm{D}$ & R100nD F70 $\mu \mathrm{D}$ & $\mathrm{RF} 2 \mu \mathrm{D}$ & R100nD F62 $\mu \mathrm{D}$ \\
\hline S03 & - & - Failed - & - & - & - & - & - & - \\
\hline \multirow[t]{2}{*}{ S04 } & 4 & Sine -6 & Argon & $2.4 \mathrm{mD}$ & RF 7mD & R200nD F500mD & RF 2.9mD & R200nD F420mD \\
\hline & 5 & A-Spike & Argon & $3.0 \mathrm{mD}$ & RF $8.5 \mathrm{mD}$ & R200nD F500mD & $\mathrm{RF} 4.5 \mathrm{mD}$ & R200nD F420mD \\
\hline
\end{tabular}


Table 5.1: Comparison of experimental results with computer model results (continued...)

\begin{tabular}{|c|c|c|c|c|c|c|c|c|}
\hline \multirow{2}{*}{ Sample \# } & \multirow{2}{*}{ Event } & \multirow{2}{*}{$\begin{array}{l}\text { Pressure } \\
\text { pulse }\end{array}$} & \multirow{2}{*}{ Fluid } & \multirow{2}{*}{$\begin{array}{c}\text { Permeability } \\
\text { (Experimental } \\
\text { results) }\end{array}$} & \multicolumn{2}{|c|}{$\begin{array}{l}\text { Permeability (Model results) } \\
\text { E = Eo }\end{array}$} & \multicolumn{2}{|c|}{$\begin{array}{l}\text { Permeability (Model results) } \\
\qquad \mathrm{E}=2.5 \mathrm{Eo}\end{array}$} \\
\hline & & & & & $\begin{array}{l}\text { Without } \\
\text { fracture }\end{array}$ & With fracture & $\begin{array}{l}\text { Without } \\
\text { fracture }\end{array}$ & With fracture \\
\hline \multirow[t]{6}{*}{ S04 } & 0 & A-Spike & $\mathrm{CO}_{2}$ & $36 \mu \mathrm{D}$ & RF $150 \mu \mathrm{D}$ & R200nD F2mD & $\mathrm{RF} 45 \mu \mathrm{D}$ & R200nD F1.85mD \\
\hline & 1 & Sine - 6 & $\mathrm{CO}_{2}$ & $29 \mu \mathrm{D}$ & RF $60 \mu \mathrm{D}$ & R200nD F2mD & $\mathrm{RF} 31 \mu \mathrm{D}$ & R200nD F1.5mD \\
\hline & 104 & Sine -6 & $\mathrm{CO}_{2}$ & 7.6 $\mathrm{DD}$ & RF $22 \mu \mathrm{D}$ & R200nD F0.65mD & $\mathrm{RF} 14 \mu \mathrm{D}$ & R200nD F0.53mD \\
\hline & 105 & A-Spike & $\mathrm{CO}_{2}$ & $6.9 \mu \mathrm{D}$ & RF $20 \mu \mathrm{D}$ & R200nD F0.65mD & $\mathrm{RF} 14 \mu \mathrm{D}$ & R200nD F0.57mD \\
\hline & 123 & A-Spike & $\mathrm{CO}_{2}$ & $2.2 \mu \mathrm{D}$ & $\mathrm{RF} 8 \mu \mathrm{D}$ & R200nD F0.2mD & RF $5.2 \mu \mathrm{D}$ & R200nD F0.19mD \\
\hline & 124 & Sine - 6 & $\mathrm{CO}_{2}$ & $2.6 \mu \mathrm{D}$ & $\mathrm{RF} 8 \mu \mathrm{D}$ & R200nD F0.2mD & RF $4.8 \mu \mathrm{D}$ & R200nD F0.19mD \\
\hline \multirow[t]{2}{*}{ S05 } & 2 & A-Spike & Argon & $2.5 \mathrm{mD}$ & $\mathrm{RF} 12 \mathrm{mD}$ & R100nD F370mD & $\mathrm{RF} 6.5 \mathrm{mD}$ & R100nD F320mD \\
\hline & 3 & Sine - 6 & Argon & $3.2 \mathrm{mD}$ & $\mathrm{RF} 5 \mathrm{mD}$ & R100nD F370mD & $\mathrm{RF} 4.5 \mathrm{mD}$ & R100nD F320mD \\
\hline \multirow[t]{3}{*}{ S05 } & 2 & A-Spike & $\mathrm{CO}_{2}$ & $64 \mu \mathrm{D}$ & $\mathrm{RF} 0.25 \mathrm{mD}$ & R100nD F4mD & $\mathrm{RF} 80 \mu \mathrm{D}$ & R100nD F3.2mD \\
\hline & 3 & Sine - 6 & $\mathrm{CO}_{2}$ & $55 \mu \mathrm{D}$ & $\mathrm{RF} 0.1 \mathrm{mD}$ & R100nD F3mD & $\mathrm{RF} 70 \mu \mathrm{D}$ & R100nD F2.7mD \\
\hline & 44 & A-Spike & $\mathrm{CO}_{2}$ & $1.2 \mu \mathrm{D}$ & $\mathrm{RF} 0.006 \mathrm{mD}$ & R100nD F100 $\mu D$ & $\mathrm{RF} 3 \mu \mathrm{D}$ & R100nD F65 $\mu \mathrm{D}$ \\
\hline
\end{tabular}


Table 5.1: Comparison of experimental results with computer model results (continued...)

\begin{tabular}{|c|c|c|c|c|c|c|c|c|}
\hline \multirow{2}{*}{ Sample \# } & \multirow{2}{*}{ Event } & \multirow{2}{*}{$\begin{array}{l}\text { Pressure } \\
\text { pulse }\end{array}$} & \multirow{2}{*}{ Fluid } & \multirow{2}{*}{$\begin{array}{c}\text { Permeability } \\
\text { (Experimental } \\
\text { results) }\end{array}$} & \multicolumn{2}{|c|}{$\begin{array}{l}\text { Permeability (Model results) } \\
\text { E = Eo }\end{array}$} & \multicolumn{2}{|c|}{$\begin{array}{l}\text { Permeability (Model results) } \\
E=2.5 E 0\end{array}$} \\
\hline & & & & & $\begin{array}{l}\text { Without } \\
\text { fracture }\end{array}$ & With fracture & $\begin{array}{l}\text { Without } \\
\text { fracture }\end{array}$ & With fracture \\
\hline & 45 & Sine - 6 & $\mathrm{CO}_{2}$ & $1.6 \mu \mathrm{D}$ & $\mathrm{RF} 0.006 \mathrm{mD}$ & R100nD F100 $\mu D$ & $\mathrm{RF} 5.5 \mu \mathrm{D}$ & R100nD F67 $\mu \mathrm{D}$ \\
\hline \multirow[t]{2}{*}{ S06 } & 1 & A-Spike & Argon & $3.7 \mathrm{mD}$ & $\mathrm{RF} 32 \mathrm{mD}$ & R200nD F350mD & $\mathrm{RF} 14.3 \mathrm{mD}$ & Cannot Match \\
\hline & 2 & Sine - 6 & Argon & $4.9 \mathrm{mD}$ & $\mathrm{RF} 5 \mathrm{mD}$ & R200nD F350mD & $\mathrm{RF} 5 \mathrm{mD}$ & R200nD F270mD \\
\hline \multirow[t]{6}{*}{ S06 } & 1 & A-Spike & $\mathrm{CO}_{2}$ & $2.44 \mathrm{mD}$ & $\mathrm{RF} 5 \mathrm{mD}$ & R200nD F90mD & $\mathrm{RF} 3 \mathrm{mD}$ & R200nD F25mD \\
\hline & 2 & Sine - 6 & $\mathrm{CO}_{2}$ & $0.84 \mathrm{mD}$ & $\mathrm{RF} 5 \mathrm{mD}$ & R200nD F8mD & $\mathrm{RF} 1.5 \mathrm{mD}$ & R200nD F7.2mD \\
\hline & 122 & Sine -6 & $\mathrm{CO}_{2}$ & $2.5 \mu \mathrm{D}$ & RF $20 \mu \mathrm{D}$ & R200nD F0.2mD & $\mathrm{RF} 4.5 \mu \mathrm{D}$ & R200nD F0.15mD \\
\hline & Bad! & A-Spike & $\mathrm{CO}_{2}$ & - & - & - & - & - \\
\hline & 123 & A-Spike & $\mathrm{CO}_{2}$ & $2.1 \mu \mathrm{D}$ & $\mathrm{RF} 15 \mu \mathrm{D}$ & R200nD F0.55mD & RF $8.5 \mu \mathrm{D}$ & R200nD F0.49mD \\
\hline & 124 & Sine - 6 & $\mathrm{CO}_{2}$ & $2.1 \mu \mathrm{D}$ & $\mathrm{RF} 2 \mu \mathrm{D}$ & R200nD F60 $\mu \mathrm{D}$ & $\mathrm{RF} 1.3 \mu \mathrm{D}$ & R200nD F51 $\mu \mathrm{D}$ \\
\hline S07 & & A-Spike & Argon & & $\mathrm{RF} 0.001 \mathrm{mD}$ & R100nD F0.05mD & $\begin{array}{l}\text { Cannot } \\
\text { Match }\end{array}$ & Cannot Match \\
\hline S08 & 2 & A-Spike & $\mathrm{CO}_{2}$ & $1 \mu \mathrm{D}$ & $\mathrm{RF} 4 \mu \mathrm{D}$ & R100nD F60 $\mu D$ & $\mathrm{RF} 2.1 \mu \mathrm{D}$ & R100nD F53 $\mu D$ \\
\hline
\end{tabular}


Table 5.1: Comparison of experimental results with computer model results (continued...)

\begin{tabular}{|c|c|c|c|c|c|c|c|c|}
\hline \multirow{2}{*}{ Sample \# } & \multirow{2}{*}{ Event } & \multirow{2}{*}{$\begin{array}{l}\text { Pressure } \\
\text { pulse }\end{array}$} & \multirow{2}{*}{ Fluid } & \multirow{2}{*}{$\begin{array}{l}\text { Permeability } \\
\text { (Experimental } \\
\text { results) }\end{array}$} & \multicolumn{2}{|c|}{$\begin{array}{c}\text { Permeability (Model results) } \\
\text { E = Eo }\end{array}$} & \multicolumn{2}{|c|}{$\begin{array}{c}\text { Permeability (Model results) } \\
\qquad \mathrm{E}=2.5 \mathrm{E} \text { ) }\end{array}$} \\
\hline & & & & & $\begin{array}{l}\text { Without } \\
\text { fracture }\end{array}$ & With fracture & $\begin{array}{l}\text { Without } \\
\text { fracture }\end{array}$ & With fracture \\
\hline & 3 & Sine - 6 & $\mathrm{CO}_{2}$ & $1.2 \mu \mathrm{D}$ & $\mathrm{RF} 4 \mu \mathrm{D}$ & R100nD F80 $\mu D$ & $\mathrm{RF} 2.1 \mu \mathrm{D}$ & R100nD F70 $\mu \mathrm{D}$ \\
\hline & 4 & Sine -6 & $\mathrm{CO}_{2}$ & $1.0 \mu \mathrm{D}$ & $\mathrm{RF} 3 \mu \mathrm{D}$ & R100nD F60 $\mu D$ & $\mathrm{RF} 1.8 \mu \mathrm{D}$ & R100nD F53 $\mu \mathrm{D}$ \\
\hline S09 & 5 & A-Spike & $\mathrm{CO}_{2}$ & $1.0 \mu \mathrm{D}$ & $\mathrm{RF} 4 \mu \mathrm{D}$ & R100nD F60 $\mu D$ & $\mathrm{RF} 2.1 \mu \mathrm{D}$ & R100nD F53 $\mu D$ \\
\hline \multirow[t]{4}{*}{ S10 } & 0 & A-Spike & $\mathrm{CO}_{2}$ & $37 \mu \mathrm{D}$ & RF $500 \mu \mathrm{D}$ & R100nD F11mD & $\mathrm{RF} 125 \mu \mathrm{D}$ & R100nD F8mD \\
\hline & 1 & Sine - 6 & $\mathrm{CO}_{2}$ & $44 \mu \mathrm{D}$ & RF $4000 \mu \mathrm{D}$ & R100nD F8mD & RF $55 \mu \mathrm{D}$ & R100nD F6mD \\
\hline & $\begin{array}{c}\text { Not } \\
\text { saved }\end{array}$ & Sine -6 & $\mathrm{CO}_{2}$ & - & $\mathrm{RF} 1.1 \mu \mathrm{D}$ & R100nD F55 $\mu \mathrm{D}$ & $\mathrm{RF} 0.9 \mu \mathrm{D}$ & R100nD F46 $\mu D$ \\
\hline & 66 & A-Spike & $\mathrm{CO}_{2}$ & $0.2 \mu \mathrm{D}$ & $\mathrm{RF} 4 \mu \mathrm{D}$ & R100nD F100 $\mu D$ & $\mathrm{RF} 2.2 \mu \mathrm{D}$ & R100nD F72 $\mu D$ \\
\hline \multirow[t]{4}{*}{ S11 } & 0 & A-Spike & $\mathrm{CO}_{2}$ & $0.09 \mu \mathrm{D}$ & $\begin{array}{l}\text { Cannot } \\
\text { Match }\end{array}$ & Cannot Match & $\begin{array}{l}\text { Cannot } \\
\text { Match }\end{array}$ & Cannot Match \\
\hline & 1 & Sine - 6 & $\mathrm{CO}_{2}$ & $0.066 \mu \mathrm{D}$ & $\mathrm{RF} 0.2 \mu \mathrm{D}$ & R100nD F2.5 $\mu \mathrm{D}$ & RF $0.14 \mu \mathrm{D}$ & Cannot Match \\
\hline & 18 & Sine -6 & $\mathrm{CO}_{2}$ & $0.027 \mu \mathrm{D}$ & RF 90nD & R100nD F60nD & RF 80nD & Cannot Match \\
\hline & 19 & A-Spike & $\mathrm{CO}_{2}$ & $0.025 \mu \mathrm{D}$ & $\begin{array}{l}\text { Cannot } \\
\text { Match }\end{array}$ & Cannot Match & $\begin{array}{l}\text { Cannot } \\
\text { Match }\end{array}$ & Cannot Match \\
\hline
\end{tabular}


Table 5.1: Comparison of experimental results with computer model results (continued...)

\begin{tabular}{|c|c|c|c|c|c|c|c|c|}
\hline \multirow{2}{*}{ Sample \# } & \multirow{2}{*}{ Event } & \multirow{2}{*}{$\begin{array}{c}\text { Pressure } \\
\text { pulse }\end{array}$} & \multirow{2}{*}{ Fluid } & \multirow{2}{*}{$\begin{array}{c}\text { Permeability } \\
\text { (Experimental } \\
\text { results) }\end{array}$} & \multicolumn{2}{|c|}{$\begin{array}{l}\text { Permeability (Model results) } \\
\text { E = Eo }\end{array}$} & \multicolumn{2}{|c|}{$\begin{array}{l}\text { Permeability (Model results) } \\
\qquad E=2.5 E 0\end{array}$} \\
\hline & & & & & $\begin{array}{l}\text { Without } \\
\text { fracture }\end{array}$ & With fracture & $\begin{array}{l}\text { Without } \\
\text { fracture }\end{array}$ & With fracture \\
\hline \multirow[t]{2}{*}{ S12 } & 0 & A-Spike & $\mathrm{CO}_{2}$ & $0.127 \mathrm{mD}$ & $\mathrm{RF} 0.5 \mathrm{mD}$ & R200nD F8mD & RF $0.23 \mathrm{mD}$ & R200nD F6.5mD \\
\hline & 1 & Sine - 6 & $\mathrm{CO}_{2}$ & $0.121 \mathrm{mD}$ & $\mathrm{RF} 5 \mathrm{mD}$ & R200nD F4mD & RF $0.45 \mathrm{mD}$ & R200nD F3.2mD \\
\hline $\mathrm{S} 12$ & 0 & A-Spike & Argon & $0.11 \mathrm{mD}$ & $\mathrm{RF} 1 \mathrm{mD}$ & R200nD F65mD & $\mathrm{RF} 0.75 \mathrm{mD}$ & R200nD F58mD \\
\hline \multirow{5}{*}{ S13 } & 2 & A-Spike & Argon & $2.7 \mu \mathrm{D}$ & RF $30 \mu \mathrm{D}$ & R100nD F1mD & $\mathrm{RF} 23 \mu \mathrm{D}$ & R100nD F0.92mD \\
\hline & 9 & A-Spike & Argon & $2.1 \mu \mathrm{D}$ & RF $20 \mu \mathrm{D}$ & R100nD F0.8mD & $\mathrm{RF} 18 \mu \mathrm{D}$ & R100nD F0.63mD \\
\hline & 10 & Sine - 6 & Argon & $2.2 \mu \mathrm{D}$ & $\mathrm{RF} 20 \mu \mathrm{D}$ & $\mathrm{R} 100 \mathrm{nD}$ F0.8mD & $\mathrm{RF} 18 \mu \mathrm{D}$ & R100nD F0.66mD \\
\hline & 30 & A-Spike & $\mathrm{CO}_{2}$ & $0.039 \mu \mathrm{D}$ & RF $0.6 \mu \mathrm{D}$ & $\mathrm{R} 100 \mathrm{nD} F 20 \mu \mathrm{D}$ & $\mathrm{RF} 0.5 \mu \mathrm{D}$ & $\mathrm{R} 100 \mathrm{nD}$ F16 $\mu \mathrm{D}$ \\
\hline & 31 & Sine - 6 & $\mathrm{CO}_{2}$ & $0.047 \mu \mathrm{D}$ & $\mathrm{RF} 0.6 \mu \mathrm{D}$ & R100nD F20 $\mu \mathrm{D}$ & $\mathrm{RF} 0.5 \mu \mathrm{D}$ & R100nD F17 $\mu \mathrm{D}$ \\
\hline
\end{tabular}


Table 5.1: Comparison of experimental results with computer model results (continued...)

\begin{tabular}{|c|c|c|c|c|c|c|c|c|}
\hline \multirow{2}{*}{ Sample \# } & \multirow{2}{*}{ Event } & \multirow{2}{*}{$\begin{array}{l}\text { Pressure } \\
\text { pulse }\end{array}$} & \multirow{2}{*}{ Fluid } & \multirow{2}{*}{$\begin{array}{l}\text { Permeability } \\
\text { (Experimental } \\
\text { results) }\end{array}$} & \multicolumn{2}{|c|}{$\begin{array}{l}\text { Permeability (Model results) } \\
\text { E = Eo }\end{array}$} & \multicolumn{2}{|c|}{$\begin{array}{c}\text { Permeability (Model results) } \\
E=2.5 E 0\end{array}$} \\
\hline & & & & & $\begin{array}{l}\text { Without } \\
\text { fracture }\end{array}$ & With fracture & $\begin{array}{l}\text { Without } \\
\text { fracture }\end{array}$ & With fracture \\
\hline & 32 & A-Spike & $\mathrm{CO}_{2}$ & $0.024 \mu \mathrm{D}$ & RF $0.4 \mu \mathrm{D}$ & R100nD F12 $\mu D$ & RF $0.4 \mu \mathrm{D}$ & R100nD F8pD \\
\hline & 33 & Sine - 6 & $\mathrm{CO}_{2}$ & $0.031 \mu \mathrm{D}$ & $\mathrm{RF} 0.4 \mu \mathrm{D}$ & R100nD F12 $\mu \mathrm{D}$ & $\mathrm{RF} 0.4 \mu \mathrm{D}$ & R100nD F9pD \\
\hline \multirow[t]{4}{*}{ S14 } & 16 & A-Spike & Argon & $1.76 \mathrm{mD}$ & $\mathrm{RF} 4 \mathrm{mD}$ & R100nD F70mD & $\mathrm{RF} 1.8 \mathrm{mD}$ & R100nD F65mD \\
\hline & 17 & Sine - 6 & Argon & $1.38 \mathrm{mD}$ & $\mathrm{RF} 2 \mathrm{mD}$ & R100nD F70mD & $\mathrm{RF} 1.2 \mathrm{mD}$ & R100nD F65mD \\
\hline & 63 & A-Spike & $\mathrm{CO}_{2}$ & $195 \mu \mathrm{D}$ & $\begin{array}{c}\text { RF } 250-300 \\
\mu \mathrm{D}\end{array}$ & R100nD F6.5mD & RF $200 \mu \mathrm{D}$ & R100nD F5.9mD \\
\hline & 64 & Sine - 6 & $\mathrm{CO}_{2}$ & $127 \mu \mathrm{D}$ & $\mathrm{RF} 140 \mu \mathrm{D}$ & R100nD F4.5mD & RF $132 \mu \mathrm{D}$ & R100nD F3.9mD \\
\hline \multirow[t]{2}{*}{ Nat Cleat (no\#) } & - & A-Spike & $\mathrm{CO}_{2}$ & - & $\mathrm{RF} 0.17 \mathrm{mD}$ & R100nD F7.5mD & RF 0.13mD & R100nD F6.8mD \\
\hline & - & Sine - 6 & $\mathrm{CO}_{2}$ & - & $\mathrm{RF} 0.1 \mathrm{mD}$ & R100nD F5mD & RF $0.078 \mathrm{mD}$ & R100nD F4.3mD \\
\hline \multirow[t]{2}{*}{ New sample -782} & - & Rising & Argon & - & - & - & RF $37 \mu \mathrm{D}$ & R100nD F0.9mD \\
\hline & - & Sine -6 & Argon & - & - & - & RF $52 \mu \mathrm{D}$ & R100nD F1.3mD \\
\hline New sample - 762 & - & Rising & Argon & - & - & - & $\begin{array}{l}\text { Cannot } \\
\text { Match }\end{array}$ & Cannot Match \\
\hline
\end{tabular}


Table 5.1: Comparison of experimental results with computer model results (continued...)

\begin{tabular}{|c|c|c|c|c|c|c|c|c|}
\hline \multirow{2}{*}{ Sample \# } & \multirow{2}{*}{ Event } & \multirow{2}{*}{$\begin{array}{l}\text { Pressure } \\
\text { pulse }\end{array}$} & \multirow{2}{*}{ Fluid } & \multirow{2}{*}{$\begin{array}{l}\text { Permeability } \\
\text { (Experimental } \\
\text { results) }\end{array}$} & \multicolumn{2}{|c|}{$\begin{array}{l}\text { Permeability (Model results) } \\
\qquad \begin{array}{c}\mathrm{E}=\mathrm{Eo} \\
\end{array}\end{array}$} & \multicolumn{2}{|c|}{$\begin{array}{c}\text { Permeability (Model results) } \\
\qquad \mathrm{E}=2.5 \mathrm{Eo}\end{array}$} \\
\hline & & & & & $\begin{array}{l}\text { Without } \\
\text { fracture }\end{array}$ & With fracture & $\begin{array}{l}\text { Without } \\
\text { fracture }\end{array}$ & With fracture \\
\hline & - & A-Spike & Argon & - & - & - & $\begin{array}{l}\text { Cannot } \\
\text { Match }\end{array}$ & Cannot Match \\
\hline & - & Falling & Argon & - & - & - & $\begin{array}{l}\text { Cannot } \\
\text { Match }\end{array}$ & Cannot Match \\
\hline New Sample - 169 & - & Rising & - & - & - & - & RF $0.3 \mu \mathrm{D}$ & $\mathrm{R} 100 \mathrm{nD} F 5 \mu \mathrm{D}$ \\
\hline
\end{tabular}




\section{CHAPTER 6: SUMMARY AND CONCLUSIONS}

\subsection{SUMMARY}

Pressure transient method in conjunction with a finite element model was used to determine the permeability of a fracture in the coal matrix. The numerical analyses were performed on fourteen different samples with different physical properties and varying confining pressures. In the numerical analyses, samples both with and without fracture conditions were considered. In some samples there were natural fractures. In the samples with no fractures, a fracture was induced mechanically. Each numerical analysis (test) was conducted for three pressure changes: namely pressure increase, pressure transient and pressure release. Two pressure transients A-Spike pressure transient and Sine-6 pressure transient were used. These pressure transients were introduced on the upstream end with a pressure maintained between $4 \mathrm{MPa}$ and $10 \mathrm{MPa}$. The downstream pressure responses corresponding to these upstream pressure pulses were measured at the downstream end to determine the permeability of coal samples. $\mathrm{CO}_{2}$ and Argon were used as the fluid media.

A comprehensive study was performed to determine the influence of different physical properties like elastic modulus, fracture width, fracture porosity of the coal matrix and fluid compressibility on the downstream pressure response. For each sample, certain experimental (events) were selected for which the experimental results are available. The numerical analyses for each experiment for each sample were performed. The properties shown in Table 3.1 were used to perform the computer model study. The downstream pressure response curves obtained from the numerical analyses were compared with the downstream pressure responses obtained from the experimental tests for each event for all the samples.

\subsection{CONCULSIONS}

- The computed results show that the elastic modulus of the coal matrix has a significant influence on the downstream pressure variation. 
- The fracture permeability value seems to decrease with the increase in the elastic modulus of the coal matrix. For example, for sample S02 - Event 47 the value of fracture permeability is $0.5 \mathrm{mD}$ when the elastic modulus was considered as Eo and it is $0.28 \mathrm{mD}$ when the elastic modulus was changed to 2.5Eo.

- The method of analysis used in this report can be employed to determine the elastic modulus of the coal matrix, indirectly, if the permeability of the coal sample is known.

- Fracture width upto $2 \mathrm{~mm}$ seems to has a significant influence on the downstream pressure response.

- Fluid compressibility values of Argon, $\mathrm{CO}_{2}$ and Water were used to determine the influence of fluid compressibility. Computed results show that the downstream pressure response for $\mathrm{CO}_{2}$ gives higher amplitude when compared to Argon.

- The amplitude of the downstream pressure response seems to be higher for low values of fluid compressibility.

- Fracture porosity shows a significant influence on the downstream pressure response. The fracture porosity values were varied keeping the value of rock porosity as a constant in order to determine its influence.

- A methodology of determining the fracture permeability was developed by integrating the finite element modeling and the available experimental results.

- The values of the fracture permeabilities for samples S01 through S14 were determined using the finite element models generated for each sample. For each experiment, the available experimental results are compared with the computed results obtained and are listed in Table 5.1. The comparison with experimentally determined permeability can be considered as good.

- Obtained computer model results compare well with the available experimental results.

- The fracture permeability values obtained for a case with fracture condition are higher than the values obtained from a case without fracture condition. 


\subsection{RECOMMENDATIONS FOR FUTURE}

a) Perform flow through experiments and compare results with those obtained from the pressure transient methods.

b) Investigate the Long-term influence of $\mathrm{CO}_{2}$ exposure on fracture permeability. 


\section{REFERENCES:}

1. ASTM Designation D 388-98a - Standard Classification of Coals by Rank.

2. Brace,W.F.Walsh, J.B., Frangos,W.T., 1968. Permeability of granite under high pressure. Journal of Geophysical Research 73, pp. 2225-2236.

3. Carmen, P.C., 1937. Fluid Flow through Granular Beds, Transactions of Institute of Chemical Engineers 15, pp. 150-166.

4. Department of Energy (DOE), 2005. Emissions of Greenhouse Gases in the United States 2004. DOE/EIA-0573 (2004).

5. Department of Energy (DOE), 2007. Emissions of Greenhouse Gases in the United States 2007. DOE/EIA-0573 (2007).

6. Evans, B.,Wong, T.F.,1992. Fault Mechanics and Transport Properties of Rocks. Academic Press, New York.

7. Gray, I. (1987) Reservoir engineering in coal seams: Part I - The physical process of gas storage and movement in coal seams, SPE Reservoir Engineering, pp. 28-34.

8. Harpalani, S., Chen, G., 1997. Influence of gas production induced volumetric strain on permeability of coal. Geotechnical and Geological Engineering 15, pp. 303-325.

9. http://en.wikipedia.org/wiki/Greenhouse_gas (2010).

10. http://en.wikipedia.org/wiki/Carboniferous (2010).

11. http://www.britannica.com/EBchecked/topic/122863/coal/50683/Structure-andproperties-of-coal (2010).

12. K. Lee Lerner and Brenda Wilmoth Lerner, 2010. "Coal", World of Earth Science.

13. Larsen, J.W., 2004. The effects of dissolved $\mathrm{CO}_{2}$ on coal structure and properties. International Journal of Coal Geology 57, pp. 63-70. 
14. Larsen, J.W., Flowers, R.A., Hall, P.J., 1997. Structural rearrangement of strained coals. Energy \& Fuels 11, 998-1002.

15. NIST: REFPROP, 2010.

16. Pachauri, R.K. and Reisinger., 2007. Intergovernmental Panel on Climate Change (IPCC), 2007. Climate Change 2007: Synthesis report. Contribution of Working Groups I, II and III to the Fourth Assessment Report of the Intergovernmental Panel on Climate Change. IPCC, Geneva, Switzerland.

17. Palmer and Mansoori., 1996. How permeability depends on stress and pore pressure in coalbeds: A New Model. Society of petroleum engineers. SPE36737.

18. Siriwardane, H., Igor Haljasmaa, Robert McLendon , Gino Irdi, Yee Soong, and Grant Bromhal., 2009. Influence of carbon dioxide on coal permeability determined by pressure transient methods. International Journal of Coal Geology, 77, pp. 109-118.

19. Van Krevelen, D.W., 1993. Coal: Typology-Physics-Chemistry-Constitution, 3rd edition. Elsevier, Amsterdam, pp. 979.

20. Xiaochao Tang, 2006. Numerical Modeling of Deformations Caused by Carbon Dioxide Sequestration in Coal Seams. Thesis: West Virginia University. 